\title{
TEOR E DISPONIBILIDADE PARA SOJA DE MICRONUTRIENTES E ELEMENTOS POTENCIALMENTE TÓXICOS EM FERTILIZANTES MINERAIS E CALCÁRIOS
}

\author{
URSULA GABE
}

Engenheiro Agrônomo

Orientador: Prof. Dr. ARNALDO ANTONIO RODELLA

Tese apresentada à Escola Superior de Agricultura

"Luiz de Queiroz", Universidade de São Paulo, para obtenção do título de Doutor em Agronomia Área de concentração: Solos e Nutrição de Plantas.

PIRACICABA

Estado de São Paulo - Brasil

Abril - 1998 
Dados Internacionais de Catalogação na Publicação (CIP) DIVISÃO DE BIBLIOTECA E DOCUMENTAÇÃO - Campus "Luiz de Queiroz"/USP

Gabe, Ursula

Teor e disponibilidade para soja de micronutrientes e elementos potencialmente tóxicos em fertilizantes minerais e calcários / Ursula Gabe. - - Piracicaba, 1998.

84 p. : il.

Tese (doutorado) - - Escola Superior de Agricultura Luiz de Queiroz, 1998.

Bibliografia.

1. Adubação 2. Análise do solo 3. Calcário 4. Elemento quimico tóxico 5.

Fertilizante 6. Micronutriente 7. Nutriçăo vegetal 8 . Soja 1 . Título

CDD 633.34 
Dedica

aos meus pais

Lor minhas raizes na terra.

$e$

a Tdalmo e Bruno

"Perdoen a cara amarrada, perdoen a falta de abraso, pendoen a falta de espaso, pendoem por tantos perigos, pendoen a falta de abrigo, pendoen a falea de ar, pentoen a faltra de escotha. Q. dias eram assimn...

Eq quando brotarem as fothas

e quando crescerem as matas quando cotherem os frutos, digan o gosto para mim."

Sounsions 


\section{SUMÁRIO}

RESUMO fertilizantes minerais...........................................................................

2.1.1 Métodos de análise..................................................................... 5

2.1.2 Teores em rochas e fertilizantes fosfatados....................................... 5

2.1.3 Teores em calcários...................................................................... 7

2.1.4 Teores em fontes de micronutrientes................................................... 9

2.2 Micronutrientes e elementos potencialmente tóxicos no solo..................... 10

2.2.1 Fatores que afetam a disponibilidade.................................................. 11

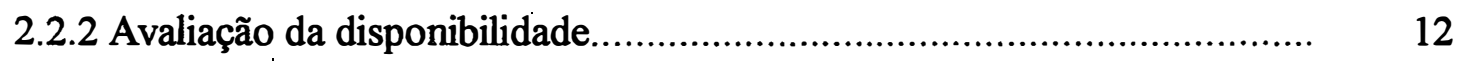

2.2.3 Níveis críticos e adequados no solo....................................................

2.3 Micronutrientes e elementos potencialmente tóxicos em soja..................... 16

2.3.1 Teores nos tecidos das plantas.......................................................... 16

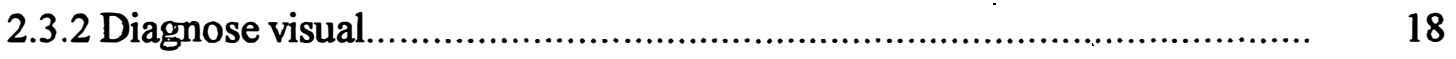

2.4 Interações entre micronutrientes e elementos potencialmente tóxicos......... 20

3 MATERIAL E MÉTODOS............................................................ 22

3.1 Teor de micronutrientes e elementos potencialmente tóxicos em calcários e fertilizantes minerais..................................................................... 22

3.2 Disponibilidade de micronutrientes e elementos potencialmente tóxicos em calcário e fertilizantes minerais, avaliada através da análise de solo.

3.3 Disponibilidade de micronutrientes e elementos potencialmente tóxicos em calcário e fertilizantes minerais, avaliada através da absorção pela soja 


\section{AGRADECIMENTOS}

- À Escola Superior de Agricultura "Luiz de Queiroz" pela boa acolhida durante o curso.

- À Comissão de Pós Graduação em Solos e Nutrição de Plantas pela oportunidade de realização do curso à nível de "doutorado direto".

- À Empresa Mato-Grossense de Pesquisa, Assistência e Extensão Rural S/A EMPAER-MT pela liberação para realização do curso.

- A Antonimar Marinho dos Santos, Tsuioshi Yamada, Janice Guedes de Carvalho e Vilma da Silva pelo apoio e incentivo para realização do curso.

- Ao Dr. Prof. Amaldo Antonio Rodella pela orientação e amizade.

- Ao Dr. Prof. José Carlos Alcarde pela orientação e contribuições na fase inicial do curso e do projeto.

- À Fundação de Amparo à Pesquisa do Estado de São Paulo - FAPESP, pela bolsa e auxílio financeiro ao projeto.

- Aos professores do curso pelos ensinamentos.

- Aos funcionários do Departamento de Química da ESALQ, especialmente, ao Cristhian e Rita pela ajuda na execução das análises e nos trabalhos de casa de vegetação.

- Ao Departamento de Solos da ESALQ pela cessão da casa de vegetação.

- Ao Departamento de Química Analítica do Centro de Energia Nuclear da Agricultura e à Seção de Fertilidade do Solo do Instituto Agronômico de Campinas pelas determinações analíticas em ICP-AES.

- A todos que direta ou indiretamente colaboraram na execução deste trabalho. 
4 RESULTADOS E DISCUSSÃO

4.1 Teor de micronutrientes e elementos potencialmente tóxicos em calcários e fertilizantes minerais.................................................................. 33

4.2 Disponibilidade de micronutrientes e elementos potencialmente tóxicos presentes em calcário e fertilizantes minerais, avaliada através da análise

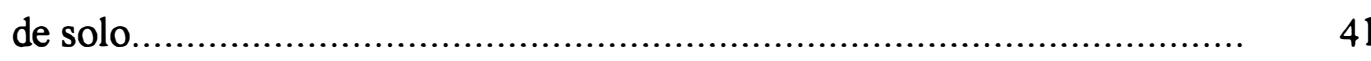

4.2.1 Cádmio, crômio, níquel e chumbo...................................................... 41

4.2.2 Boro, cobre, ferro, manganês e zinco.................................................. 47

4.3 Disponibilidade de micronutrientes e elementos potencialmente tóxicos presentes em calcário e fertilizantes minerais, avaliada através da absorção pela soja.................................................................. 52

4.3.1 Cádmio, crômio, chumbo e níquel ................................................. 52

4.3.2 Teores de micronutrientes na matéria seca, produção de matéria seca e

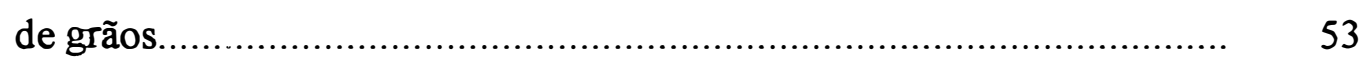

4.3.3 Teores de macronutrientes na matéria seca............................................. 65

4.3.4 Teores de micronutrientes na matéria seca em função da quantidade adicionada e dos teores extraídos pelo DTPA-TEA e Mehlich 3............ 67

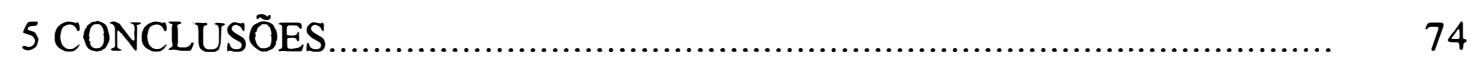






\section{TEOR E DISPONIBILIDADE PARA SOJA DE MICRONUTRIENTES E ELEMENTOS POTENCIALMENTE TÓXICOS EM FERTILIZANTES MINERAIS E CALCÁRIOS}

Autor: URSULA GABE

Orientador: Dr. ARNALDO ANTONIO RODELLA

\section{RESUMO}

Amostras de 60 fertilizantes minerais e calcários foram avaliadas quanto ao teor de $\mathrm{B}, \mathrm{Fe}, \mathrm{Mn}, \mathrm{Zn}, \mathrm{Cu}, \mathrm{Ni}, \mathrm{Pb}, \mathrm{Cd}, \mathrm{Cr}, \mathrm{Co}, \mathrm{Sr}$ e $\mathrm{Ba}$. Dentre estes materiais analisados, escolheu-se uma rocha fosfatada, um termofosfato, um calcário, uma mistura NPK e uma fonte de micronutrientes para conduzir dois experimentos em vasos, em casa de vegetação: um com Latossolo Roxo (LR) e outro com Areia Quartzosa (AQ). Os tratamentos constaram da aplicação isolada ou combinada dos cinco materiais aos solos, um tratamento completo e um teste, em quatro repetições, perfazendo 52 unidades experimentais para cada solo (13 tratamentos $\times 4$ repetições). Os materiais foram incubados com a terra por 90 dias, após os quais uma amostra de cada parcela foi analisada quanto ao teor de $\mathrm{Fe}, \mathrm{Mn}, \mathrm{Zn}, \mathrm{Cu}, \mathrm{Ni}, \mathrm{Cr}, \mathrm{Cd} \mathrm{e} \mathrm{Pb}$, usando os extratores DTPA-TEA e Mehlich 3 e de B pelo método de extração em água quente. Após a incubação, as unidades experimentais, arranjadas em delineamento em blocos casualizados, receberam a cultura da soja Glicine max (L.) Merril, var. IAC 8, que foi conduzida até o final do ciclo. A parte aérea das plantas foi colhida e avaliada quanto teor dos elementos e quanto à produção de matéria seca. A análise dos fertilizantes e calcários revelou a predominância de Fe e Mn na maioria das amostras; teores importantes de B 
em rochas e fertilizantes fosfatados; altos teores de $\mathrm{Cr}$ nos termofosfatos e baixas concentrações de $\mathrm{Cd}, \mathrm{Pb}, \mathrm{Co}$ e $\mathrm{Ni}$ nas amostras em geral. Para a cultura da soja, o calcário atuou como fonte de $\mathrm{Mn}$, a mistura 4-14-8 como fonte de B, $\mathrm{Zn}, \mathrm{Cu}$ e $\mathrm{Mn}$ e a fonte de micronutrientes, BR 5, mostrou ser uma eficiente fonte de $\mathrm{Zn}$ e B. As elevadas quantidades de $\mathrm{Mn}, \mathrm{Zn}$ e $\mathrm{B}$ adicionadas pela mistura 4-14-8 proporcionaram um nível excessivo destes nutrientes na parte aérea das plantas e as mais baixas produções de matéria seca e de grãos entre os tratamentos. $\mathrm{O}$ pH e a textura mostraram ser importantes atributos dos solos na disponibilidade dos elementos estudados. 


\title{
CONCENTRATION AND AVAILABILITY FOR SOYBEAN OF MICRONUTRIENTS AND POTENTIALLY TOXIC ELEMENTS PRESENT IN MINERAL FERTILIZERS AND LIMESTONES
}

\author{
Author: URSULA GABE \\ Adviser: Dr. ARNALDO ANTONIO RODELLA
}

\section{SUMMARY}

Samples of mineral fertilizers and limestones in a total of 60 were evaluated concernig the concentration of $\mathrm{B}, \mathrm{Fe}, \mathrm{Mn}, \mathrm{Zn}, \mathrm{Cu}, \mathrm{Ni}, \mathrm{Cd}, \mathrm{Cr}, \mathrm{Co}, \mathrm{Sr}$, and $\mathrm{Ba}$. Considering the different types of materials: rock phosphate, fused phosphate, limestone, NPK mixture and micronutrient source, one sample of each one was selected to be used in a pot trial with two soils. The 13 studied treatments consisted in the application to soil of the below mentioned materials, with the main objective of studying the nutrient source in presence and absence of limestone. A check and a complete treatment, where all nutrients were supplied by chemicals, were also included. After a period of 90 days of incubation, one soil sample from each pot was drawn for the determination of $\mathrm{Fe}, \mathrm{Mn}$, $\mathrm{Zn}, \mathrm{Cu}, \mathrm{Ni}, \mathrm{Cr}, \mathrm{Cd}$, and $\mathrm{Pb}$ in DTPA-TEA and Mehlich 3 extracts and also $\mathrm{B}$ extracted by hot water method. The incubated soils were used to carry out a greenhouse pot trial where soybean was cultivated up to the end of its cycle. A randomized block scheme was adopted. The dry matter production of soybean plants and its trace elements concentration were evaluated. Fertilizers analysis indicated $\mathrm{Fe}$ and $\mathrm{Mn}$ as major components in most of samples. Boron was present in rock phosphate and phosphatic fertilizers as well. High concentration of $\mathrm{Cr}$ in fused phosphate and low concentrations of 
$\mathrm{Cd}, \mathrm{Pb}, \mathrm{Co}$ and, $\mathrm{Ni}$ were observed for samples in general. Considering the nutrient uptake of the soybean plants it was observed that the studied material acted as nutrients sources in different ways: limestone for $\mathrm{Mn}$; the NPK mixture (4-14-8) for $\mathrm{B}, \mathrm{Zn}, \mathrm{Cu}$ and $\mathrm{Mn}$; and micronutrient source for $\mathrm{Zn}$ and $\mathrm{B}$. The high amounts of $\mathrm{Mn}, \mathrm{Zn}$ and, $\mathrm{B}$ supplied to soil by the NPK mixture caused the lowest level of dry matter and grains production among the treatments, which was attributed to the excessive levels of those elements in soybean plants. Soil $\mathrm{pH}$ and texture proved to be chief factors to understand the availability of the studied elements. 


\section{INTRODUÇÃO}

A análise química de fertilizantes simples, misturas NPK e calcários para confirmar a garantia de composição fornecida pelo fabricante tornou-se um procedimento quase rotineiro. $\mathrm{O}$ alto custo destes insumos é um dos fatores mais importantes para a tomada desta descisão por parte dos produtores agrícolas e as indústrias, por outro lado, têm interesse em conquistar a confiança dos agricultores, oferecendo insumos com suas composições comprovadas pela análise.

Mas, além dos elementos garantidos, principalmente, os fertilizantes fontes de fósforo e os calcários possuem outros elementos em sua constituição, que parecem não interessar aos agricultores e indústrias. São também escassos os estudos realizados sobre a pureza dos fertilizantes e calcários, ou seja, sobre quais são estes outros elementos, qual a faixa de concentração em que ocorrem e quais os seus efeitos quando aplicados aos solos.

Estes outros elementos podem ser os micronutrientes ( $\mathrm{Fe}, \mathrm{Mn}, \mathrm{Zn}, \mathrm{Cu}, \mathrm{Mo}$, Ni e B) que, embora requeridos em pequenas quantidades, são essenciais à nutrição das plantas. Elementos potencialmente tóxicos, como $\mathrm{Cd}, \mathrm{Pb}$ e $\mathrm{Cr}$ estão também, evidentemente, presentes nestes insumos. Os micronutrientes são elementos que podem causar alterações no equilíbrio natural dos solos, mas os resultados de sua aplicação a solos deficientes tendem a ser antes benéficos do que prejudiciais. No entanto, não se pode ignorar as consequências da adição aos solos de elementos potencialmente tóxicos e de micronutrientes em quantidades que possam provocar toxicidade às plantas e prejuízos à produção.

O conhecimento da concentração destes elementos nos fertilizantes e calcários, da contribuição para o acúmulo no solo e da disponibilidade às plantas são importantes e 
devem ser considerados tanto nos estudos que envolvem o uso e eficiência destes insumos, a fertilidade do solo e a avaliação do meio ambiente como no setor produtivo.

No estudo da avaliação da disponibilidade às plantas, existe a dificuldade em separar o efeito dos numerosos elementos presentes em um único material. Conhecendo esta limitação, no presente trabalho propôs-se a:

- determinar os teores dos elementos cobre $(\mathrm{Cu})$, ferro $(\mathrm{Fe})$, zinco $(\mathrm{Zn})$, manganês $(\mathrm{Mn})$, boro $(\mathrm{B})$, níquel $(\mathrm{Ni})$, cobalto $(\mathrm{Co})$, chumbo $(\mathrm{Pb})$, crômio $(\mathrm{Cr})$, cádmio $(\mathrm{Cd})$, estrôncio $(\mathrm{Sr})$ e bário $(\mathrm{Ba})$ em fertilizantes minerais e calcários;

- avaliar a fitodisponibilidade dos elementos $\mathrm{Cu}, \mathrm{Fe}, \mathrm{Zn}, \mathrm{Mn}, \mathrm{B}, \mathrm{Pb}, \mathrm{Ni}, \mathrm{Cr}$ e $\mathrm{Cd}$ presentes em fertilizantes minerais e em um calcário após sua aplicação aos solos e - verificar os efeitos da calagem sobre a fitodisponibilidade destes elementos. 


\section{REVISÃO DE LITERATURA}

Alguns termos usados para denominar o conjunto de elementos em estudo no presente trabalho são bastante polêmicos, cabendo aqui algumas referências. Os elementos essenciais para as plantas $\mathrm{Fe}, \mathrm{Mn}, \mathrm{Zn}, \mathrm{Cu}$ e $\mathrm{B}$ e, provavelmente, $\mathrm{Ni}$ e $\mathrm{Co}$, que ainda são classificados como benéficos, são designados micronutrientes. Os elementos $\mathrm{Cd}, \mathrm{Pb}, \mathrm{Cr}, \mathrm{Ba}$ e $\mathrm{Sr}$ também ocorrem nos tecidos vegetais mas não são essenciais, nem benéficos, podendo ser classificados como tóxicos (Malavolta, 1994).

Estes elementos ocorrem nos calcários e fertilizantes minerais e são, frequentemente, denominados de elementos traços, apesar de que os teores de $\mathrm{Fe}, \mathrm{Mn}$, $\mathrm{Ba}$ e $\mathrm{Sr}$ em muitos materiais ultrapassem o valor de $0,1 \%$ que, segundo Adriano (1986), é o limite para que um elemento seja considerado traço em materiais naturais, na litosfera; em tecidos vegetais e animais, o autor refere-se ao limite de $0,01 \%$ como consenso entre cientistas da área de bioquímica e biomédica. Malavolta (1994) considerou o termo "elementos traços" como não adequado para estes elementos, visto que o qualificativo "traço" na Química Analítica Quantitativa é reservado para designar concentrações de qualquer elemento que não pode, por muito baixo, ser quantificado pelo método empregado na sua determinação.

Outra denominação comumente utilizada é "metais pesados". A expressão é mais usada para se referir aos elementos contaminantes do ar, água, solo e alimentos, mas se aplica a elementos que têm peso específico maior que $5,0 \mathrm{~g} \mathrm{~cm}^{-3}$, sendo que Malavolta (1994) inclui também os elementos com número atômico maior do que 20 , englobando metais, semi-metais e mesmo não metais como o selênio. 


\subsection{Micronutrientes e elementos potencialmente tóxicos em calcários e fertilizantes minerais}

Bergmann (1992) relatou: "Informações de prejuízos às plantas causados por metais pesados têm sido abundantes já há algum tempo, mas recentemente, esse número tem aumentado dramaticamente." A contribuição global dos fertilizantes e calcários para o incremento desses metais nos solos é bem menor do que a precipitação atmosférica e deposição de cinzas, principalmente em zonas altamente industrializadas ou às margens de rodovias, mas tanto estes insumos como águas contaminadas, estercos, lodos de esgoto, compostos de lixo urbanos e pesticidas, podem elevar expressivamente os teores nos solos (Kabata-Pendias \& Pendias, 1984; Alloway, 1990; Adriano, 1986).

As opiniões sobre a importância destes elementos presentes nos calcários e fertilizantes variam bastante, o que é compreensível devido à complexidade do assunto; está-se envolvido com um grande número de elementos, cuja concentração varia não somente de uma região geográfica para outra, mas entre pontos específicos de uma camada geológica em exploração. Além disso, estes elementos podem não ser provenientes do material de origem, mas de outras fontes usadas no processamento da obtenção dos insumos comerciais, como catalizadores ou outros reagentes, corrosão dos equipamentos, ou mesmo, o atrito entre o maquinário e o material na moagem e peneiramento pode aumentar a quantidade de alguns metais no produto final (Chichilo \& Whittaker, 1961).

As primeiras avaliações destes elementos em fertilizantes e calcários foram motivados por interesse nas concentrações de micronutrientes. A falta de resposta à aplicação de micronutrientes em experimentos de campo com soja em solos sob vegetação de cerrado verificada por Miyasaka et al. (1964), Mascarenhas et al. (1967) e Mascarenhas et al. (1973), levou os últimos autores a sugerirem que o fato ocorria devido à presença destes elementos nos calcários e fertilizantes usados nos experimentos. 


\subsubsection{Métodos de análise}

A análise de fertilizantes e calcários para determinação de metais pesados comumente é feita pela digestão de uma porção da amostra com ácidos fortes concentrados a quente e posterior determinação por espectofotometria de absorção atômica (AAS) ou espectrofotometria de emissão atômica por plasma (ICP-AES), obtendo-se segundo Ure (1990), os falsos teores totais. A metodologia oficial, Brasil (1988) e Kane (1995), recomenda a utilização de $\mathrm{HCl}$ concentrado.

As diferenças entre as metodologias empregadas nos estudos referidos na literatura são o uso de um ou da combinação dos seguintes ácidos: $\mathrm{HCl}, \mathrm{H}_{2} \mathrm{SO}_{4}, \mathrm{HNO}_{3} \mathrm{e}$ $\mathrm{HClO}_{4}$. Alguns estudos usam a digestão com $\mathrm{HF}$ que pode gerar resultados mais elevados, pois ataca minerais silicatados que permanecem insolúveis na digestão com outros ácidos, mas ainda não é eficiente na obtenção da total dissolução. Os métodos de fusão com metaborato de lítio ou $\mathrm{Na}_{2} \mathrm{CO}_{3}$ são mais eficientes na dissolução de amostras contendo silicatos (Ure, 1990), mas são pouco usados nas análises de fertilizantes.

\subsubsection{Teores em rochas e fertilizantes fosfatados}

A presença de cádmio nas rochas e fertilizantes fosfatados tem motivado nas últimas décadas um número razoável de estudos. Os fertilizantes contaminados por este elemento potencialmente prejudicial à saúde humana são um meio de entrada na cadeia alimentar, pois uma vez no solo, pode ser absorvido pelas plantas, as quais são direta ou indiretamente consumidas pelo homem (Adriano, 1986).

Os fertilizantes fosfatados contêm diferentes quantidades de cádmio e outros metais pesados, o que está muito relacionado com a origem geológica das rochas usadas como matérias primas. Segundo Alloway (1990), os teores relativamente altos de cádmio encontrados na maioria das fosforitas, tornam os fertilizantes fosfatados a fonte de 
contaminação mais comum dos solos cultivados. A concentração nessas rochas pode chegar a $980 \mathrm{mg} \mathrm{kg}^{-1}$ (USDA-USDI ${ }^{1}$, citado por Mulla et al., 1980).

A maioria das jazidas de rochas fosfatadas em exploração no Brasil são apatíticas. Os teores de cádmio nestas rochas são menores que $2,0 \mathrm{mg} \mathrm{kg}^{-1}$ (Langenbach \& Sarpa, 1985) e que 7,0 $\mathrm{mg} \mathrm{kg}^{-1}$ (Amaral Sobrinho et al., 1992), que comparados com os de outros países como E.U.A. (5 a $200 \mathrm{mg} \mathrm{kg}^{-1}$ ), Austrália (18 a $91 \mathrm{mg} \mathrm{kg}^{-1}$ ) e africanos (3 a $75 \mathrm{mg} \mathrm{kg}^{-1}$ ), são relativamente baixos (Mortvedt et al., 1981; Williams \& David, 1973; Sauerbeck, 1985).

O cádmio contido nas rochas fosfatadas é transferido quase que totalmente para os fertilizantes no seu processamento. Williams \& David (1973) verificaram estreita correlação entre os teores de cádmio nos fertilizantes e nas rochas usadas nas suas obtenções; verificaram também estreita correlação entre os teores de cádmio e fósforo, zinco e fósforo, e zinco e cádmio, estes últimos com uma relação igual a 10:1. Wakefield $^{2}$, citado por Mortvedt (1987), verificou que o superfosfato continha mais que $60 \%$ do cádmio existente na rocha e, aproximadamente, $30 \%$ dele foi encontrado no fosfogesso.

A calcinação da rocha a altas temperaturas leva a uma redução de 80 a $90 \%$ do seu teor de cádmio, mas tem o inconveniente de consumir grande quantidade de energia (Sauerbeck, 1985). Amaral Sobrinho et al. (1992) verificaram baixo teor de cádmio (3,1 $\mathrm{mg} \mathrm{kg}^{-1}$ ) em amostra do termofosfato Yoorin, produto obtido da fusão a temperatura de $1500^{\circ} \mathrm{C}$ da mistura da rocha fosfatada e aditivos fontes de magnésio e sílica. Por outro lado, os mesmos autores verificaram elevado teor de níquel no produto ( $\left.3.300 \mathrm{mg} \mathrm{kg}^{-1}\right)$.

Watanabe (1984) observou a acumulação de $\mathrm{Cr}$ em solos que receberam pesadas aplicações de fosfato magnesiano fundido, obtido com a adição da rocha serpentinita; verificou uma variação na concentração de Cr nesse fertilizante, no Japão, de 0,1 a 2,7 g

1 United States Department of Agriculture (USDA) and United States Department of the Interior (USDI). Development of phosphate resourses in S. E. Idaho: Final Environment Impact Statement, 1977, v.1, p. 52-54.

2 WAKEFIELD, Z. T. Distribuition of cadmium and selected heavy metals in phosphate fertilizer processing. Bull. Y-159. National Fertilizer Development Center, Tennessee Valley Authority, Muscle Shoals, AL. 1980. 
$\mathrm{kg}^{-1}$. Amaral Sobrinho et al. (1992) verificaram teores relativamente baixos de $\mathrm{Cr}: 9,7 \mathrm{mg}$ $\mathrm{kg}^{-1}$ no termofosfato Yoorin e $1,9 \mathrm{mg} \mathrm{kg}^{-1}$ na apatita de Araxá.

Segundo Lopes \& Guilherme (1991), a frequente ocorrência de deficiências de micronutrientes em plantas cultivadas no Brasil pode ser atribuída, entre outros fatores, ao aumento no uso de adubos de alta concentração, os quais contêm menores quantidades de micronutrientes como impurezas. No entanto, Mascarenhas et al. (1973) apresenta concentrações de $\mathrm{Cu}, \mathrm{Fe}, \mathrm{Mn}, \mathrm{Zn}$ e Mo em superfosfato triplo e superfosfato simples, que se mostram, sem exceção, maiores no fertilizante mais concentrado em fósforo. A grandeza destas diferenças chega a compensar as doses menores a serem aplicadas em função da maior concentração de P. Arora et al. (1975) verificou teores em superfosfato simples e superfosfato triplo, respectivamente, de 15,5 e $49,3 \mathrm{mg} \mathrm{kg}^{-1} \mathrm{de}$ $\mathrm{Cu}$, de 165,3 e $418,0 \mathrm{mg} \mathrm{kg}^{-1}$ de $\mathrm{Zn}$ e 132,5 e $212,5 \mathrm{mg} \mathrm{kg}^{-1}$ de $\mathrm{B}$. Em amostra de fosfato diamônico (DAP), os últimos autores obtiveram a concentração de $396,3 \mathrm{mg} \mathrm{kg}^{-1}$ de boro.

Baseando-se apenas nos teores dos nutrientes nos fertilizantes e nas quantidades comumente aplicadas aos solos para a cultura da soja (Sousa et al., 1993), e não em evidências experimentais, é lícito esperar que as concentrações de micronutrientes acima referidas possam contribuir para incrementos na produção. $\mathrm{O}$ mesmo pode ser afirmado com relação aos teores de $\mathrm{Mn}$ e $\mathrm{Zn}$ verificados por Amaral Sobrinho et al. (1992) no termofosfato Yoorin e na apatita de Araxá: $2.220 \mathrm{mg} \mathrm{kg}^{-1}$ e $3.915 \mathrm{mg} \mathrm{kg}^{-1}$ de $\mathrm{Mn}$ e 374,5 $\mathrm{mg} \mathrm{kg}^{-1}$ e 740,5 $\mathrm{mg} \mathrm{kg}^{-1}$ de $\mathrm{Zn}$, respectivamente.

\subsubsection{Teores em calcários}

Valadares et al. (1974) determinaram os teores de micronutrientes em amostras de calcário do Estado de São Paulo e Chichilo \& Whittaker (1958) e Chichilo \& Whittaker (1961), em amostras de várias regiões dos Estados Unidos; ambos trabalhos indicam consideráveis concentrações de Fe, Mn, Zn e Mo. Os autores, baseando-se em cálculos a partir de doses de calcário aplicadas ao solo e de quantidades de micronutrientes 
removidas pelas colheitas, concluíram que os calcários podem suprir parcial ou totalmente a demanda destes elementos pelas culturas.

As faixas de concentrações de micronutrientes em calcários agrícolas são bastante amplas (Tabela 1) e esta amplitude pode estar relacionada com a origem geológica das rochas. Valadares et al. (1974) verificaram que a amostra de calcário magmático analisada foi mais rica do que os calcários sedimentares e estes mais ricos do que os metamórficos.

Tabela 1. Faixas de concentração de micronutrientes em calcários agrícolas. *

\begin{tabular}{|c|c|c|c|c|c|}
\hline Referência** & $\overline{\mathrm{Fe}}$ & $\mathrm{Mn}$ & $\overline{\mathrm{Zn}}$ & $\overline{\mathrm{Cu}}$ & $\mathrm{B}^{* * *}$ \\
\hline & $\cdots$ & …................ & $\mathrm{mg} \mathrm{kg}^{-1}$. & & $\ldots$ \\
\hline \multirow[t]{2}{*}{ Chichilo \& Whittaker (1958) } & $100-31.100$ & $20-3.000$ & $<1-425$ & $0,3-89,0$ & $1-21$ \\
\hline & $(4.300)$ & $(330)$ & (31) & $(2,7)$ & (4) \\
\hline \multirow[t]{2}{*}{ Chichilo \& Whittaker $(1961)^{2}$} & $200-12.700$ & $20-2.320$ & $4-427$ & $<0,3-5,2$ & $<1-18$ \\
\hline & $(3.500)$ & $(240)$ & (44) & $(1,1)$ & (3) \\
\hline \multirow[t]{2}{*}{ Valadares et al. $(1974)^{3}$} & $159-33.110$ & $30-1850$ & $7,5-46$ & $5,4-42,2$ & N. A. \\
\hline & $(3.905)$ & $(810)$ & $(15,2)$ & $(11,0)$ & \\
\hline Amaral Sobrinho et al. (1992) & $376-4.599$ & $46-221$ & $12,5-78,1$ & $2,5-11,0$ & N. A. \\
\hline
\end{tabular}

Amaral Sobrinho et al. (1992) verificaram pequena variação na concentração de metais pesados, assim como teores relativamente baixos, em calcários comercializados no Estado de Minas Gerais; os maiores teores de $\mathrm{Cd}, \mathrm{Pb}, \mathrm{Ni}$ e $\mathrm{Cr}$ foram, respectivamente, $3,4 \mathrm{mg} \mathrm{kg}^{-1}, 27,9 \mathrm{mg} \mathrm{kg}^{-1}, 19,0 \mathrm{mg} \mathrm{kg}^{-1}, 0,6 \mathrm{mg} \mathrm{kg}^{-1}$. Entretanto, Amaral (1993) usou, em experimento em vasos, um calcário dolomítico comercializado no mesmo Estado, contendo teores elevados de alguns metais pesados: $12.948 \mathrm{mg} \mathrm{kg}^{-1} \mathrm{de} \mathrm{Zn}, 46.434 \mathrm{mg}$ $\mathrm{kg}^{-1}$ de Fe, $3.125 \mathrm{mg} \mathrm{kg}^{-1}$ de $\mathrm{Mn}, 107,20 \mathrm{mg} \mathrm{kg}^{-1}$ de $\mathrm{Cd} \mathrm{e} 2.851 \mathrm{mg} \mathrm{kg}^{-1}$ de $\mathrm{Pb}$. 


\subsubsection{Teores em fontes de micronutrientes}

As fontes puras de micronutrientes, praticamente, não são usadas nas aplicações via solo devido aos seus altos custos e às quantidades necessárias serem relativamente grandes (1 a $\left.10 \mathrm{~kg} \mathrm{ha}^{-1}\right)$, tomando as aplicações antieconômicas.

O zinco é um dos micronutrientes mais fornecido às plantas através de aplicações via solo, geralmente associado às formulações NPK. O óxido de $\mathrm{Zn}$, uma das fontes mais usadas, é obtido pela oxidação do minério esfarelita ou de outras fontes, como cinzas das indústrias de galvanização, pigmentos, baterias e outras. $\mathrm{O}$ sulfato de $\mathrm{Zn}$ hidratado também é obtido destes produtos. Tanto a esfarelita como os subprodutos industriais possuem metais pesados indesejáveis em sua constituição (Ponchio \& Ballio, 1988).

Segundo Amaral Sobrinho et al. (1992), o teor de $275 \mathrm{mg} \mathrm{kg}^{-1}$ de chumbo que verificaram em adubo formulado pode ser resultante do enriquecimento da fórmula com alguma fonte de rinco.

$\mathrm{O} \mathrm{ZnO}$ puro apresenta $78 \%$ de $\mathrm{Zn}$, sendo que algumas fontes entram no mercado com menos de $50 \%$, devido à presença de impurezas. Vários são os processos que podem ser usados para remover estas impurezas, mas a maioria dos produtos é comercializada sem purificação, podendo conter quantidades apreciáveis de metais pesados como $\mathrm{Pb}$, Cd, Ni e Cr (Mortvedt, 1985a).

Em quatro amostras de $\mathrm{ZnO}$ comerciais, Alcarde \& Rodella (1993) verificaram uma grande variação nos teores de $\mathrm{Pb}\left(153,3\right.$ a 2.054,1 $\left.\mathrm{mg} \mathrm{kg}^{-1}\right)$ e de $\mathrm{Cd}(7,7$ a $82,7 \mathrm{mg}$ $\left.\mathrm{kg}^{-1}\right)$. No entanto, Mortvedt (1985b) ao analisar fontes de zinco provenientes de subprodutos industriais usados na agricultura dos Estados Unidos obteve valores bem mais elevados: 4 a $2.165 \mathrm{mg} \mathrm{kg}^{-1}$ de cádmio, 19 a $8.950 \mathrm{mg} \mathrm{kg}^{-1}$ de níquel e 50 a 52.000 $\mathrm{mg} \mathrm{kg}^{-1}$ de chumbo. Considerando as doses de zinco comumente aplicadas aos solos no Brasil, várias destas fontes excedem, em algumas vezes, as quantidades desses elementos adicionadas por ha $a o^{-1}$, permitidas pela legislação da República Federal da Alemanha (Bergmann, 1992). 
As fritas ( FTE - "frited trace elements") são silicatos complexos obtidos pela fusão de silicatos ou fosfatos com uma ou mais fontes simples de micronutrientes, podendo também conter elementos indesejáveis. As fritas são também usadas em associação com as misturas NPK e, segundo Volkweiss (1991), são mais apropriadas para progamas de manutenção de níveis de micronutrientes no solo do que para corrigir severas deficiências, pois se dissolvem mais ou menos lentamente no solo. Mas Vale (1997) verificou alta solubilidade em água do B presente em várias fritas analisadas. Provavelmente, estes produtos receberam a adição de uma fonte solúvel de $\mathrm{B}$. Para culturas sensíveis a concentrações mais elevadas de B nos solos, como soja, um pequeno excesso na dose do fertilizante pode provocar um aumento imediato na quantidade disponivel do elemento e causar danos à cultura.

A disponibilidade de metais potencialmente tóxicos presentes nestes fertilizantes ainda não foi elucidada, mas os seus efeitos devem ser mínimos devido às taxas muito baixas aplicadas aos solos. Por exemplo, a aplicação ao solo de $\mathrm{ZnO}$ (60\% Zn) contendo $500 \mathrm{mg} \mathrm{kg}^{-1}$ de $\mathrm{Pb}$ em uma dose de $5 \mathrm{~kg}$ de $\mathrm{Zn}$ por hectare irá resultar em uma dose de somente $4 \mathrm{~g}$ de $\mathrm{Pb}$ por hectare. Por outro lado, estes metais são relativamente imóveis nos solos, podendo ser acumulados na camada superficial. Assim, a aplicação destes subprodutos por vários anos em uma mesma área pode tornar seus níveis significantes no solo (Mortvedt, 1985a).

\subsection{Micronutrientes e elementos potencialmente tóxicos no solo}

Os teores totais no solo, em geral, não dão uma boa idéia da disponibilidade dos micronutrientes e elementos tóxicos para as plantas. Admite-se que os elementos contidos nas estruturas de minerais encontram-se ligados de tal forma que impede sua liberação para as plantas. Várias outras formas são reconhecidas como disponíveis: as solúveis em água, as trocáveis, complexadas ou adsorvidas. Além disso, há uma série de fatores do solo que tem influência na disponibilidade destas formas (Raij \& Bataglia, 1991). 


\subsubsection{Fatores que afetam a disponibilidade}

Os metais pesados podem ocorrer nos solos sob diversas formas: na forma iônica ou na forma complexada na solução do solo, como íons trocáveis no material orgânico ou inorgânico de troca ativa, como íons mais firmemente presos aos complexos de troca, como íons quelados em complexos orgânicos ou organominerais, incorporados em sesquióxidos precipitados ou sais insolúveis, incorporados nos microrganismos e nos seus resíduos biológicos, ou ainda, presos nas estruturas cristalinas dos minerais primários ou secundários. A distribuição de um metal entre estas várias formas fisico-químicas é influenciada por numerosas propriedades do solo incluindo o valor de $\mathrm{pH}$, o potencial redox, a textura, a composição mineral (conteúdo e tipo de argilas e de óxidos de $\mathrm{Fe}, \mathrm{Al}$ e Mn), as características do perfil, a CTC, a quantidade e o tipo de componentes orgânicos no solo e na solução, a presença de outros metais pesados, a temperatura do solo e seu conteúdo de água e outros fatores que afetam a atividade microbiana. Todos estes fatores que afetam a distribuição dos metais pesados no sistema solo, controlam suas solubilidades e, consequentemente, suas mobilidades no meio e suas disponibilidades às plantas (Adriano, 1986; Kabata-Pendias \& Pendias, 1984).

Os elementos competem entre si e com os compostos orgânicos e inorgânicos por sítios de adsorção ou por ligações complexantes disponiveis. Assim, a retenção dos metais não é afetada apenas por sua concentração na solução, mas também pela concentração de todos os outros constituintes do sistema. O cádmio, por exemplo, está fortemente associado ao zinco na geoquímica, mas parece ter uma afinidade muito maior por grupos $\mathrm{SH}$ em enzimas e proteínas do que o zinco, de onde provém sua ação tóxica. Quando a concentração de cádmio não for muito elevada, seu efeito tóxico pode ser amenizado pela adição de rinco ao solo (Bergmann, 1992).

A adsorção é, provavelmente, o processo de maior importância na química dos metais pesados no solo. A quantidade de cátions que pode ser adsorvida por troca de íons da solução pela fase sólida em condições específicas de temperatura, força iônica e $\mathrm{pH}$, é 
chamada de capacidade de troca catiônica (CTC) e é dependente das espécies envolvidas. Assim, uma fração dos vários metais pesados encontra-se associada às superficies de partículas argilosas, orgânicas e aos precipitados insolúveis como hidróxidos, carbonatos e fosfatos, por meio de ligações eletrovalentes. Estes íons simples ou complexos, estão em equilibrio com o sistema aquoso, podendo tornarem-se disponíveis para o sistema radicular das plantas (Sposito, 1989).

A CTC de um solo é de grande importância na determinação da extensão com que os metais pesados são adsorvidos aos constituintes da fase sólida. Devido a essa importância, até recentemente, a legislação dos Estados Unidos estabelecia a quantidade de metais pesados que podia ser aplicada aos solos em função da CTC (Logan \& Chaney, 1983).

A capacidade do solo em reter metais, geralmente, é aumentada com a elevação do $\mathrm{pH}$. O efeito do $\mathrm{pH}$ na adsorção de um cátion metálico é, principalmente, o resultado de mudanças nas cargas líquidas de prótons na superficie das partículas do solo. Quando o $\mathrm{pH}$ aumenta, a carga líquida de prótons pode diminuir até valores negativos e, assim, a atração eletrostática das partículas aumenta (Sposito, 1989). A relativa remoção de alguns metais foi assim sumarizada por Fuller (1976): em solos ácidos ( $\mathrm{pH} \mathrm{4,2} \mathrm{a} \mathrm{6,6),} \mathrm{Cd,}$ $\mathrm{Hg}$, Ni e Zn são relativamente disponíveis; As, $\mathrm{Be}$ e $\mathrm{Cr}$ são moderadamente disponíveis; e $\mathrm{Cu}, \mathrm{Pb}$ e Se são lentamente disponíveis.

A umidade do solo também afeta a capacidade de retenção de metais por influenciar as reações redox. Bingham et al. (1976) mostraram que sob condições redutoras a solubilidade do $\mathrm{Cd}$, $\mathrm{Cu}$ e $\mathrm{Zn}$ diminuíam e a de $\mathrm{Fe}$ e Mn aumentavam.

\subsubsection{Avaliação da disponibilidade}

A avaliação da disponibilidade de micronutrientes no solo exige métodos que apresentem boa correlação com a absorção pelas plantas. Muitos extratores têm sido usados nesta diagnose. Um extrator, em particular, superior em todas as condições de 
solo e planta, será dificilmente encontrado. Contudo, vários extratores são usados com sucesso; os mais comuns são os ácidos diluídos e os quelatos (Lindsay \& Cox, 1985).

Apesar do extrator DTPA-TEA (ácido dietileno triamino pentaacético + trietanolamina) ter sido desenvolvido para uso em solos calcários (Lindsay \& Norvell, 1978), estudos indicam que é aplicável a solos ácidos com resultados tão bons quanto nos alcalinos e superior a extratores ácidos diluídos. No Brasil, há evidências de que as soluções complexantes, como DTPA-TEA e EDTA (ácido etileno diamino tetraacético), são melhores do que as ácidas, como Mehlich $1\left(\mathrm{HCl} \mathrm{0,05} \mathrm{mol} \mathrm{L}^{-1}+\mathrm{H}_{2} \mathrm{SO}_{4} 0,025 \mathrm{~mol} \mathrm{~L}^{-1}\right.$ e $\mathrm{HCl} \mathrm{0,1} \mathrm{mol} \mathrm{L}^{-1}$ (Lantmann \& Meurer, 1982; Muraoka et al., 1983a, 1983b; Ribeiro \& Tucunango Sarabia, 1984).

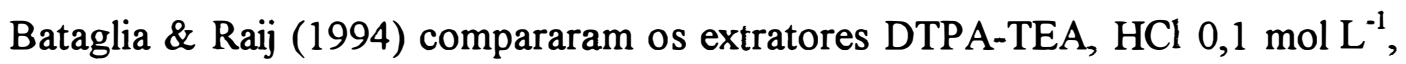
Mehlich 1 e EDTA, e verificaram para o DTPA-TEA coeficientes de correlação ligeiramente superiores aos demais para milho; para arroz, o DTPA-TEA foi mais eficiente do que o $\mathrm{HCl} 0,1 \mathrm{~mol} \mathrm{~L}^{-1}$ e superior aos demais na discriminação dos efeitos da calagem na disponibilidade de zinco. Por outro lado, Haq \& Miller (1972) concluíram que é necessário incluir o $\mathrm{pH}$ do solo na equação para predizer a concentração de $\mathrm{Zn}$ em plantas de milho, ao usar o método DTPA-TEA, em solos com $\mathrm{pH}$ menor do que 7.

Outros metais pesados como $\mathrm{Cd}, \mathrm{Ni}, \mathrm{Pb}$ e $\mathrm{Cr}$ podem ser extraídos dos solos com soluções contendo quelatos, como o DTPA-TEA. Dang et al. (1990) verificaram que o DTPA-TEA foi adequado para avaliar $\mathrm{Cd}, \mathrm{Ni}, \mathrm{Pb}$ e $\mathrm{Zn}$ disponíveis em solos que receberam esses elementos para cebola e feno grego. Roca \& Pomares (1991) consideraram que todos os quelatos, incluindo DTPA-TEA, foram adequados para avaliar a disponibilidade de metais pesados em solos, para alface. Haq et al. (1980) obtiveram boa predição da disponibilidade de $\mathrm{Zn}, \mathrm{Cd}$ e $\mathrm{Ni}$ para plantas de beterraba cultivadas em solos contaminados, quando os teores extraídos pelo DTPA-TEA foram associados ao $\mathrm{pH}$, matéria orgânica e/ou CTC dos solos.

A solução Mehlich $3\left(\mathrm{CH}_{3} \mathrm{COOH} 0,2 \mathrm{~mol} \mathrm{~L}^{-1}+\mathrm{NH}_{4} \mathrm{NO}_{3} 0,25 \mathrm{~mol} \mathrm{~L}^{-1}+\mathrm{NH}_{4} \mathrm{~F}\right.$ 0,015 mol L${ }^{-1}+\mathrm{HNO}_{3} 0,013 \mathrm{~mol} \mathrm{~L}^{-1}+$ EDTA $0,001 \mathrm{~mol} \mathrm{~L}^{-1}$ ), proposta por Mehlich (1984) como um extrator multielementar, foi comparada inicialmente com outros extratores e apenas recentemente, alguns trabalhos têm sido feitos envolvendo plantas. 
Mulchi et al. (1991) estudadaram vários extratores para metais pesados em solos tratados com lodo de esgoto e verificaram que Mehlich 1, Mehlich 3 e DTPA-TEA foram adequados para determinar a disponibilidade de $\mathrm{Zn}, \mathrm{Cu}, \mathrm{Ni}$ e $\mathrm{Cd}$ para fumo, mas observaram que Mehlich 3 não foi adequado para Mn e que nenhum dos três extratores foi eficiente para $\mathrm{Fe} \mathrm{e} \mathrm{Pb}$.

$\mathrm{Na}$ literatura pode-se verificar que a ineficiência dos extratores em avaliar a disponibilidade, principalmente de elementos tóxicos, está relacionada a solos com baixos teores destes elementos. Abreu et al. (1995) verificaram a ineficiência do DTPA-TEA e Mehlich 3 na avaliação da disponibilidade de $\mathrm{Pb}, \mathrm{Cd}, \mathrm{Cr}$ e $\mathrm{Ni}$ para trigo e $\mathrm{Pb}$ e $\mathrm{Cd}$ para feijão em solos contendo, em média, $1,7 \mathrm{mg} \mathrm{dm}^{-3} \mathrm{de} \mathrm{Pb}, 0,07 \mathrm{mg} \mathrm{dm}^{-3} \mathrm{de} \mathrm{Cd}, 0,11 \mathrm{mg}$ $\mathrm{dm}^{-3}$ de $\mathrm{Cr}$ e $0,38 \mathrm{mg} \mathrm{dm}^{-3}$ de Ni.

A literatura tem sido unânime em indicar a água quente como melhor extrator para avaliar a disponibilidade de boro às plantas (Cox \& Kamprath, 1972; Reisenauer et al., 1973). Algumas variações na metodologia ocorrem como a extração por refluxo, por simples fervura ou em microondas, a substituição da água por uma solução de $\mathrm{CaCl}_{2}$ ou $\mathrm{BaCl}_{2}$ para obter extratos mais límpidos, o tempo de fervura, entre outras. Apesar destas variações, os resultados obtidos quase sempre se correlacionam melhor com o boro extraído pelas plantas do que por extratores ácidos.

\subsubsection{Níveis críticos e adequados no solo}

Estes níveis nos solos devem estar sempre associados a plantas, pois as espécies vegetais e até variedades comportam-se diferentemente diante dos teores de nutrientes no solo. $\mathrm{Na}$ maioria dos casos de estudos com micronutrientes são escolhidas espécies sensíveis a baixos teores no solo, assim os níveis críticos são normalmente altos para espécies ou variedades menos sensíveis (Raij \& Bataglia, 1991).

Os níveis críticos de micronutrientes extraídos pelo DTPA-TEA para milho sugeridos por Lindsay \& Norvell (1978) são: $0,8 \mathrm{mg} \mathrm{kg}^{-1}$ para $\mathrm{Zn}, 1,0 \mathrm{mg} \mathrm{kg}^{-1}$ para $\mathrm{Mn}$, 
$0,2 \mathrm{mg} \mathrm{kg}^{-1}$ para Cu e 4,5 $\mathrm{mg} \mathrm{kg}^{-1}$ para Fe. Ritchey et al. (1986) verificou também para milho um valor muito próximo para $\mathrm{Zn}: 0,7 \mathrm{mg} \mathrm{kg}^{-1}$.

Para solos do Estado de São Paulo, foram estabelecidas classes de interpretação de teores de micronutrientes metálicos extraídos pelo método DTPA-TEA e de B extraído pelo método da água quente (Tabela 2).

Em experimento em vasos, com soja cultivar Paraná, Buzetti (1988) obteve níveis críticos de 0,11 a $0,23 \mathrm{mg} \mathrm{kg}^{-1}$ para $\mathrm{B}$, extraído pelo método da água quente, quando relacionou os teores no solo, com e sem calcário, com $90 \%$ da produção de matéria seca e de grãos; para $\mathrm{Zn}$ estes valores, extraídos pelo DTPA-TEA, ficaram entre 0,27 e 0,37 $\mathrm{mg} \mathrm{kg}^{-1}$.

Tabela 2. Classes de interpretação de teores de micronutrientes em solos usadas no Estado de São Paulo.

\begin{tabular}{cccccc}
\hline \hline Classes & $\mathrm{B}$ & $\mathrm{Cu}$ & $\mathrm{Fe}$ & $\mathrm{Mn}$ & $\mathrm{Zn}$ \\
\hline & $\ldots \ldots \ldots \ldots \ldots \ldots \ldots \ldots \ldots \ldots \ldots \ldots \ldots \ldots \ldots \ldots \ldots \ldots \ldots \ldots \ldots \ldots \ldots \ldots \ldots \ldots \ldots \ldots \ldots \ldots \ldots \ldots \ldots \ldots \ldots \ldots \ldots \ldots \ldots \ldots \ldots \ldots \ldots \ldots \ldots \ldots \ldots \ldots \ldots \ldots \ldots \ldots \ldots$ \\
Baixo & $<0,20$ & $<0,20$ & $<5$ & $<1,2$ & $<0,5$ \\
Médio & $0,20-0,60$ & $0,20-0,80$ & $5-12$ & $1,2-4,0$ & $0,5-1,2$ \\
Alto & $>0,60$ & $>0,80$ & $>12$ & $>4,0$ & $>1,2$ \\
\hline \hline
\end{tabular}

Fonte: Abreu (1995).

Os teores totais dos metais pesados $\mathrm{Cd}, \mathrm{Pb}, \mathrm{Cr}$ e Ni nos solos são mais frequentes na literatura do que os "disponiveis". Os teores totais de $\mathrm{Cd}$ muito raramente excedem o valor de $1,0 \mathrm{mg} \mathrm{kg}^{-1}$ em solos agrícolas não contaminados; segundo Kabata-Pendias \& Pendias (1985), todos os valores que excedem $0,5 \mathrm{mg} \mathrm{kg}^{-1}$ refletem o impacto antropogênico na camada superficial do solo. Os teores de $\mathrm{Pb}$ mais comuns não ultrapassam $50 \mathrm{mg} \mathrm{kg}^{-1}$. Os níveis de $\mathrm{Cr}$ e $\mathrm{Ni}$ são bastante dependentes do material de origem do solo; a serpentinita é rica nestes elementos. A maioria dos solos contém entre 5 e $1.000 \mathrm{mg} \mathrm{kg}^{-1}$ de $\mathrm{Cr}$ e entre 1 a $50 \mathrm{mg} \mathrm{kg}^{-1} \mathrm{de} \mathrm{Ni}$, podendo em solos originários da rocha serpentinita, chegar a $7.000 \mathrm{mg} \mathrm{kg}^{-1}$ (Adriano, 1986). 
Em geral, os solos contêm menos do que $20 \mathrm{mg} \mathrm{kg}^{-1}$ de $\mathrm{Pb}$ extraído pelo DTPATEA; em plantas, as concentrações são geralmente menores do que $1 \mathrm{mg} \mathrm{kg}^{-1} \mathrm{em}$ sementes e frutas, e de 1 a $3 \mathrm{mg} \mathrm{kg}^{-1}$ em folhas e nas raízes as concentrações podem ser bem mais elevadas, quando os teores no solo forem altas (Wallace \& Wallace, 1994).

A diagnose da disponibilidade de metais é dificultada, entre outros fatores, pelas baixas concentrações nos solos. Abreu et al. (1995), em estudo com o objetivo de comparar métodos de análise de solo para avaliar a disponibilidade de $\mathrm{Cr}, \mathrm{Cd}, \mathrm{Pb}$ e $\mathrm{Ni}$, usaram amostras da camada superficial dos tipos mais representativos de solos do Estado de São Paulo; verificaram as seguintes faixas de teores, expressos em $\mathrm{mg} \mathrm{dm}^{-3}$, para os métodos Mehlich 3 e DTPA-TEA, respectivamente: 4,6 a 11,0 e 0,6 a 5,9 de $\mathrm{Pb}, 0,25$ a 0,65 e 0,02 a 0,14 de $\mathrm{Cd}, 0,36$ a 1,85 e 0,03 a 0,18 de $\mathrm{Cr}$ e 0,41 a 1,90 e 0,09 a 0,90 de $\mathrm{Ni}$.

\subsection{Micronutrientes e elementos potencialmente tóxicos em soja}

A falta e o excesso de nutrientes para as plantas são, normalmente, manifestados pela redução na produção ou por sintomas na parte aérea ou nas raízes e estão associados aos niveis "disponíveis" do nutriente no solo e às concentrações nos tecidos das plantas. Por esta razão, na diagnose do estado nutricional das plantas pode-se usar a sintomatologia, a análise de solo e a análise de tecidos das plantas ou a combinação destes procedimentos.

\subsubsection{Teores nos tecidos das plantas}

A análise química das plantas de soja é feita, rotineiramente, em folhas com pecíolo, recém maduras, na época de pleno florescimento. Esta convenção é feita para que se obtenha resultados comparáveis. Nos diferentes estádios do ciclo da cultura, ocorre a redistribuição de nutrientes entre os diversos tecidos das plantas, o que provoca a variação na concentração de um determinado nutriente na mesma parte da planta em 
estádios diferentes do ciclo. Mascarenhas (1973) e Bataglia \& Mascarenhas (1977) verificaram em soja que $\mathrm{Cu}, \mathrm{Mn}$ e $\mathrm{Zn}$ são redistribuídos da parte vegetativa para a reprodutiva, sendo que as concentrações nas folhas e hastes diminuem com o florescimento e aumentam nas vagens e sementes até a maturação. Pode-se verificar a mesma tendência para $\mathrm{Zn}$ nos resultados mostrados por Vitti (1982) quando obteve teores adequados de 25 a $44 \mathrm{mg} \mathrm{kg}^{-1}$ nas folhas na fase de florescimento e de 20 a $32 \mathrm{mg}$ $\mathrm{kg}^{-1}$ no final do ciclo (todas as folhas misturadas), ao estudar os cultivares Santa Rosa e IAC-2 cultivados em vasos com dois Latossolos Vermelho Escuro, um de textura média e outro, arenosa.

Segundo Tanaka et al. (1993) a interpretação dos resultados analíticos de micronutrientes em folhas de soja no Brasil é feita com base em classes de interpretação calibradas nos Estados Unidos (Tabela 3).

Tabela 3. Interpretação dos teores de micronutrientes em folhas de soja.

\begin{tabular}{|c|c|c|c|c|c|}
\hline \multirow[b]{2}{*}{ Nutriente } & \multicolumn{5}{|c|}{ Interpretação } \\
\hline & Deficiente & Baixo & Suficiente & Alto & Excessivo \\
\hline & \multicolumn{5}{|c|}{$\ldots$} \\
\hline B & $<10$ & $11-20$ & $21-55$ & $56-80$ & $>80$ \\
\hline $\mathrm{Cu}$ & $<5$ & $6-9$ & $10-30$ & $31-50$ & $>50$ \\
\hline $\mathrm{Fe}$ & $<30$ & $31-50$ & $51-350$ & $351-500$ & $>500$ \\
\hline $\mathrm{Mn}$ & $<15$ & $16-20$ & $21-100$ & $101-250$ & $>250$ \\
\hline $\mathrm{Zn}$ & $<11$ & $12-20$ & $21-50$ & $51-75$ & $>75$ \\
\hline
\end{tabular}

Fonte: Peck (1979).

Buzetti (1988), em experimento em vasos, com soja cultivar Paraná, obteve níveis críticos de 36 e $53 \mathrm{mg} \mathrm{kg}^{-1}$ de $\mathrm{Zn}$ quando relacionou os teores na parte aérea das plantas no final do ciclo com $90 \%$ da produção, respectivamente, de matéria seca e de grãos; para $B$ estes valores foram 56 e $36 \mathrm{mg} \mathrm{kg}^{-1}$.

Poucos são os dados na literatura sobre as concentrações de metais pesados não essenciais em soja. Mortvedt (1987) verificou, em solos cultivados, recebendo aplicações 
de fertilizantes e estercos por 70 anos, concentrações de $0,032 \mathrm{mg} \mathrm{kg}^{-1}$ de $\mathrm{Cd}$ e $2,9 \mathrm{mg}$ $\mathrm{kg}^{-1}$ de Ni em grãos de soja; os teores totais nos solos foram de $0,21 \mathrm{mg} \mathrm{kg}^{-1}$ de $\mathrm{Cd}$ e 30 $\mathrm{mg} \mathrm{kg}^{-1}$ de Ni. Em seis áreas cultivadas por 52 anos recebendo 30 e $56 \mathrm{~kg} \mathrm{ha}^{-1}$ de $\mathrm{P}$ e K na forma de superfosfato e $\mathrm{KCl}$, respectivamente, o mesmo autor verificou concentrações médias de $0,043 \mathrm{mg} \mathrm{kg}^{-1}$ em folhas e $0,044 \mathrm{mg} \mathrm{kg}^{-1}$ em grãos de soja.

Pierzynski \& Schwab (1993) verificaram, em solos aluviais contaminados, concentrações de $931 \mathrm{mg} \mathrm{kg}^{-1}$ de $\mathrm{Zn}, 14,0 \mathrm{mg} \mathrm{kg}^{-1}$ de Cd e 17,8 $\mathrm{mg} \mathrm{kg}^{-1}$ de $\mathrm{Pb}$ na matéria seca de plantas de sojas cultivadas em vasos até os 30 dias após a semeadura; os teores totais nos solos foram de $933 \mathrm{mg} \mathrm{kg}^{-1}$ de $\mathrm{Zn}, 6,9 \mathrm{mg} \mathrm{kg}^{-1}$ de Cd e $95 \mathrm{mg} \mathrm{kg}^{-1} \mathrm{de} \mathrm{Pb}$.

\subsubsection{Diagnose visual}

A deficiência ou toxicidade de um elemento traduz-se em anormalidades visíveis nas plantas que são típicas para cada elemento, pois qualquer que seja a espécie de planta, um dado nutriente exerce sempre as mesmas funções. O sintoma visível é o fim de uma série de eventos e antes do aparecimento do sintoma característico, o crescimento e a produção já poderão ter sido limitados (Malavolta, 1989).

Os sintomas de deficiência dos micronutrientes, com excessão do Mo, aparecem primeiro nas folhas mais novas das plantas e os de toxidez nas mais velhas o que se deve a baixa mobilidade destes elementos dentro da planta (Marschner, 1986).

A cultura da soja requer quantidades relativamente baixas de boro, sendo mais sensivel à toxidez do que à deficiência deste elemento. Por isso, é uma planta boa indicadora para a toxidez de B (deMooy et al., 1973). Os sintomas de deficiência aparecem primeiro como um crescimento retardado das partes apicais. As folhas mais novas são deformadas, enrugadas e, às vezes mais grossas e de cor verde azulada escura. As hastes tornam-se quebradiças, indicando um distúrbio na transpiração. Em condições de severa deficiência, os pontos de crescimento podem morrer, o tamanho da planta é reduzido, o florescimento e a frutificação podem ser restritos ou inibidos. Os efeitos tóxicos resultam no amarelecimento das pontas das folhas que pode propagar-se para as 
margens e entre as nervuras laterais, progredindo rapidamente para necrose. As folhas são bronzeadas, com aparência de queimadas e caem prematuramente (Mengel \& Kirkby, 1987).

O zinco é considerado imóvel sob condições de deficiência e, por isso, os sintomas de deficência aparecem primeiro nas folhas mais novas. Em condições de intensa deficiência, os sintomas são característicos e fáceis de identificar: as plantas são raquíticas, os internódios e pecíolos são pequenos, as folhas estreitas e malformadas, o que resulta na clássica "roseta" (Brennan et al., 1993). A toxidez de $\mathrm{Zn}$ resulta em uma redução no crescimento das raízes e tamanho das folhas, seguida por clorose (Mengel \& Kirkby, 1987). White et al. (1979a) descreveram os sintomas de toxidez em plantas de soja em diferentes estádios de crescimento: nas folhas primárias observaram clorose clara generalizada e nas primeiras folhas trifoliadas, uma severa clorose internerval, e depois apareceram pigmentos púrpuras nas nervuras das folhas $\mathrm{e}$, subsequentemente, nas hastes e pecíolos; estes sintomas foram acompanhados da morte da gema apical e definhamento das plantas.

Sintomas de deficiência de $\mathrm{Fe}$ em soja aparecem nos estádios iniciais de crescimento. As áreas entre as nervuras das folhas novas ficam amareladas. Em caso de deficiência severa, as nervuras também amarelecem e finalmente toda a planta se torna esbranquiçada (Nelson \& Barber, 1964). Segundo Adriano (1986), os sintomas de toxidez variam entre espécies de plantas e estádios de crescimento das mesmas. Em soja, Bataglia \& Mascarenhas (1981) revelam que os sintomas visuais de toxidez de Fe são bastante semelhantes aos da deficiência de $\mathrm{K}$.

Os sintomas foliares característicos de deficiência de $\mathrm{Mn}$ aparecem inicialmente como clorose internerval difusa no limbo expandido das folhas mais novas, que se distingue da clorose causada pela deficiência de Fe por ser um reticulado mais grosseiro (Hannam \& Ohki, 1988). A toxicidade de Mn caracteriza-se pelo enrugamento das folhas, por clorose internerval que inicia nas margens das folhas, progredindo para a porção basal, e por pequenas manchas necróticas (Parker et al, 1969).

A deficiência de $\mathrm{Cu}$ é caracterizada por clorose, internódios curtos e morte apical (Tanaka et al., 1993). Segundo Malavolta (1980), a inibição do crescimento das raízes é a 
mais rápida resposta à toxicidade de $\mathrm{Cu}$. $\mathrm{Na}$ parte aérea, as folhas mostram sintomas cloróticos que progridem da base para a ponta ao longo da nervura principal; segue-se o aparecimento de manchas aquosas e amareladas na lâmina e, finalmente, ocorre a queda das folhas.

As primeiras evidências da essencialidade de Ni para plantas superiores ocorreram em plantas de soja, sendo que as plantas com teores muito baixos do elemento apresentavam as folhas mais novas com a pontas necróticas (Eskew et al., 1983). O sintoma mais comum da toxidez de $\mathrm{Ni}$ é a clorose, que parece ser uma clorose induzida pela deficiência de Fe (Kabata-Pendias \& Pendias, 1985).

Os sintomas de elevados níveis de elementos potencialmente tóxicos em plantas são apresentados por Kabata-Pendias \& Pendias (1985): a toxidez de Cd traduz-se em clorose, folhas com margens pardas, pecíolos e nervuras avermelhadas, folhas enroladas e raízes curtas e pardas; o excesso de $\mathrm{Cr}$ apresenta-se como clorose nas folhas mais novas e raízes mal formadas; quantidades excessivas $\mathrm{Pb}$ provocam a coloração verde escura das folhas, o murchamento das folhas mais velhas e reduzido desenvolvimento da parte aérea e das raízes.

\subsection{Interações entre micronutrientes e elementos potencialmente tóxicos}

O balanço químico em qualquer organismo vivo é a condição básica para o seu adequado crescimento e desenvolvimento. As interações entre os elementos são tão importantes quanto a deficiência e a toxicidade na fisiologia das plantas. Elas podem ser antagônicas ou sinérgicas. $\mathrm{O}$ antagonismo ocorre quando o efeito fisiológico combinado de dois ou mais elementos é menor do que os efeitos independentes e o sinergismo ocorre quando o efeito combinado é maior. Estas interações podem também referir-se à habilidade de um elemento em estimular ou inibir a absorção de outros elementos pelas plantas. Todas estas reações são muito variáveis, podendo ocorrer no interior das células, dentro das membranas e também na superficie das raizes das plantas. $\mathrm{O}$ maior número de reações antagônicas têm sido observadas para $\mathrm{Fe}, \mathrm{Mn}, \mathrm{Cu}$ e $\mathrm{Zn}$, que são, sem dúvida, os 
elementos chave na fisiologia das plantas. As reações sinérgicas entre micronutrientes não são comumente observadas (Kabata-Pendias \& Pendias, 1984).

As interações $\mathrm{Zn}$ e outros micronutrientes são as mais citadas. O mecanismo bioquímico que fundamenta a fitotoxicidade de $\mathrm{Zn}$ ainda não foi identificado em nenhuma planta, embora diferentes respostas tenham sido observadas. Em solos fortemente ácidos, a maioria das espécies torna-se clorótica, quando exposta à níveis excessivos de $\mathrm{Zn}$, sendo que a aplicação de sulfato ou quelato de Fe corrige a deficiência, indicando que o $\mathrm{Zn}$ interfere na absorção, na translocação de Fe ou na sua utilização nas folhas (Chaney, 1993). White et al (1979b) verificaram em soja que doses crescentes de $\mathrm{Zn}$ provocaram um aumento na concentração de Mn nas folhas e nas raizes; o teor de Fe nas folhas diminuiu com a elevação das doses de $\mathrm{Zn}$ e, nos tratamentos com doses mais altas de $\mathrm{Zn}$, as folhas apresentavam-se severamente cloróticas, apesar de não conterem níveis deficientes de $\mathrm{Fe}$. Segundo Chaney (1993), o Zn pode interferir na utilização do $\mathrm{Fe}$ nas células das folhas, talvez na biossíntese de clorofila.

A interação entre $\mathrm{Zn}$ e B também tem sido observada. Singh et al. (1990) verificaram que a aplicação de $\mathrm{B}$ aumentou a concentração nos tecidos e a absorção de B por plantas de trigo, mais quando não foram feitas aplicações de $\mathrm{Zn}$ ao solo do que quando foram aplicadas doses de $\mathrm{Zn}$.

Muito importantes para aplicação prática são os efeitos antagônicos do $\mathrm{Ca}$ e $\mathrm{P}$ sobre metais pesados como $\mathrm{Be}, \mathrm{Cd}, \mathrm{Pb}$ e $\mathrm{Ni}$, que muitas vezes causam riscos à saúde (Kabata-Pendias \& Pendias, 1985). 


\section{MATERIAL E MÉTODOS}

O estudo foi conduzido em três etapas, denominadas da seguinte forma: "Teor de micronutrientes e elementos potencialmente tóxicos em calcários e fertilizantes minerais"; "Disponibilidade de micronutrientes e elementos potencialmente tóxicos em calcário e fertilizantes minerais, avaliada através da análise de solo" e "Disponibilidade de micronutrientes e elementos potencialmente tóxicos em calcário e fertilizantes minerais, avaliada através da absorção pela soja".

\subsection{Teor de micronutrientes e elementos potencialmente tóxicos em calcários e fertilizantes minerais}

Analisaram-se 23 amostras de calcário procedentes de empresas mineradoras de diferentes estados do País, 23 amostras de fertilizantes fosfatados e 2 de fosfogesso, enviadas por indústrias nacionais, 4 de misturas NPK e 8 de fontes de micronutrientes adquiridas junto a misturadoras e agricultores da região de Piracicaba (SP).

O preparo das amostras e dos extratos foram feitos segundo Brasil (1988). No preparo dos extratos, adicionou-se $10 \mathrm{ml}$ de $\mathrm{HCl}$ concentrado a $1,0000 \mathrm{~g}$ da amostra, fervendo-se até próximo à secura; o resíduo foi dissolvido em $20 \mathrm{ml}$ de $\mathrm{HCl} 2 \mathrm{~mol} \mathrm{~L}^{-1}$, ligeiramente fervido e depois filtrado, completando-se o volume a $100 \mathrm{ml}$ com água destilada. Estas extrações foram feitas em séries de 15 amostras, sempre com uma prova em branco, e em três repetições.

As concentrações de $\mathrm{B}, \mathrm{Fe}, \mathrm{Mn}, \mathrm{Cu}, \mathrm{Ni}, \mathrm{Co}, \mathrm{Cr}$ e $\mathrm{Pb}$ foram determinadas em espectrofotômetro de emissão atômica com plasma acoplado indutivamente (ICP-AES), marca Jarrell-Ash, mod. 975, usando corretor de background (spectrumshifter). Zinco, 
Cd e também $\mathrm{Cu}$ foram deternninados em espectrômetro de absorção atômica (AAS), marca Intralab, mod. AA 12/1475. Para a determinação de $\mathrm{Cd}$, novos extratos em uma relação final material:solução de 5:100 foram preparados, visando concentrar o elemento na solução e colocá-lo na faixa de deteç̧ão; o método de adição padrão foi usado para superar o efeito da complexidade da matriz. $\mathrm{O} \mathrm{Cu}$ foi determinado em ambas as técnicas visando avaliar a interferência espectral do cálcio determinado em ICP-AES nos diferentes materiais analisados. Empregaram-se as seguintes linhas espectrais (nm): B249,67, Ba-455,40, Cd-228,80, Cr-267,72, Cu-324,75, Co-228,22, Fe-259,84, Mn257,61, Ni-231,60, Pb-220,35, Sr-421,5 e Zn-213,90.

\subsection{Disponibilidade de micronutrientes e elementos potencialmente tóxicos em calcário e fertilizantes minerais, avaliada através da análise de solo}

Em casa de vegetação, foram conduzidos experimentos com dois tipos de solo, um em Areia Quartzosa (AQ) e outro em Latossolo Roxo (LR). As unidades experimentais foram vasos de plástico com $3 \mathrm{~kg}$ de terra que foi coletada na camada entre 10 a $60 \mathrm{~cm}$ de profundidade de cada tipo de solo, seca ao ar, homogeneizada e passada em peneira de $4 \mathrm{~mm}$ de malha. As características químicas e granulométricas dos solos estão na Tabela 4. Na análise mineralológica foram identificados os minerais caulinita, gibsita e vermiculita na fração argila do solo LR e caulinita, gibsita, verniculita (pouca) e mica (presença) na fração argila do solo $\mathrm{AQ}$; na fração silte de ambos solos foram identificados feldspato e pirofilita.

Adotou-se o delineamento inteiramente casualisado, aplicando-se 13 tratamentos, com 4 repetições, perfazendo 52 unidades experimentais para cada tipo de solo. Os tratamentos constaram de doses distintas para cada tipo de solo dos seguintes materiais, misturados com a terra das unidades experimentais: calcário magnesiano, rocha fosfatada, termofosfato magnesiano fundido, fonte de boro e zinco (BR 5) e mistura NPK, 4-14-8 (Tabela 5). Os tratamentos foram estabelecidos para permitir a verificação do efeito do 
$\mathrm{pH}$ do solo na disponibilidade dos elementos a serem estudados. O tratamento 1 (teste) não recebeu nenhuma fonte de micronutriente e o tratamento 2 (completo) recebeu doses de fontes puras de $\mathrm{Mn}, \mathrm{Fe}, \mathrm{Zn}, \mathrm{Cu}$ e $\mathrm{B}$ para suprir a demanda por estes elementos

Tabela 4. Características químicas e granulométricas dos solos usados nos experimentos.

\begin{tabular}{|c|c|c|}
\hline Características analisadas & Solo $\mathrm{AQ}$ & Solo LR \\
\hline pH em água $(1: 2,5)^{1}$ & 5,0 & 5,1 \\
\hline pH em $\mathrm{CaCl}_{2}(1: 2,5)^{1}$ & 4,3 & 4,4 \\
\hline Matéria orgânica $\left(\mathrm{mg} \mathrm{dm}^{-3}\right)^{1,2}$ & 10 & 13 \\
\hline$P\left(\mathrm{mg} \mathrm{dm}^{-3}\right)^{1,3}$ & 3 & 1 \\
\hline $\left.\mathrm{K}(\mathrm{mmol} \mathrm{dm})^{-3}\right)^{1,3}$ & 0,2 & 0,3 \\
\hline $\left.\mathrm{Ca}(\mathrm{mmol} \mathrm{dm})^{-3}\right)^{1,4}$ & 1 & 3 \\
\hline $\left.\mathrm{Mg}(\mathrm{mmol} \mathrm{dm})^{-3}\right)^{1,4}$ & 1 & 1 \\
\hline $\mathrm{Al}\left(\mathrm{mmol} \mathrm{dm}^{-3}\right)^{1,4}$ & 4 & 4 \\
\hline $\mathrm{H}+\mathrm{Al}\left(\mathrm{mmol} \mathrm{dm}^{-3}\right)^{1,5}$ & 16 & 34 \\
\hline $\mathrm{SB}\left(\mathrm{mmol} \mathrm{dm}{ }^{-3}\right)$ & 2,2 & 4,4 \\
\hline $\mathrm{T}\left(\mathrm{mmol} \mathrm{dm}{ }^{-3}\right)$ & 18,2 & 38,3 \\
\hline$V(\%)$ & 12 & 11 \\
\hline $\mathrm{m}(\%)$ & 65 & 48 \\
\hline $\mathrm{Fe}\left(\mathrm{mg} \mathrm{kg}^{-1}\right)^{6}$ & 10,0 & 3,3 \\
\hline $\operatorname{Mn}\left(\mathrm{mg} \mathrm{kg}^{-1}\right)^{6}$ & 3,5 & 5,4 \\
\hline $\mathrm{Zn}\left(\mathrm{mg} \mathrm{kg}^{-1}\right)^{6}$ & 0,06 & 0,15 \\
\hline $\mathrm{Cu}\left(\mathrm{mg} \mathrm{kg}^{-1}\right)^{6}$ & 0,02 & 0,40 \\
\hline $\mathrm{B}\left(\mathrm{mg} \mathrm{kg}^{-1}\right)^{7}$ & 0.01 & 0.02 \\
\hline Areia $(\%)^{8}$ & 88 & 26 \\
\hline Silte $(\%)^{8}$ & 4 & 15 \\
\hline Argila $(\%)^{8}$ & 8 & 59 \\
\hline
\end{tabular}

${ }^{1}$ Segundo Raij et al. (1987); ${ }^{2}$ Método colorimétrico; ${ }^{3}$ Resina trocadora de íons; ${ }^{4} \mathrm{KCl} \mathrm{1M;}$ Acetato de cálcio $1 \mathrm{M}$ a pH 7,0; ${ }^{6}$ DTPA-TEA, segundo Lindsay e Norvell (1978); ${ }^{7}$ Extração com água quente (Abreu et al., 1994) e determinação colorimétrica com Azometina H; ${ }^{8}$ Método do hidrômetro de Boyoucos (EMBRAPA, 1979). 
pela cultura da soja. Nos tratamentos 12 e 13, a rocha fosfatada, a mistura 4-14-8 e BR 5 foram combinadas, com e sem calcário, respectivamente, com o objetivo de adicionar uma dose intermediária ou uma mais elevada dos elementos em estudo.

Tabela 5. Quantidades aplicadas dos materiais aos tratamentos dos experimentos com os solos AQ e LR.

\begin{tabular}{|c|c|c|c|}
\hline \multicolumn{2}{|r|}{ TRATAMENTOS } & \multicolumn{2}{|c|}{ DOSES* } \\
\hline $\mathrm{N}^{\circ}$ & Discriminação & Solo AQ & Solo LR \\
\hline & & \multicolumn{2}{|c|}{ 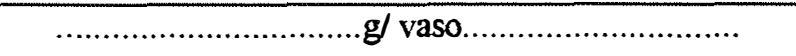 } \\
\hline 1 & Teste & 0,00 & 0,00 \\
\hline 2 & Completo & 0,00 & 0,00 \\
\hline 3 & Calcánio & 0,99 & 2,58 \\
\hline 4 & Rocha fosfatada & 3,60 & 4,65 \\
\hline 5 & Termofosfato & 6,24 & 8,04 \\
\hline 6 & BR 5 & 0,11 & 0,14 \\
\hline 7 & $4-14-8$ & 7,74 & 9,99 \\
\hline 8 & Calcário + rocha fosfatada & $0,99+3,60$ & $2,58+4,65$ \\
\hline 9 & Calcário + termofosfato & $0,99+6,24$ & $2,58+8,04$ \\
\hline 10 & Calcário + BR 5 & $0,99+0,11$ & $2,58+0,14$ \\
\hline 11 & Calcánio + 4-14-8 & $0,99+7,74$ & $2,58+9,99$ \\
\hline 12 & Calcário+rocha fosfatada+BR 5+4-14-8 & $0,99+3,60+0,11+7,74$ & $2,58+4,58+0,14+9,99$ \\
\hline 13 & Rocha fosfatada + BR $5+4-14-8$ & $3,60+0,11+7,74$ & $4,58+0,14+9,99$ \\
\hline
\end{tabular}

* As quantidades somadas correspondem, respectivamente, aos materiais discriminados nos tratamentos.

O calcário foi dosado para elevar a saturação por bases dos solos a $70 \%$. Os tratamentos 1 (teste) e 2 (completo) receberam uma dose equivalente de $\mathrm{CaO}$ puro (P.A.). A dose das fontes de fósforo foi calculada para fornecer $150 \mathrm{mg} \mathrm{kg}^{-1} \mathrm{P}$ para $\mathrm{O}$ solo $\mathrm{AQ}$ e $200 \mathrm{mg} \mathrm{kg}^{-1} \mathrm{P}$ para o solo $\mathrm{LR}$, com base no teor total de $\mathrm{P}_{2} \mathrm{O}_{5}$ da rocha fosfatada, no teor solúvel em ácido cítrico a $2 \%$ do termofosfato e solúvel em água + citrato neutro de amônio da mistura 4-14-8.

Os teores dos elementos em estudo presentes nos materiais estudados estão na Tabela 6. A quantidade dos macronutrientes e dos micronutrientes e elementos tóxicos 
correspondentes às doses dos materiais aplicadas aos tratamentos em ambos solos estão nas Tabelas 7 e 8 , respectivamente.

Tabela 6. Teores de micronutrientes e elementos potencialmente tóxicos nos fertilizantes e no calcário.

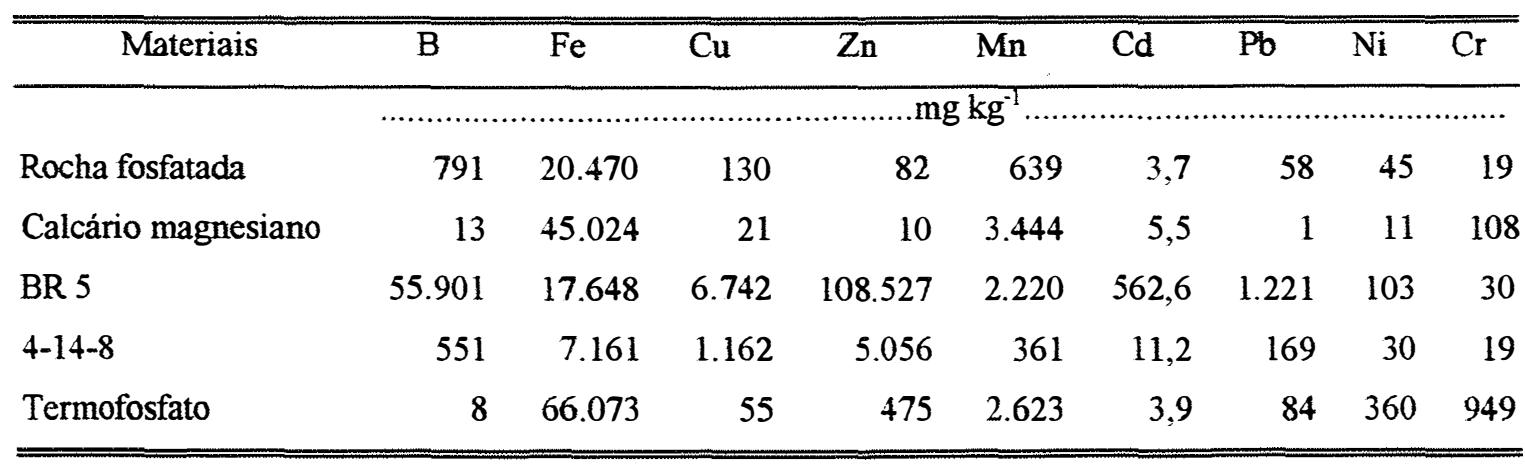

O calcário e os fertilizantes foram misturados com a terra das unidades experimentais de acordo com os tratamentos, procedendo-se, então, a incubação por 90 dias. As unidades experimentais receberam água destilada em quantidade necessária para atingir $60 \%$ do poder de embebição de cada solo. Esta umidade foi mantida durante todo o período de incubação através da pesagem aleatória de 5 vasos, repondo-se a água ao se observar a perda de 20 a $25 \%$ da água inicialmente adicionada.

Após os 90 dias de incubação, a terra das parcelas foi seca ao ar, novamente homogeneizada e retiradas amostras que foram passadas em peneira de $2 \mathrm{~mm}$ de malha para serem analisadas. Procedeu-se a determinação de $\mathrm{pH}, \mathrm{Ca}, \mathrm{Mg}, \mathrm{K}, \mathrm{P}, \mathrm{Al}, \mathrm{H}+\mathrm{Al}$, segundo Raij et al. (1987), e dos teores de $\mathrm{Fe}, \mathrm{Mn}, \mathrm{Zn}, \mathrm{Cu}, \mathrm{Ni}, \mathrm{Cd}, \mathrm{Cr}$ e Pb, extraídos com DTPA-TEA (Lindsay \& Norvell, 1978) e com Mehlich 3 (Mehlich, 1984) e determinados em espectrômetro de emissão atômica por plasma (ICP-AES), marca Jobin, modelo JY 50P, simultâneo.

A extração do boro foi feita com solução de $\mathrm{BaCl}_{2}$ 0,125\%. Colocou-se $10 \mathrm{~g}$ de terra e $20 \mathrm{ml}$ da solução em saquinho plástico que foi selado e aquecido em forno microondas à potência de $700 \mathrm{~W}$ por 4 minutos, sendo a suspensão depois de fria, filtrada através de papel de filtro Whatman 42 (Abreu et al., 1994). A determinação foi feita pelo método da azometina $\mathrm{H}$ (Wolf, 1974). 
Procedeu-se a análise de variância e comparação de médias pelo teste de Tukey para os teores dos elementos em estudo nos solos e análise de regressão para as quantidades destes elementos adicionadas aos solos e os teores dos metais extraídos pelos métodos Mehlich 3 e DTPA-TEA e de B, extraído pelo método da água quente.

Tabela 7. Doses de macronutrientes aplicadas aos tratamentos dos experimentos através dos materiais estudados.

\begin{tabular}{|c|c|c|c|c|c|c|c|c|c|c|}
\hline \multirow[b]{2}{*}{ TRAT. } & \multicolumn{5}{|c|}{ Solo AQ } & \multicolumn{5}{|c|}{ Solo LR } \\
\hline & $\mathrm{N}$ & $\mathrm{P}^{*}$ & $\mathrm{~K}$ & $\mathrm{Ca}$ & $\mathrm{Mg}$ & $\mathrm{N}$ & $\mathrm{P}^{*}$ & $\mathrm{~K}$ & $\mathrm{Ca}$ & $\mathrm{Mg}$ \\
\hline & & 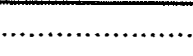 & & & $\cdots$ & vaso... & …................. & $\ldots \ldots \ldots$ & $\ldots \ldots \ldots$ & $\ldots \ldots \ldots$ \\
\hline 1 & 0,00 & 0,00 & 0,00 & 0,00 & 0,00 & 0,00 & 0,00 & 0,00 & 0,00 & 0,00 \\
\hline 2 & 0,00 & 0,00 & 0,00 & 0,00 & 0,00 & 0,00 & 0,00 & 0,00 & 0,00 & 0,00 \\
\hline \multirow[t]{2}{*}{3} & $=$ & $0, \overline{0} 6$ & $=$ & 0,40 & 0,04 & $=$ & $0, \overline{0} 7$ & $=$ & 1,04 & 0,11 \\
\hline & - & 0,59 & - & - & - & - & 0,77 & - & - & - \\
\hline 5 & - & 0,47 & - & - & - & - & 0,61 & - & - & - \\
\hline 6 & - & - & - & - & - & - & - & - & - & - \\
\hline 7 & 0,31 & 0,47 & 0,51 & - & - & 0,40 & 0,61 & 0,66 & - & - \\
\hline \multirow[t]{2}{*}{8} & - & 0,06 & - & 0,40 & 0,04 & - & 0,07 & - & 1,04 & 0,11 \\
\hline & - & 0,59 & - & 0,40 & 0,04 & - & 0,77 & - & - & - \\
\hline 9 & - & 0,47 & - & 0,40 & 0,04 & - & 0,61 & - & 1,04 & 0,11 \\
\hline 10 & - & - & - & 0,40 & 0,04 & - & - & - & 1,04 & 0,11 \\
\hline 11 & 0,31 & 0,47 & 0,51 & 0,40 & 0,04 & 0,40 & 0,61 & 0,66 & 1,04 & 0,11 \\
\hline \multirow[t]{2}{*}{12} & 0,15 & $0,03+0,22$ & 0,24 & 0,40 & 0,04 & 0,18 & $0,03+0,28$ & 0,30 & 1,04 & 0,11 \\
\hline & - & $0,32+0,22$ & - & - & - & - & $0,33+0,28$ & - & - & - \\
\hline \multirow[t]{2}{*}{13} & 0,15 & $0,03+0,22$ & 0,24 & - & - & 0,18 & $0,03+0,28$ & 0,30 & - & - \\
\hline & - & $0,32+0,22$ & - & - & - & - & $0,33+0,28$ & - & - & - \\
\hline
\end{tabular}

* Nos tratamentos 4, 8, 12 e 13, a $1^{\underline{a}}$ linha mostra a dose de $\mathrm{P}$ considerando o teor solúvel em ácido cítrico a $2 \%(3,65 \%)$ e a $2^{\underline{a}}$, o teor total $(38,0 \%)$, na rocha fosfatada. Nos tratamentos 12 e 13 , essas doses estão somadas à dose da fórmula 4-14-8,considerando o teor de $\mathrm{P}$ solúvel em água + CNA (14,0\%). 
Tabela 8. Quantidade de micronutrientes e elementos potencialmente tóxicos adicionada aos tratamentos dos experimentos, expressa em mg por vaso.

\begin{tabular}{|c|c|c|c|c|c|c|c|c|c|}
\hline Tratamentos & $\mathrm{B}$ & $\overline{\mathrm{Fe}}$ & $\mathrm{Mn}$ & $\overline{\mathrm{Zn}}$ & $\overline{\mathrm{Cu}}$ & $\mathrm{Ni}$ & $\mathrm{Cd}$ & $\mathrm{Cr}$ & $\mathrm{Pb}$ \\
\hline & \multicolumn{9}{|c|}{ Solo AQ } \\
\hline 1 & 0,00 & 0,00 & 0,00 & 0,00 & 0,00 & 0,00 & 0,00 & 0,00 & 0,00 \\
\hline $2^{*}$ & 1,13 & 30,00 & 15,00 & 15,00 & 6,00 & 0,00 & 0,00 & 0,00 & 0,00 \\
\hline 3 & 0,01 & 44,57 & 3,41 & 0,01 & 0,02 & 0,01 & 0,01 & 0,11 & 0,00 \\
\hline 4 & 2,85 & 73,69 & 2,30 & 0,30 & 0,47 & 0,16 & 0,01 & 0,07 & 0,21 \\
\hline 5 & 0,06 & 412,30 & 16,37 & 2,96 & 0,34 & 2,25 & 0,02 & 5,92 & 0,52 \\
\hline 6 & 5,59 & 1,94 & 0,25 & 11,94 & 0,74 & 0,01 & 0,06 & 0,00 & 0,13 \\
\hline 7 & 4,26 & 55,43 & 2,79 & 39,13 & 8,99 & 0,23 & 0,08 & 0,15 & 1,31 \\
\hline 8 & 2,86 & 118,26 & 5,71 & 0,31 & 0,49 & 0,17 & 0,02 & 0,18 & 0,21 \\
\hline 9 & 0,07 & 456,87 & 19,78 & 2,97 & 0,36 & 2,26 & 0,03 & 6,03 & 0,52 \\
\hline 10 & 5,60 & 46,51 & 3,66 & 11,95 & 0,76 & 0,02 & 0,07 & 0,11 & 0,13 \\
\hline 11 & 4,27 & 100,00 & 6,20 & 39,14 & 9,01 & 0,24 & 0,09 & 0,26 & 1,31 \\
\hline 12 & 9,14 & 111,61 & 6,20 & 30,61 & 5,26 & 0,18 & 0,12 & 0,22 & 0,86 \\
\hline \multirow[t]{2}{*}{13} & 9,13 & 67,04 & 2,79 & 30,60 & 5,24 & 0,17 & 0,11 & 0,11 & 0,86 \\
\hline & \multicolumn{9}{|c|}{ Solo LR } \\
\hline 1 & 0,00 & 0,00 & 0,00 & 0,00 & 0,00 & 0,00 & 0,00 & 0,00 & 0,00 \\
\hline $2 *$ & 1,13 & 0,00 & 15,00 & 15,00 & 6,00 & 0,00 & 0,00 & 0,00 & 0,00 \\
\hline 3 & 0,03 & 116,16 & 8,89 & 0,03 & 0,05 & 0,03 & 0,01 & 0,28 & 0,00 \\
\hline 4 & 3,68 & 95,19 & 2,97 & 0,38 & 0,60 & 0,21 & 0,02 & 0,09 & 0,27 \\
\hline 5 & 0,08 & 660,07 & 21,09 & 3,82 & 0,44 & 2,89 & 0,03 & 7,63 & 0,68 \\
\hline 6 & 7,83 & 2,47 & 0,31 & 15,19 & 0,94 & 0,01 & 0,08 & 0,00 & 0,17 \\
\hline 7 & 5,50 & 71,54 & 3,61 & 50,51 & 11,61 & 0,30 & 0,10 & 0,19 & 1,69 \\
\hline 8 & 3,71 & 211,25 & 11,86 & 0,41 & 0,65 & 0,24 & 0,03 & 0,37 & 0,27 \\
\hline 9 & 0,11 & 776,23 & 29,98 & 3,85 & 0,49 & 2,92 & 0,04 & 7,91 & 0,68 \\
\hline 10 & 7,86 & 118,63 & 9,20 & 15,41 & 0,99 & 0,04 & 0,09 & 0,28 & 0,17 \\
\hline 11 & 5,53 & 187,70 & 12,50 & 50,51 & 11,66 & 0,33 & 0,11 & 0,47 & 1,69 \\
\hline 12 & 11,96 & 192,24 & 12,13 & 38,59 & 6,58 & 0,19 & 0,15 & 0,41 & 1,07 \\
\hline 13 & 11,93 & 76,08 & 3,24 & 38,56 & 6,53 & 0,22 & 0,14 & 0,13 & 1,07 \\
\hline
\end{tabular}

* Micronutrientes adicionados na forma de fontes puras (P.A.): $\mathrm{B}\left(\mathrm{H}_{3} \mathrm{BO}_{3}\right)$, Fe (EDTA$\left.\mathrm{Na}_{2}+\mathrm{FeSO}_{4} \cdot 7 \mathrm{H}_{2} \mathrm{O}\right), \mathrm{Mn}\left(\mathrm{MnCl}_{2} \cdot 4 \mathrm{H}_{2} \mathrm{O}\right), \mathrm{Zn}\left(\mathrm{ZnSO}_{4} \cdot 7 \mathrm{H}_{2} \mathrm{O}\right)$ e $\mathrm{Cu}\left(\mathrm{CuSO}_{4} \cdot 5 \mathrm{H}_{2} \mathrm{O}\right)$. 


\subsection{Disponibilidade de micronutrientes e elementos potencialmente tóxicos em calcário e fertilizantes minerais, avaliada através da absorção pela soja}

Após a amostragem da terra para análise, as unidades experimentais dos dois experimentos da segunda parte foram arranjadas em delineamento em blocos ao acaso para receberem a cultura da soja, Glicine max (L.) Merril, variedade IAC-8.

Na Tabela 9, são apresentados os resultados da análise de rotina da terra no final da incubação. A metodologia foi a mesma empregada na caracterização inicial dos solos (Tabela 4). Com base nestes resultados e nas doses de macronutrientes aplicadas através dos materiais testados, complementou-se com fontes "puras" (P.A.) de N, P, K, Ca, Mg e $\mathrm{S}$ na forma de soluções/suspensões de $\left(\mathrm{NH}_{4}\right) \mathrm{SO}_{4}, \mathrm{NH}_{4} \mathrm{NO}_{3}, \mathrm{KH}_{2} \mathrm{PO}_{4}, \mathrm{~K}_{2} \mathrm{SO}_{4}, \mathrm{KCl}$, $\mathrm{CaSO}_{4} .2 \mathrm{H}_{2} \mathrm{O}, \mathrm{MgSO}_{4} .7 \mathrm{H}_{2} \mathrm{O}$ e $\mathrm{MgCl}_{2} .6 \mathrm{H}_{2} \mathrm{O}$, misturadas à terra ainda seca das parcelas (Tabela 10). Nitrogênio e potássio foram parcelados em três aplicações iguais: na semeadura, aos 30 e 50 dias após a mesma.

Após a homogeinização da terra e das soluções/suspensões fertilizantes, cada vaso recebeu seis sementes de soja. A primeira irrigação e a reposição da água nas primeiras semanas foi feita da mesma forma que na incubação, e depois uma ou duas vezes ao dia, de acordo com a necessidade das plantas, usando sempre água destilada.

A semeadura foi feita aos 20 dias de setembro de 1996. Quinze dias depois da semeadura foi feito um desbaste, deixando três plantas por vaso. A cultura foi conduzida até o final do ciclo.

A colheita foi efetuada aos 18 dias de fevereiro de 1997. As vagens foram colhidas e os grãos separados das mesmas. As plantas foram cortadas a aproximadamente $1 \mathrm{~cm}$ da superficie da terra dos vasos.

As folhas, hastes e vagens foram lavadas com água destilada corrente, colocadas em sacos de papel, devidamente identificados, e levadas a estufa com circulação forçada de ar a temperatura entre 65 e $70^{\circ} \mathrm{C}$ para secagem até peso constante. As folhas que caíram durante o ciclo foram juntadas a este material. Os grãos foram colocados 
separadamente em outros sacos, passando pelo mesmo processo de secagem. As folhas +hastes+vagens (matéria seca) e os grãos de cada unidade experimental, após secos, foram pesados. A matéria seca foi moída em moinho tipo Wiley, passada em peneira de $1 \mathrm{~mm}$ de malha, perfeitamente homogeneizada e acondicionada em sacos plásticos, para posteriores análises.

Procedeu-se a digestão nitro-perclórica da matéria seca para análise dos macronutrientes $(\mathrm{P}, \mathrm{K}, \mathrm{Ca}, \mathrm{S}$ e $\mathrm{Mg})$, micronutrientes $(\mathrm{Cu}, \mathrm{Fe}, \mathrm{Mn}, \mathrm{Zn}$ e $\mathrm{Ni})$ e elementos potencialmente tóxicos $(\mathrm{Pb}, \mathrm{Cd}, \mathrm{Cr}$ e $\mathrm{Al})$. Para isso foi transferido 1,0000 $\mathrm{g}$ da matéria seca para tubos de digestão, adicionou-se $5 \mathrm{~mL}$ de $\mathrm{HNO}_{3}$ concentrado, deixando em temperatura ambiente durante a noite. No dia seguinte, juntou-se mais $5 \mathrm{~mL}$ do ácido e iniciou-se a digestão a baixa temperatura, aumentando-a gradativamente até $160^{\circ} \mathrm{C}$, mantendo-a até o extrato atingir coloração amarelo-palha. Depois de frio, juntou-se $2 \mathrm{~mL}$ de $\mathrm{HClO}_{4}$ concentrado, aquecendo novamente a $210^{\circ} \mathrm{C}$ até próximo à secura. Esfriou-se para acrescentar $5 \mathrm{~mL}$ de $\mathrm{HCl} 1 \mathrm{~mol} \mathrm{~L}^{-1}$, aquecendo então levemente. $\mathrm{O}$ extrato foi transferido para balão volumétrico de $50 \mathrm{~mL}$, completando-se o volume com água destilada (método adaptado de Bataglia et al., 1983).

Estes elementos foram determinados em espectrômetro de emissão atômica por plasma (ICP-AES), marca Jobin Yvon, modelo JY 50P, 40,68 MHz, simultâneo; com exceção do $\mathrm{K}$ que foi determinado por fotometria de chama. $\mathrm{O}$ nitrogênio foi determinado em extratos obtidos por ataque sulfúrico através de destilador micro Kjeldahl e titulação.

$\mathrm{O}$ boro foi determinado em extratos obtidos via seca. Incinerou-se $0,2500 \mathrm{~g}$ do tecido vegetal a $500^{\circ} \mathrm{C}$ durante 2 horas. As cinzas foram dissolvidas com $10 \mathrm{~mL}$ de solução $\mathrm{HCl} 1 \mathrm{~mol} \mathrm{~L}^{-1}$. A determinação foi feita por espectrofotometria em soluções contendo $2 \mathrm{~mL}$ do extrato, $2 \mathrm{~mL}$ de solução tampão (250g de acetato de amônio, $15 \mathrm{~g}$ de $\mathrm{Na}_{2}$ EDTA, $400 \mathrm{~mL}$ de água e $125 \mathrm{~mL}$ de ácido acético glacial) e $2 \mathrm{~mL}$ de solução de azometina $\mathrm{H}$ a $4,5 \mathrm{~g} \mathrm{~kg}^{-1}$ em ácido ascórbico $20 \mathrm{~g} \mathrm{~kg}^{-1}$ (Wolf, 1974). 
Tabela 9. Resultados da análise de rotina da terra depois da incubação (média das quatro repetições).

\begin{tabular}{|c|c|c|c|c|c|c|c|c|c|c|c|}
\hline SOLO & TRAT. & $\begin{array}{c}\mathbf{p H} \\
\text { (água) }\end{array}$ & $\begin{array}{c}\mathbf{C a} \\
\ldots \ldots . .\end{array}$ & $\begin{array}{c}\mathbf{M g} \\
\ldots \ldots \ldots\end{array}$ & $\begin{array}{l}\mathbf{A l} \\
\ldots \ldots \ldots\end{array}$ & $\begin{array}{l}\mathrm{H}+\mathrm{Al} \\
\mathrm{mmol} \mathrm{kg}\end{array}$ & $\mathbf{K}$ & $\overline{\text { SB }}$ & $\bar{T}$ & $\begin{array}{l}\mathrm{V} \\
\%\end{array}$ & $\begin{array}{c}\mathbf{P} \\
\mathrm{mg} \mathrm{kg}^{-1}\end{array}$ \\
\hline \multirow{13}{*}{$\mathbf{A Q}$} & 1 & 6,4 & 13,4 & 3,7 & 0,1 & 3,0 & 0,4 & 17,5 & 20,5 & 85 & 3 \\
\hline & 2 & 6,3 & 13,8 & 3,3 & 0,3 & 3,7 & 0,2 & 17,3 & 21,0 & 82 & 3 \\
\hline & 3 & 6,6 & 12,0 & 3,2 & 0,1 & 3,5 & 0,2 & 15,4 & 18,9 & 81 & 4 \\
\hline & 4 & 5,3 & 5,9 & 0,9 & 1,3 & 8,2 & 0,2 & 6,9 & 15,1 & 46 & 20 \\
\hline & 5 & 8,1 & 13,3 & 7,5 & 0,3 & 0,0 & 0,2 & 21,0 & 21,0 & 100 & 101 \\
\hline & 6 & 5,1 & 4,9 & 4,9 & 2,8 & 8,6 & 0,3 & 10,1 & 18,7 & 54 & 3 \\
\hline & 7 & 5,0 & 12,7 & 7,8 & 1,4 & 10,9 & 4,4 & 24,9 & 35,8 & 70 & 81 \\
\hline & 8 & 6,6 & 9,1 & 2,5 & 0,1 & 3,2 & 0,4 & 12,0 & 15,2 & 79 & 21 \\
\hline & 9 & 8,4 & 14,0 & 5,7 & 0,2 & 0,0 & 0,3 & 20,0 & 20,0 & 100 & 110 \\
\hline & 10 & 6,7 & 8,2 & 7,6 & 0,0 & 4,3 & 0,4 & 16,2 & 20,5 & 79 & 4 \\
\hline & 11 & 4,8 & 17,0 & 8,6 & 1,2 & 10,8 & 4,4 & 30,0 & 40,8 & 74 & 80 \\
\hline & 12 & 5,1 & 12,8 & 7,8 & 0,7 & 9,1 & 2,2 & 22,9 & 32,0 & 72 & 45 \\
\hline & 13 & 4,8 & 8,8 & 3,6 & 1,6 & 13,2 & 2,7 & 15,1 & 28,3 & 53 & 45 \\
\hline \multirow{13}{*}{$\mathbf{L R}$} & 1 & 5,9 & 22,9 & 6,4 & 0,2 & 11,7 & 0,7 & 30,0 & 41,7 & 72 & 1 \\
\hline & 2 & 5,8 & 21,6 & 5,7 & 0,4 & 12,0 & 0,6 & 27,9 & 39,9 & 70 & 1 \\
\hline & 3 & 5,9 & 22,1 & 5,7 & 0,1 & 14,3 & 0,6 & 28,5 & 42,8 & 67 & 2 \\
\hline & 4 & 5,4 & 18,1 & 1,3 & 0,7 & 23,2 & 0,5 & 19,9 & 43,1 & 46 & 28 \\
\hline & 5 & 6,7 & 24,2 & 16,2 & 0,1 & 8,5 & 0,5 & 40,8 & 49,4 & 83 & 60 \\
\hline & 6 & 5,2 & 6,5 & 1,5 & 6,0 & 29,2 & 0,6 & 8,6 & 37,8 & 23 & 2 \\
\hline & 7 & 4,9 & 22,9 & 5,2 & 2,8 & 27,6 & 5,6 & 33,7 & 61,3 & 55 & 50 \\
\hline & 8 & 6,0 & 24,4 & 4,5 & 0,0 & 12,5 & 0,6 & 29,6 & 42,1 & 70 & 9 \\
\hline & 9 & 7,3 & 35,1 & 14,5 & 0,1 & 2,2 & 0,4 & 50,0 & 52,1 & 96 & 74 \\
\hline & 10 & 5,9 & 24,4 & 4,9 & 0,1 & 14,9 & 0,6 & 29,9 & 44,8 & 67 & 2 \\
\hline & 11 & 4,8 & 36,0 & 7,1 & 2,4 & 24,2 & 5,7 & 48,9 & 73,1 & 67 & 58 \\
\hline & 12 & 5,2 & 28,7 & 5,2 & 0,4 & 17,0 & 3,0 & 36,8 & 53,9 & 68 & 24 \\
\hline & 13 & 4,8 & 17,0 & 1,8 & 2,5 & 25,9 & 3,0 & 21,7 & 47,6 & 46 & 21 \\
\hline
\end{tabular}


Tabela 10. Doses dos macronutrientes aplicadas aos tratamentos dos experimentos na forma de soluções/suspensões de fontes puras.

\begin{tabular}{|c|c|c|c|c|c|c|c|c|c|c|c|c|}
\hline \multirow[b]{2}{*}{ TRAT. } & \multicolumn{6}{|c|}{ Solo AQ } & \multicolumn{6}{|c|}{ Solo LR } \\
\hline & $\mathrm{N}$ & $\mathrm{P}$ & $\mathrm{K}$ & $\mathrm{Ca}$ & $\mathrm{Mg}$ & S & $\mathrm{N}$ & $\mathrm{P}$ & $\mathrm{K}$ & $\mathrm{Ca}$ & $\mathrm{Mg}$ & $S$ \\
\hline & & & & & . & $\ldots . \mathrm{m}$ & raso... & $\ldots \ldots \ldots$ & $\ldots \ldots \ldots$ & $\ldots \ldots \ldots$ & $\ldots \ldots \ldots$ & $\ldots \ldots$ \\
\hline 1 & 450 & 470 & 510 & 0 & 130 & 180 & 450 & 610 & 660 & 0 & 340 & 180 \\
\hline 2 & 450 & 470 & 510 & 0 & 130 & 180 & 450 & 610 & 660 & 0 & 340 & 180 \\
\hline 3 & 450 & 470 & 510 & 0 & 90 & 180 & 450 & 610 & 660 & 0 & 230 & 180 \\
\hline 4 & 450 & 410 & 510 & 270 & 90 & 180 & 450 & 540 & 660 & 270 & 90 & 180 \\
\hline 5 & 450 & 0 & 510 & 0 & 0 & 180 & 450 & 0 & 660 & 0 & 0 & 180 \\
\hline 6 & 450 & 470 & 510 & 270 & 90 & 180 & 450 & 610 & 660 & 270 & 90 & 180 \\
\hline 7 & 140 & 0 & 0 & 0 & 90 & 0 & 50 & 0 & 0 & 0 & 90 & 0 \\
\hline 8 & 450 & 410 & 510 & 0 & 90 & 180 & 450 & 540 & 660 & 0 & 230 & 180 \\
\hline 9 & 450 & 0 & 510 & 0 & 0 & 180 & 450 & 0 & 660 & 0 & 0 & 180 \\
\hline 10 & 450 & 470 & 510 & 0 & 90 & 180 & 450 & 610 & 660 & 0 & 230 & 180 \\
\hline 11 & 140 & 0 & 0 & 0 & 90 & 0 & 50 & 0 & 0 & 0 & 230 & 0 \\
\hline 12 & 300 & 220 & 270 & 0 & 90 & 0 & 270 & 360 & 360 & 0 & 230 & 0 \\
\hline 13 & 300 & 220 & 270 & 0 & 90 & 0 & 270 & 360 & 360 & 0 & 190 & 0 \\
\hline
\end{tabular}

Foi feita análise de variância e comparação de médias, usando o teste de Tukey, para as concentrações dos micronutrientes e elementos potencialmente tóxicos na matéria seca, produção de matéria seca e produção de grãos. Efetuou-se também análise de regressão para as concentrações dos elementos na matéria seca, os teores extraídos dos solos e as quantidades adicionadas dos elementos. 


\section{RESULTADOS E DISCUSSÃO}

\subsection{Teor de micronutrientes e elementos potencialmente tóxicos em calcários e fertilizantes minerais}

A maioria dos elementos analisados foram detectados através dos métodos empregados, com exceção do $\mathrm{Co}, \mathrm{Ba}$ e $\mathrm{Sr}$. Todas as amostras de calcário apresentaram teores de Co menores que $10 \mathrm{mg} \mathrm{kg}^{-1}$, o que concorda com os resultados obtidos por Chichilo \& Whittaker (1958), Chichilo \& Whittaker (1961) e Valadares et al. (1974). As amostras de ácido fosfórico tiveram os menores teores tanto de Ba como de $\mathrm{Sr}$ (Tabela $11)$.

Os teores mais elevados de $\mathrm{Fe}, \mathrm{Mn}, \mathrm{Zn}, \mathrm{Ni}, \mathrm{Cr}, \mathrm{Ba}$ e $\mathrm{Sr}$ foram observados nos termofosfatos. Os teores de $\mathrm{Cr}$ nas três amostras analisadas excedem em muito o valor de $9,7 \mathrm{mg} \mathrm{kg}^{-1}$ obtido por Amaral Sobrinho et al. (1992). No entanto, os teores de Ni são bastante inferiores ao valor de $3.300 \mathrm{mg} \mathrm{kg}^{-1}$, observado pelos mesmos autores (Tabela 11). As matérias primas usadas no processamento destes fertilizantes são, além das rochas fosfatadas, materiais fontes de magnésio e sílica, sendo empregadas escórias da produção de ferro e níquel ou rochas magnesianas, como a serpentinita (Guardani, 1987). Desta forma, presume-se que as variações nos teores destes elementos sejam resultantes do uso alternativo destes materiais. Os teores de $\mathrm{Cr}$ próximos a $1.000 \mathrm{mg} \mathrm{kg}^{-1}$ verificados neste estudo estão dentro da faixa de 100 a $2.700 \mathrm{mg} \mathrm{kg}^{-1}$ observada por Watanabe (1984) em termofosfatos magnesianos fundidos usando a serpentinita.

Os concentrados apatíticos apresentaram teores mais elevados do que as rochas fosfatadas para a maioria dos elementos analisados, podendo-se concluir que junto ao 
processo de concentração de $\mathrm{P}_{2} \mathrm{O}_{5}$ são aumentados também os teores de metais pesados. Estes concentrados entram na rota de obtenção do ácido fosfórico, que é usado no processamento do superfosfato triplo, fosfato monoamônico (MAP) e fosfato diamônico (DAP), obtendo-se o subproduto fosfogesso que é aplicado aos solos para corrigir os baixos teores de $\mathrm{Ca}$ em subsuperficie.

Tanto $\mathrm{Ba}$ como Sr praticamente desapareceram nas amostras de ácido fosfórico e, em consequência, apareceram em níveis também baixos nas amostras de MAP e DAP, níveis estes semelhantes aos observados por Raven \& Loeppert (1997). Boa parte do Sr permaneceu no fosfogesso, mas o $\mathrm{Ba}$ foi bastante reduzido neste subproduto. $\mathrm{O}$ mesmo foi observado nas amostras de superfosfato simples que é o resultado da reação do concentrado apatítico com ácido sulfúrico, não havendo separação do gesso no produto final.

Não é de se estranhar que o Sr esteja presente em alta proporção no fosfogesso, visto que seu raio iônico está muito próximo ao do $\mathrm{Ca}$, favorecendo a coprecipitação. $\mathrm{O}$ $\mathrm{Ba}$, que tem raio iônico maior do que o $\mathrm{Ca}$, apresentou-se em baixos teores, sendo possível, desde que ele não esteja presente em algum rejeito do processo, que ele tenha se insolubilizado durante o ataque da amostra para análise, como $\mathrm{BaSO}_{4}$, que é bastante insolúvel.

Senesi et al. (1983) verificaram, em cinco amostras de superfosfato simples, concentrações de $\mathrm{Sr}$ entre 31,2 e $62,0 \mathrm{mg} \mathrm{kg}^{-1}$ e de Ba entre 113,0 e 500,0 $\mathrm{mg} \mathrm{kg}^{-1}$, de $\mathrm{Sr}$ muito inferiores e de $\mathrm{Ba}$ superiores aos obtidos no presente estudo (Tabela 11). As concentrações de $\mathrm{Sr}$ nas rochas fosfatadas foram também superiores à maior concentração verificada por Kpomblekou-A \& Tabatabai (1994) em 14 amostras de rochas procedentes da África, EUA e Peru.

A maioria das rochas fosfatadas mostraram-se ricas em B. Pode-se observar que o elemento permanece nas amostras de superfosfato simples, mas deve ser perdido no processamento para obtenção do ácido fosfórico, sendo que o gesso também mostrou-se pobre no elemento. Os trabalhos sobre o assunto quase sempre enfocam apenas os elementos metálicos, sendo o boro excluído das análises. Os resultados obtidos neste estudo para as fontes fosfatadas estão próximos aos de Arora et al. (1974), devendo-se 
destacar os elevados teores de uma das amostras de rocha fosfatada (Catalão) e da mistura 4-14-8 (Tabela 11). Para calcários, Chichilo \& Whittaker (1958) e Chichilo \& Whittaker (1961) obtiveram teores de B de 1 a 21 e média de $4 \mathrm{mg} \mathrm{kg}^{-1}$, quando analisaram 254 amostras. No presente estudo, a maioria das amostras apresentou valores inferiores a $10 \mathrm{mg} \mathrm{kg}^{-1}$ (Tabela 12) e apenas uma amostra, proveniente de Pântano Grande (RS), superou a concentração de $21 \mathrm{mg} \mathrm{kg}^{-1}$.

Os baixos teores de $\mathrm{Cd}$ verificados nas rochas e fertilizantes fosfatados confirmam aqueles observados por Langenbach \& Sarpa (1985) e Amaral Sobrinho et al. (1992), mantendo-se numa faixa de concentração bastante inferior àquelas verificadas nestes materiais nos E.U.A. de 5 a $200 \mathrm{mg} \mathrm{kg}^{-1}$ (Mortvedt et al., 1981), na Austrália de 18 a 91 $\mathrm{mg} \mathrm{kg}^{-1}$ (Williams \& David, 1973) e na África de 3 a $75 \mathrm{mg} \mathrm{kg}^{-1}$ (Sauerbeck, 1985).

Ao contrário do que foi sugerido por Williams \& David (1973) a partir da elevada correlação obtida entre os teores de $\mathrm{Cd}$ e $\mathrm{P}$ em fertilizantes fosfatados, o $\mathrm{Cd}$ não foi concentrado nas amostras de ácido fosfórico em relação às rochas, devendo-se levar em conta que a faixa de concentração de $\mathrm{Cd}$ nas amostras consideradas pelos autores tenha sido de 18 a $91 \mathrm{mg} \mathrm{kg}^{-1}$, bem mais ampla do que no presente estudo $\left(1,7\right.$ a $\left.7,1 \mathrm{mg} \mathrm{kg}^{-1}\right)$. Considerando os produtos procedentes de Jacupiranga (Tabela 11), aproximadamente metade do $\mathrm{Cd}$ da rocha de origem foi observada no ácido fosfórico e $20 \%$ no fosfogesso e o superfosfato simples mantém aproximadamente $60 \%$, proporções inferiores mas próximas àquelas encontradas por Wakefield ${ }^{1}$, citado por Mortvedt (1987).

As amostras dos concentrados apatíticos e de superfosfato simples, originários da mesma rocha (Araxá), apresentaram teores destacadamente altos de $\mathrm{Zn}$. No entanto, $\mathrm{Zn}$ e $\mathrm{Cu}$ encontram-se dentro dos intervalos de concentrações observados por Senesi \& Polemio (1981), Charter et al. (1993) e Raven \& Loeppert (1997), em diversos fertilizantes fosfatados e misturas NPK. A mistura 4-14-8 destaca-se com teores de 1.163 $\mathrm{mg} \mathrm{kg}{ }^{-1}$ de $\mathrm{Cu}$ e $5.056 \mathrm{mg} \mathrm{kg}^{-1}$ de $\mathrm{Zn}$. Como não há nenhuma referência a estes teores pelo fabricante, o agricultor poderá fazer uso da mistura e ainda aplicar uma fonte destes

\footnotetext{
${ }^{1}$ Wakefield, Z. T. Distribuition of cadmium and selected heavy metals in phosphate fertilizer processing. Bull. Y-159. National Fertilizer Development Center, Tennessee Valley Authority, Muscle Shoals, Al. 1980.
} 
micronutrientes, o que poderá, ao longo da exploração agrícola do solo, conduzir ao acúmulo em níveis tóxicos para as culturas.

As amostras de calcário provenientes do Estado de Minas Gerais foram as que apresentaram os teores mais elevados de $\mathrm{Mn}$ e de $\mathrm{Fe}$, bastante superiores às demais amostras, bem como àqueles encontrados por Valadares et al. (1974) para calcários do Estado de São Paulo. Raij (1991) refere-se a similaridade, tanto no comportamento químico como em ocorrência geológica, entre os dois elementos. Neste estudo, as amostras que apresentaram os maiores teores de $\mathrm{Mn}$, também tiveram as maiores concentrações de $\mathrm{Fe}$, obtendo-se um elevado coeficiente de correlação $(R=0,84)$ entre os teores dos dois elementos.

Como esperado, $\mathrm{Cd}$ e $\mathrm{Pb}$ foram detectados em niveis mais elevados nas fontes de micronutrientes. $\mathrm{O}$ maior teor de $\mathrm{Cd}$ foi encontrado em uma fonte de $\mathrm{B}$ e $\mathrm{Zn}$ (BR 5), destacando-se dos valores obtidos no Brasil por Alcarde \& Rodella (1993) em amostras comerciais de óxido de zinco ( 7,7 a $82,7 \mathrm{mg} \mathrm{kg}^{-1}$ ); $\mathrm{Pb}$ também aparece em maior concentração, em algumas amostras, do que o intervalo de 153,3 a $2.054,1 \mathrm{mg} \mathrm{kg}^{-1}$, observados pelos mesmos autores (Tabela 13). No entanto, os teores destes elementos potencialmente tóxicos foram muito inferiores aos encontrados por Mortvedt (1985b) em fontes de $\mathrm{Zn}$ provenientes de subprodutos industriais usados na agricultura americana.

As amostras dos materiais analisados apresentaram teores de cálcio bastante variáveis, sendo que nos extratos a concentração variou desde traços a $4 \mathrm{mg} \mathrm{mL}^{-1}$. Segundo Winge et al.(1985), a determinação de Cu através de ICP-AES está sujeita a interferência espectral do $\mathrm{Ca}$ presente na matriz. Na Figura 1, pode-se identificar a ocorrência de um erro sistemático aditivo que torna os teores de $\mathrm{Cu}$ determinados por ICP-AES cerca de $25 \mathrm{mg} \mathrm{kg}^{-1}$ mais elevados que os determinados por AAS nos materiais ricos em $\mathrm{Ca}$, com concentrações de 1,0 a $4,0 \mathrm{mg} \mathrm{mL}^{-1}$ nos extratos, como os calcários, superfosfatos, fosfogessos e termofosfatos. 


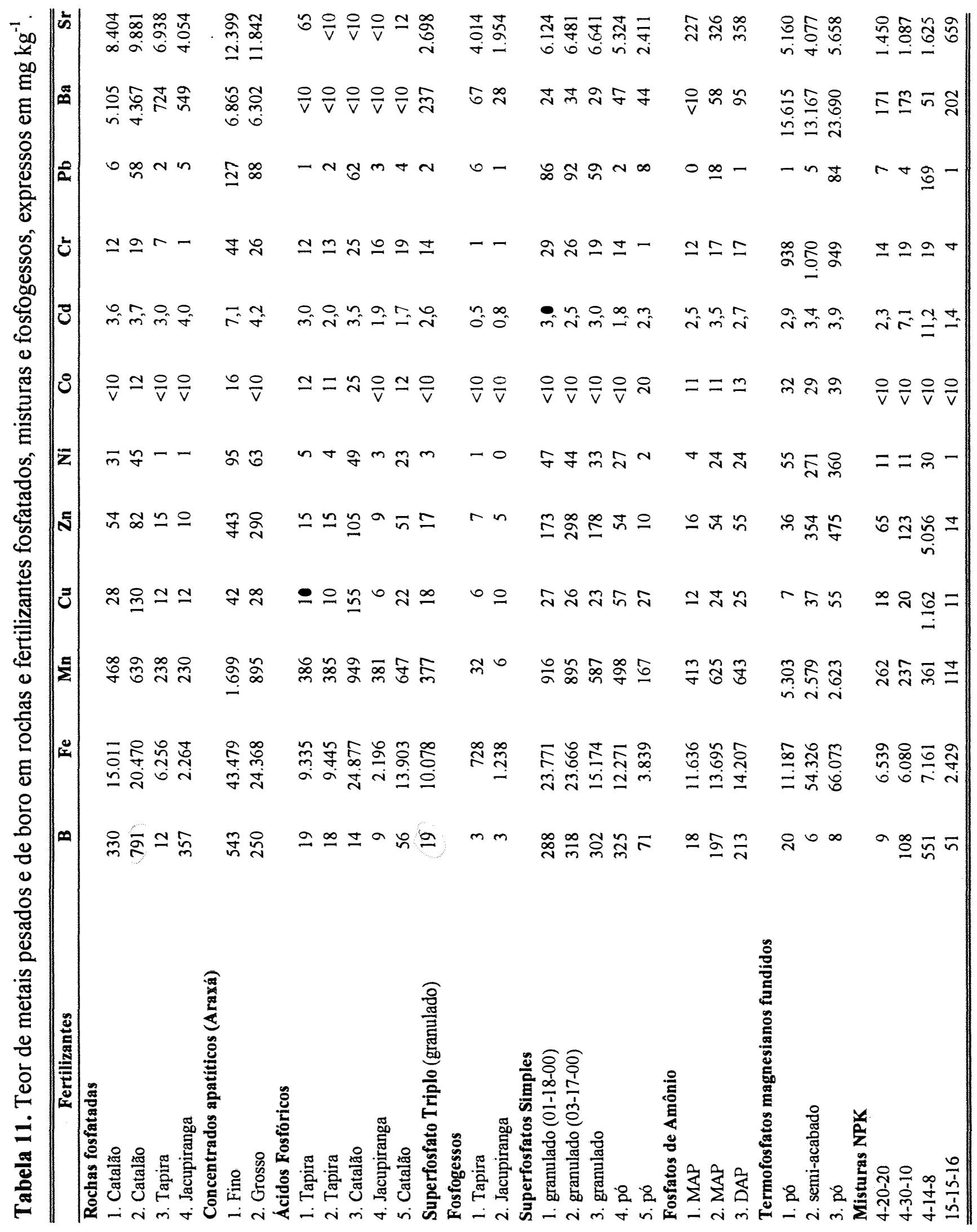


Tabela 12. Teores mínimo e máximo, mediana e média dos micronutrientes e elementos potencialmente tóxicos nas 23 amostras de calcários analisadas.

\begin{tabular}{|c|c|c|c|c|}
\hline Elemento & Mínimo & Máximo & Mediana & Média \\
\hline & \multicolumn{4}{|c|}{$\mathrm{mg} \mathrm{kg}^{-1}$} \\
\hline B & 1 & 53 & 6,3 & 8,6 \\
\hline $\mathrm{Fe}$ & 72 & 45.024 & $2.167,7$ & $7.140,0$ \\
\hline $\mathrm{Mn}$ & 8 & 5.518 & 357,3 & $1.062,6$ \\
\hline $\mathrm{Cu}$ & 3 & 21 & 5,3 & 7,6 \\
\hline $\mathrm{Zn}$ & 5 & 57 & 12,0 & 16,0 \\
\hline $\mathrm{Ni}$ & 0,1 & 13,0 & 0,9 & 2,1 \\
\hline $\mathrm{Cd}$ & 3,1 & 6,8 & 4,3 & 8,8 \\
\hline $\mathrm{Pb}$ & 0,3 & 27,1 & 3,0 & 5,7 \\
\hline $\mathrm{Cr}$ & 0 & 108 & 2,3 & 10,6 \\
\hline $\mathrm{Ba}$ & $<10$ & 1.265 & 43,0 & - \\
\hline $\mathrm{Sr}$ & 36 & 4.736 & 401,0 & 824,4 \\
\hline
\end{tabular}




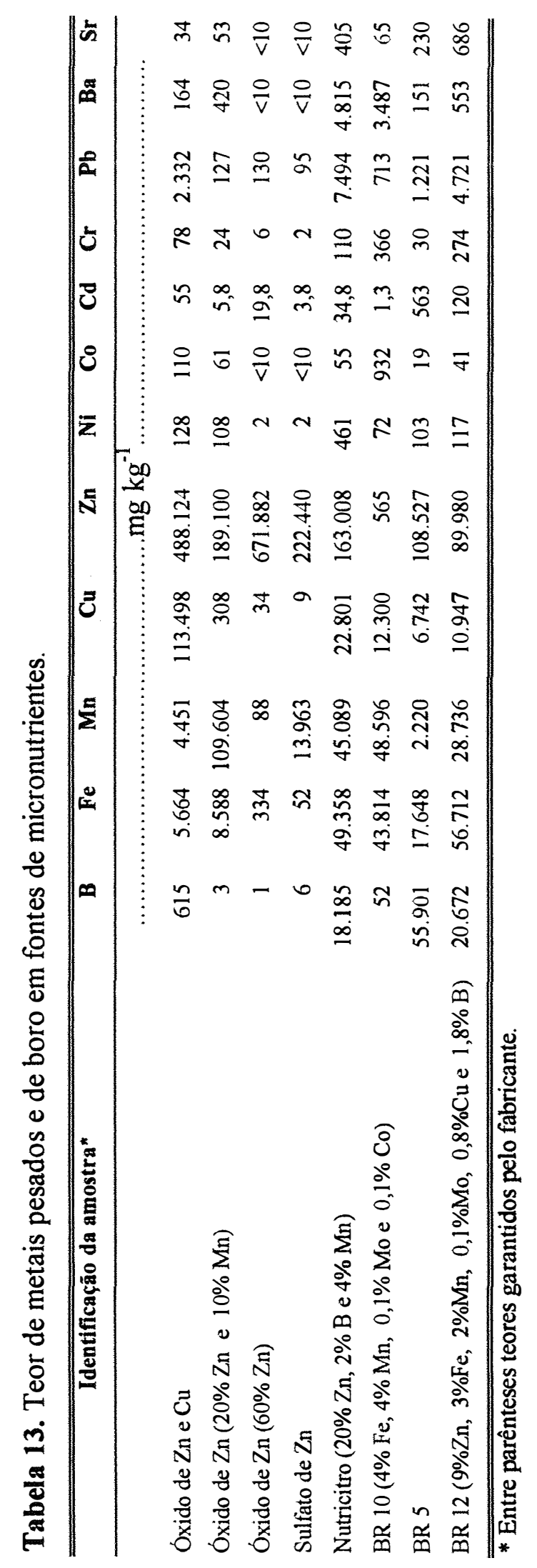




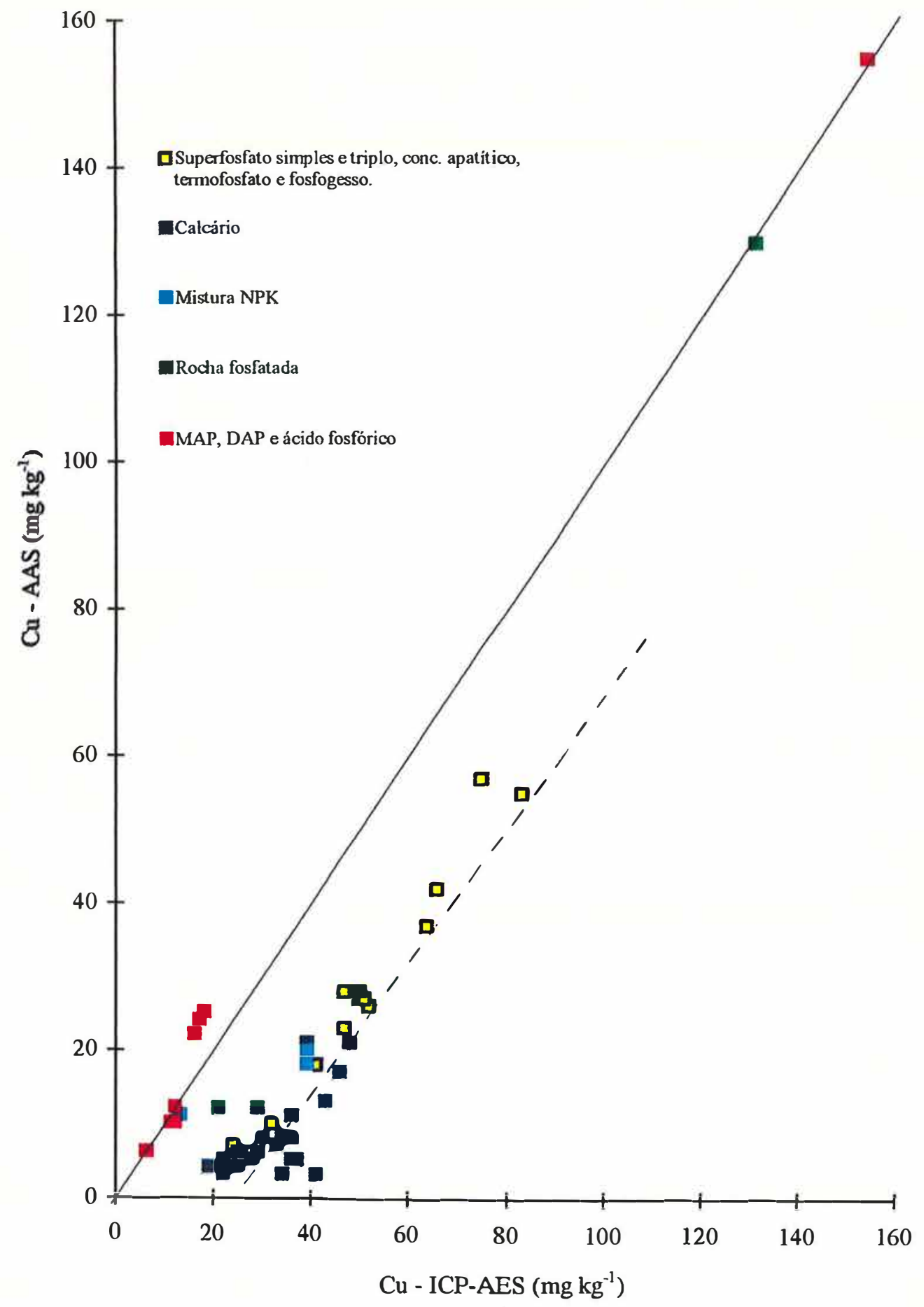

Figura 1. Relação entre os teores de Cu determinados por ICP-AES e por AAS. 


\subsection{Disponibilidade de micronutrientes e elementos potencialmente tóxicos presentes em calcário e fertilizantes minerais, avaliada através da análise de solo}

\subsubsection{Cádmio, crômio, níquel e chumbo}

Cádmio e $\mathrm{Pb}$ extraídos com a solução Mehlich 3 apresentaram-se em concentrações muito baixas nos extratos das amostras de solo de todas as parcelas experimentais (dados não apresentados). O mesmo ocorreu para $\mathrm{Cd}, \mathrm{Ni}$ e $\mathrm{Cr}$ extraídos pelo método DTPA-TEA. A determinação destes elementos foi prejudicada pelos baixos teores nos solos, pela diluição destes provocada pela relação solo:solução de 1:10 do método Mehlich 3 e pelo baixo poder de extração do DTPA-TEA.

Os melhores limites de deteç̧ão para ICP-AES relatados por Parsons et al. (1983) são bastante baixos: 0,00008 $\mathrm{mg} \mathrm{L}^{-1}$ para $\mathrm{Cr}, 0,0002 \mathrm{mg} \mathrm{L}^{-1}$ para $\mathrm{Ni}, 0,00007 \mathrm{mg}$ $\mathrm{L}^{-1}$ para $\mathrm{Cd} \mathrm{e} 0,001 \mathrm{mg} \mathrm{L}^{-1}$ para $\mathrm{Pb}$. No entanto, estes limites foram obtidos em soluções aquosas. Os extratos de solos são matrizes muito mais complexas, sendo a precisão dos resultados bastante afetada em concentrações tão baixas.

Abreu et al. (1995) verificaram uma baixa eficiência destes extratores em avaliar a disponibilidade de metais pesados em solos não contaminados. Esta constatação e os elevados coeficientes de variação para $\mathrm{Ni}$ e $\mathrm{Cr}$ extraídos com a solução Mehlich 3, obtidos no presente estudo (Tabelas 14 e 15), podem estar relacionados a estas características dos métodos. $\mathrm{O}$ fato de não ser significativa a correlação entre os teores de $\mathrm{Pb}$ extraídos pelo DTPA-TEA e as quantidades adicionadas (Figura $2 \mathrm{c}$ ) e as diferenças significativas entre os tratamentos para os teores extraídos de $\mathrm{Pb}$ (Tabelas 16 e 17) não puderam ser relacionados a fatores ligados aos tratamentos.

Apenas os tratamentos que receberam o termofosfato (5 e 9) apresentaram concentrações de $\mathrm{Cr}$ e $\mathrm{Ni}$ nos extratos obtidos pelo método Mehlich 3 que puderam ser quantificados satisfatoriamente. Os elevados coeficientes de determinação obtidos para a relação entre quantidades adicionadas e teores nos solos destes elementos se deve à separação dos pontos em dois grupos: o dos tratamentos 5 e 9 e todos os demais, estes 
aglomerados em concentrações mais baixas (Figura 2a e b). Excluídos os pontos dos tratamentos 5 e 9 , a correlação entre as variáveis não é significativa. O termofosfato foi o único material fertilizante que provocou nítida elevação das concentrações destes metais nos solos, mas apenas superiores aos valores mínimos obtidos por Abreu et al. (1995).

O baixo teor de matéria orgânica dos solos usados no presente estudo pode ter contribuído para os reduzidos níveis $\mathrm{Cd}, \mathrm{Cr}, \mathrm{Ni}$ e $\mathrm{Pb}$ nos solos. $\mathrm{Na}$ coleta da terra para os experimentos nos vasos, a camada superficial de 0 a $10 \mathrm{~cm}$ do solo foi desprezada. A matéria orgânica possui habilidade quelante e capacidade de troca cationnica que contribuem para o acúmulo destes elementos na camada superficial (Adriano, 1986).

Tabela 14. Teores médios de metais pesados extraídos pelo método Mehlich 3 no experimento com o solo AQ (média das 4 repetições).*

\begin{tabular}{|c|c|c|c|c|c|c|}
\hline TRAT. & $\mathrm{Fe}$ & $\mathrm{Mn}$ & $\mathrm{Zn}$ & $\overline{\mathrm{Cu}}$ & $\overline{\mathrm{Ni}}$ & $\mathrm{Cr}$ \\
\hline & .......... & .......... & .........mg & $\cdots$ & $\cdots$ & ........... \\
\hline 1 & 71,17 cdef & 5,95 ef & $0,38 \mathrm{f}$ & 0,12 ef & $0,03 \mathrm{c}$ & $0,04 \mathrm{~b}$ \\
\hline 2 & $80,91 \mathrm{~cd}$ & 11,01 a & $5,29 \mathrm{c}$ & $1,97 \mathrm{a}$ & $0,05 \mathrm{bc}$ & $0,04 \mathrm{~b}$ \\
\hline 3 & 74,49 cdef & $6,87 \mathrm{de}$ & $0,00 \mathrm{f}$ & $0,00 \mathrm{f}$ & $0,02 \mathrm{c}$ & $0,04 \mathrm{~b}$ \\
\hline 4 & 74,57 cdef & 7,09 de & $0,00 \mathrm{f}$ & $0,00 \mathrm{f}$ & $0,06 \mathrm{bc}$ & $0,07 \mathrm{~b}$ \\
\hline 5 & $169,55 \mathrm{a}$ & $10,68 \mathrm{ab}$ & $0,40 \mathrm{f}$ & 0,06 ef & $0,59 \mathrm{a}$ & $0,80 \mathrm{a}$ \\
\hline 6 & $64,26 \mathrm{def}$ & 6,17 ef & $2,90 \mathrm{~d}$ & $0,00 \mathrm{f}$ & $0,03 \mathrm{c}$ & $0,06 \mathrm{~b}$ \\
\hline 7 & $101,93 \mathrm{~b}$ & $10,84 \mathrm{ab}$ & 12,80 a & $1,56 \mathrm{~b}$ & $0,10 b c$ & $0,12 \mathrm{~b}$ \\
\hline 8 & 60,78 ef & 6,25 ef & $0,03 \mathrm{f}$ & $0,00 \mathrm{f}$ & $0,12 \mathrm{~b}$ & $0,14 \mathrm{~b}$ \\
\hline 9 & 178,94 a & 11,27 a & 0,67 ef & $0,37 \mathrm{de}$ & $0,63 \mathrm{a}$ & 0,91 a \\
\hline 10 & $56,10 \mathrm{f}$ & $5,31 \mathrm{f}$ & $2,42 \mathrm{de}$ & 0,21 ef & $0,04 \mathrm{bc}$ & $0,02 \mathrm{~b}$ \\
\hline 11 & $102,31 \quad b$ & 11,10 a & 12,25 a & $2,01 \quad \mathrm{a}$ & $0,02 \mathrm{c}$ & $0,01 \quad b$ \\
\hline 12 & 79,76 cde & $8,27 \mathrm{~cd}$ & $7,94 \mathrm{~b}$ & $0,58 \mathrm{~d}$ & $0,06 b c$ & $0,02 \mathrm{~b}$ \\
\hline 13 & 88,84 bc & $9,44 \mathrm{bc}$ & $9,93 \mathrm{~b}$ & $1,07 \mathrm{c}$ & $0,07 \mathrm{bc}$ & $0,08 \mathrm{~b}$ \\
\hline CV\% & 8,7 & 7,1 & 19,1 & 22,6 & 25,9 & 34,1 \\
\hline DMS & 20,06 & 1,49 & 2,01 & 0,35 & 0,09 & 0,15 \\
\hline
\end{tabular}

* Médias seguidas por letras distintas diferem entre si ao nível de significância de 0,05 pelo teste de Tukey. $\mathrm{Cd}$ e $\mathrm{Pb}$ não incluídos. 
Tabela 15. Teores médios de metais pesados extraídos pelo método Mehlich 3 no experimento com o solo LR (média das 4 repetições). ${ }^{*}$

\begin{tabular}{|c|c|c|c|c|c|c|}
\hline TRAT. & $\mathrm{Fe}$ & $\mathrm{Mn}$ & $\overline{\mathrm{Zn}}$ & $\mathrm{Cu}$ & $\mathrm{Ni}$ & $\overline{C r}$ \\
\hline & & & $\ldots \ldots$ & $\mathrm{g}^{-1}$ & & $\ldots \ldots$ \\
\hline 1 & 11,66 cde & $5,95 \mathrm{de}$ & $0,18 \mathrm{~g}$ & 0,91 ef & 0,03 cde & $0,05 \mathrm{~d}$ \\
\hline 2 & $11,30 \mathrm{de}$ & $9,42 \mathrm{c}$ & $2,42 \mathrm{~d}$ & $2,01 \mathrm{bc}$ & $0,01 \mathrm{e}$ & $0,04 \mathrm{~d}$ \\
\hline 3 & $10,34 \mathrm{de}$ & $5,08 \mathrm{e}$ & $0,08 \mathrm{~g}$ & 0,86 ef & $0,01 \mathrm{e}$ & $0,06 \mathrm{~d}$ \\
\hline 4 & $10,41 \mathrm{de}$ & $6,25 \mathrm{de}$ & $0,07 \mathrm{~g}$ & $0,78 \mathrm{f}$ & $0,02 \mathrm{de}$ & $0,04 \mathrm{~d}$ \\
\hline 5 & 53,08 a & $10,95 \mathrm{~b}$ & $0,68 \mathrm{fg}$ & $1,39 \mathrm{de}$ & $0,26 \mathrm{a}$ & 0,27 a \\
\hline 6 & $11,31 \mathrm{de}$ & $7,05 \mathrm{~d}$ & $2,01 \mathrm{de}$ & 0,84 ef & $0,00 \mathrm{e}$ & $0,07 \mathrm{~cd}$ \\
\hline 7 & $14,24 \mathrm{~cd}$ & $6,85 \mathrm{~d}$ & $6,91 \mathrm{~b}$ & $2,21 \quad a b$ & $0,09 \mathrm{~b}$ & $0,11 \mathrm{~cd}$ \\
\hline 8 & $9,28 \mathrm{e}$ & $5,38 \mathrm{e}$ & $0,30 \mathrm{fg}$ & 1,05 def & 0,04 bcde & $0.15 b c$ \\
\hline 9 & 52,74 a & $11,32 \mathrm{~b}$ & 0,87 efg & $1,55 \mathrm{~cd}$ & $0,20 \mathrm{a}$ & $0,20 \mathrm{ab}$ \\
\hline 10 & $10,92 \mathrm{de}$ & $5,73 \mathrm{de}$ & $1,38 \mathrm{def}$ & $1,37 \mathrm{de}$ & 0,08 bcd & $0,10 \mathrm{~cd}$ \\
\hline 11 & $23,65 \mathrm{~b}$ & 13,27 a & 9,16 a & 2,75 a & 0,05 bcde & $0,05 \mathrm{~d}$ \\
\hline 12 & $15,52 \mathrm{c}$ & $7,02 \mathrm{~d}$ & $5,39 \mathrm{c}$ & $2,69 \mathrm{a}$ & $0,08 \mathrm{bc}$ & $0,06 \mathrm{~d}$ \\
\hline 13 & $14,11 \mathrm{~cd}$ & $8,83 \mathrm{c}$ & $6,02 \mathrm{bc}$ & $2,58 \quad \mathrm{a}$ & 0,04 bcde & $0,03 \mathrm{~d}$ \\
\hline CV \% & 8,2 & 7,0 & 17,1 & 13,9 & 39,0 & 37,7 \\
\hline DMS & 3,91 & 1,38 & 1,16 & 0,56 & 0,07 & 0,09 \\
\hline
\end{tabular}

* Médias seguidas por letras distintas diferem entre si ao nível de significância de 0,05 pelo teste de

Tukey. $\mathrm{Cd}$ e $\mathrm{Pb}$ não incluídos. 
Tabela 16. Teores médios de metais pesados extraídos pelo método DTPA-TEA e de boro extraído pelo método da água quente, no experimento com o solo AQ (média das 4 repetições).*

\begin{tabular}{|c|c|c|c|c|c|c|}
\hline TRAT. & B & $\mathrm{Fe}$ & $\mathrm{Mn}$ & $\overline{\mathrm{Zn}}$ & $\mathrm{Cu}$ & $\overline{\mathrm{Pb}}$ \\
\hline & \multicolumn{6}{|c|}{ 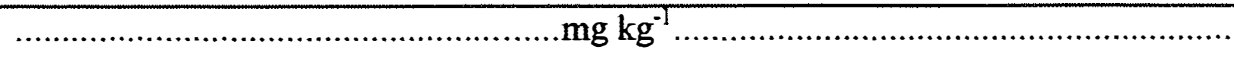 } \\
\hline 1 & $0,01 \mathrm{e}$ & $7,90 \mathrm{~g}$ & $1,26 \mathrm{f}$ & 0,16 e & $0,06 \mathrm{ghi}$ & $0,03 \mathrm{~g}$ \\
\hline 2 & $0,24 \mathrm{~d}$ & $12,71 \mathrm{c}$ & $5,12 \mathrm{~d}$ & $1,60 \mathrm{~d}$ & $1,10 \mathrm{~b}$ & $0,03 \mathrm{~g}$ \\
\hline 3 & $0,01 \mathrm{e}$ & 8,80 efg & $1,58 \mathrm{f}$ & $0,00 \mathrm{e}$ & $0,02 \mathrm{i}$ & $0,00 \mathrm{~g}$ \\
\hline 4 & $0,01 \mathrm{e}$ & 9,76 def & 2,25 ef & $0,00 \mathrm{e}$ & $0,03 \mathrm{i}$ & $0,04 \mathrm{fg}$ \\
\hline 5 & $0,01 \mathrm{e}$ & $8,61 \mathrm{fg}$ & $1,90 \mathrm{f}$ & $0,06 \mathrm{e}$ & $0,04 \mathrm{hi}$ & $0,00 \mathrm{~g}$ \\
\hline 6 & $0,89 \mathrm{~b}$ & $10,31 \mathrm{~d}$ & $3,41 \mathrm{e}$ & $1,33 \mathrm{~d}$ & $0,10 \mathrm{fg}$ & $0,01 \mathrm{~g}$ \\
\hline 7 & $0,56 \mathrm{c}$ & $15,07 \mathrm{~b}$ & $8,67 \mathrm{~b}$ & 8,26 a & $1,21 \mathrm{a}$ & $0,00 \mathrm{~g}$ \\
\hline 8 & $0,01 \mathrm{e}$ & $7,98 \mathrm{~g}$ & $1,67 \mathrm{f}$ & $0,00 \mathrm{e}$ & $0,03 \mathrm{hi}$ & 0,08 ef \\
\hline 9 & $0,02 \mathrm{e}$ & $12,66 \mathrm{c}$ & 2,39 ef & $0,16 \mathrm{e}$ & $0,09 \mathrm{fgh}$ & $0,12 \mathrm{de}$ \\
\hline 10 & $1,25 \mathrm{a}$ & $9,83 \mathrm{de}$ & $1,91 \mathrm{f}$ & $1,07 \mathrm{~d}$ & $0,12 \mathrm{f}$ & $0,15 \mathrm{~cd}$ \\
\hline 11 & $0,47 \mathrm{c}$ & 18,06 a & 11,09 a & 8,23 a & $0,86 \mathrm{c}$ & 0,19 bc \\
\hline 12 & $1,27 \mathrm{a}$ & $14,43 \quad b$ & $6,57 \mathrm{c}$ & $5,26 \mathrm{c}$ & 0,40 e & $0,23 \mathrm{ab}$ \\
\hline 13 & $1,24 \mathrm{a}$ & $15,59 \mathrm{~b}$ & $6,76 \mathrm{c}$ & $6,87 b$ & $0,59 \mathrm{~d}$ & $0,26 \mathrm{a}$ \\
\hline CV\% & 18,0 & 4,1 & 11,3 & 11,7 & 6,4 & 21,5 \\
\hline DMS & 0,21 & 1,18 & 1,18 & 0,74 & 0,06 & 0,05 \\
\hline
\end{tabular}

* Médias seguidas por letras distintas diferem entre si ao nível de significância de 0,05 pelo teste de Tukey. Cd, Cr e Ni não incluídos. 
Tabela 17. Teores médios de metais pesados extraídos pelo método DTPA-TEA e de boro extraído pelo método da água quente no experimento com o solo LR (média das 4 repetições).*

\begin{tabular}{|c|c|c|c|c|c|c|}
\hline TRAT. & $\bar{B}$ & $\mathrm{Fe}$ & $\mathrm{Mn}$ & $\mathrm{Zn}$ & $\overline{\mathrm{Cu}}$ & $\overline{\mathrm{Pb}}$ \\
\hline & \multicolumn{6}{|c|}{ 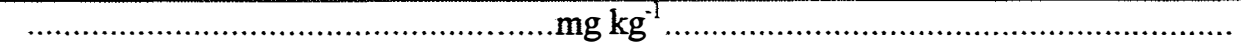 } \\
\hline 1 & $0,00 \mathrm{f}$ & $2,93 \mathrm{fgh}$ & $2,58 \mathrm{fg}$ & $0,13 \mathrm{hi}$ & $0,36 \mathrm{f}$ & 0,39 cde \\
\hline 2 & $0,12 \mathrm{f}$ & $2,99 \mathrm{efg}$ & $4,76 \mathrm{~cd}$ & $1,28 \mathrm{f}$ & $0,74 \mathrm{~cd}$ & 0,38 cde \\
\hline 3 & $0,04 \mathrm{f}$ & 3,48 def & 2,99 efg & $0,12 \mathrm{hi}$ & 0,48 e & 0,42 bcd \\
\hline 4 & $0,05 \mathrm{f}$ & $3,52 \mathrm{de}$ & $4,02 \mathrm{de}$ & $0,13 \mathrm{hi}$ & 0,46 ef & $0,45 \mathrm{bc}$ \\
\hline 5 & $0,04 \mathrm{f}$ & 8,39 a & 3,57 ef & $0,31 \mathrm{~h}$ & $0,66 \mathrm{~d}$ & 0,66 a \\
\hline 6 & $1,23 \mathrm{~b}$ & 3,38 defg & $5,03 \mathrm{~cd}$ & $1,44 \mathrm{e}$ & $0,54 \mathrm{e}$ & $0,31 \mathrm{e}$ \\
\hline 7 & $0,69 \mathrm{~d}$ & $5,09 \mathrm{c}$ & $6,86 \mathrm{~b}$ & $5,30 \mathrm{~b}$ & $1,16 \mathrm{a}$ & 0,36 cde \\
\hline 8 & $0,03 \mathrm{f}$ & $2,85 \mathrm{gh}$ & $2,49 \mathrm{fg}$ & $0,04 j$ & 0,44 ef & 0,39 cde \\
\hline 9 & $0,04 \mathrm{f}$ & $5,05 \mathrm{c}$ & $2,06 \mathrm{~g}$ & $0,21 \mathrm{hi}$ & $0,49 \mathrm{e}$ & 0,40 cde \\
\hline 10 & $0,94 \mathrm{c}$ & $2,40 \mathrm{~h}$ & $2,02 \mathrm{~g}$ & $0,68 \mathrm{~g}$ & 0,45 ef & 0,36 cde \\
\hline 11 & 0,50 e & $5,94 \mathrm{~b}$ & 12,13 a & 5,85 a & $1,05 \mathrm{~b}$ & 0,39 cde \\
\hline 12 & $1,19 \mathrm{~b}$ & $3,54 \mathrm{de}$ & $4,86 \mathrm{~cd}$ & $3,21 \mathrm{~d}$ & $0,69 \mathrm{~cd}$ & $0,50 \mathrm{~b}$ \\
\hline 13 & $1,47 \mathrm{a}$ & $3,79 \mathrm{~d}$ & $5,88 \mathrm{bc}$ & $3,54 \mathrm{c}$ & $0,78 \mathrm{c}$ & 0,32 de \\
\hline CV \% & 13,3 & 5,70 & 10,23 & 4,59 & 6,53 & 9,74 \\
\hline DMS & 0,16 & 0,58 & 1,16 & 0,20 & 0,10 & 0,10 \\
\hline
\end{tabular}

* Médias seguidas por letras distintas diferem entre si ao nível de significância de 0,05 pelo teste de

Tukey. Cd, Cr e Ni não incluidos. 


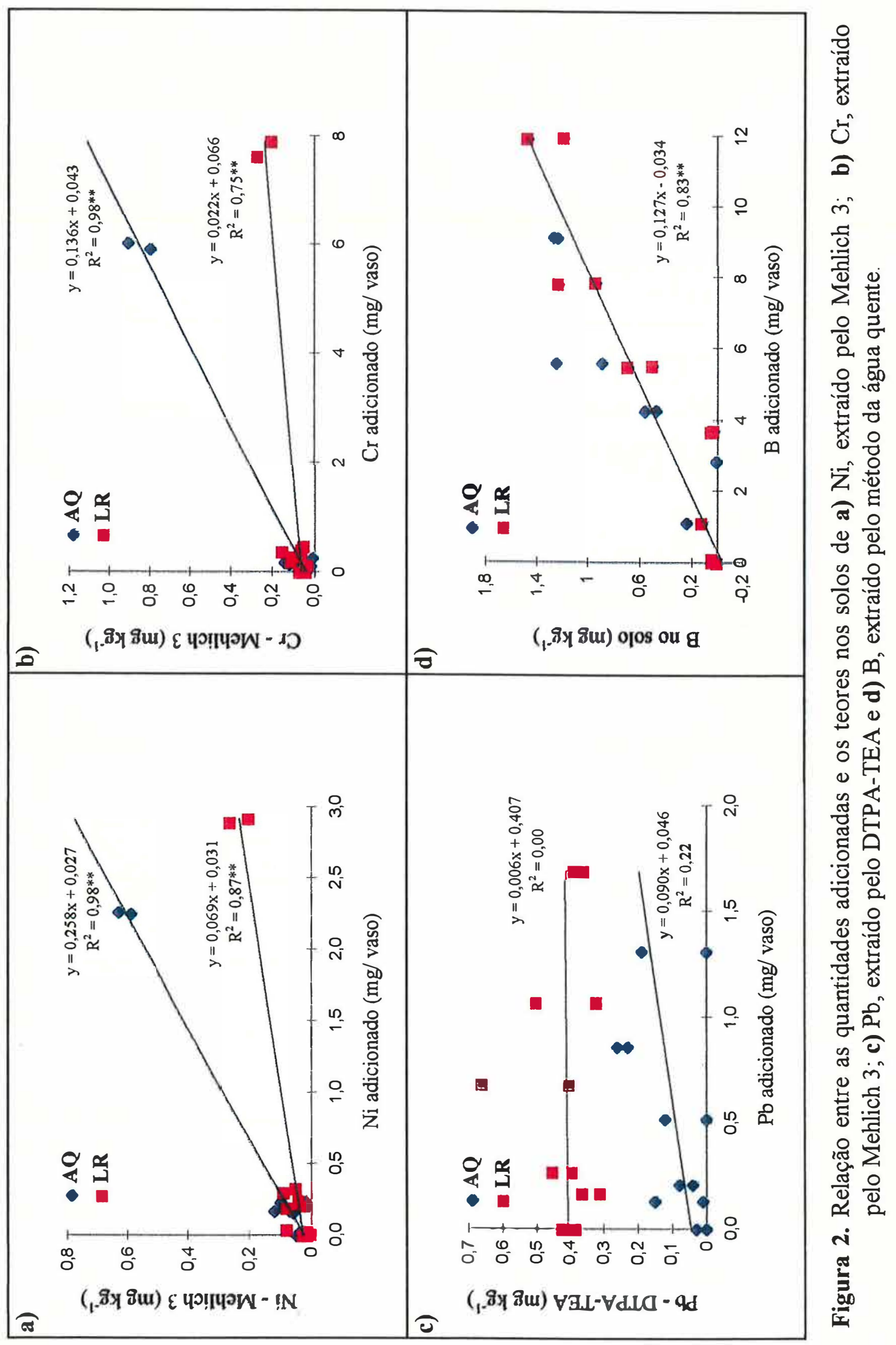




\subsubsection{Boro, cobre, ferro, manganês e zinco}

Houve diferença significativa entre os tratamentos para os teores destes micronutrientes metálicos extraídos pelos métodos Mehlich 3 e DTPA-TEA, e também para os teores de boro extraído pelo método da água quente, tanto no solo LR como no AQ (Tabelas 14, 15, 16 e 17).

As doses de boro adicionadas aos solos promoveram um aumento linear nos teores de boro extraído pelo método da água quente. $\mathrm{O}$ coeficiente angular da reta (Figura 2d) permite uma estimativa de recuperação média de $38 \%$ do $\mathrm{B}$ adicionado nos experimentos através dos diferentes materiais fertilizantes. Ribeiro \& Tucunango Sarabia (1984) obtiveram uma estimativa de 50\%, ao aplicarem seis doses crescentes do micronutriente na forma de $\mathrm{H}_{3} \mathrm{BO}_{3}$ em cinco Latossolos.

A literatura mostra que alguns atributos dos solos como o $\mathrm{pH}$, a textura, a mineralogia, o teor de matéria orgânica, afetam a disponibilidade de B (Reisenauer et al., 1973; Goldberg, 1993). Os solos usados neste estudo são bastante distintos quanto a textura e os tratamentos proporcionaram uma ampla faixa de $\mathrm{pH}$, diferenças que afetaram a quantidade extraída, considerando os diferentes tratamentos e também os solos estudados.

Uma vez que o teor extraído no tratamento 1 (teste) foi praticamente nulo, a porcentagem de $\mathrm{B}$ recuperado de alguns materiais fertilizantes pode ser calculado através do quociente entre o teor extraído e a quantidade adicionada. No tratamento 2, que recebeu a dose de $\mathrm{H}_{3} \mathrm{BO}_{3}$, recuperou-se $64 \%$ do $\mathrm{B}$ aplicado ao solo $\mathrm{AQ}(\mathrm{pH} \mathrm{6,3)} \mathrm{e} 32 \%$ ao solo LR ( $\mathrm{pH}$ 5,8). Segundo Goldberg and Glaubig (1985), os óxidos de alumínio possuem elevado poder de adsorção de $\mathrm{B}$, exibindo o pico de adsorção entre pH 6 e 8 . Sendo o solo LR bastante argiloso, constituído predominantemente por caulinita e gibsita, com pH favorável à adsorção, esta menor quantidade extraída de $\mathrm{B}$ em relação ao solo AQ era esperada.

Os índices de recuperação de B nos tratamentos que receberam a fonte BR $5+$ calcário foram tão bons quanto àqueles obtidos nos tratamentos com $\mathrm{H}_{3} \mathrm{BO}_{3}$, o que 
confirma a alta solubilidade do boro presente em algumas fritas, observada por Vale (1997). A mistura 4-14-8 pode consistir-se de uma boa fonte do elemento, visto que elevou o teor no solo para valores acima de $0,20 \mathrm{mg} \mathrm{dm}^{-3}$, nível crítico obtido por Bataglia \& Raij (1990) para girassol; o índice de recuperação ficou próximo a 35\% para os dois solos. Por outro lado, apesar da quantidade adiconada de boro aos solos através da rocha fosfatada nos tratamentos 4 (sem calcário) e 8 (com calcário) ser maior do que a dose do tratamento com $\mathrm{H}_{3} \mathrm{BO}_{3}$, não houve diferença significativa na extração de $\mathrm{B}$ entre estes tratamentos e o tratamento 1 (teste), tanto no solo LR como no AQ (Tabelas $16 \mathrm{e}$ 17). A recuperação do $B$ aplicado não chegou a $5 \%$, o que indica a baixa solubilidade da forma química presente na rocha fosfatada.

As diferenças entre os solos, principalmente o teor de argila, afetaram muito mais a relação entre as quantidades adicionadas e os teores extraídos dos elementos metálicos do que do boro. Assim, as regressões correspondentes são apresentadas para cada solo, separadamente (Tabela 18).

Os teores de $\mathrm{Fe}$ extraídos tanto pelo método Mehlich 3 como pelo DTPA-TEA foram expressivamente superiores no solo AQ (Figura 3a). A relação entre a quantidade adicionada e os teores extraídos pelo método Mehlich 3 foi significativa ao nível de $1 \%$, independente do $\mathrm{pH}$. Os teores extraídos pelo DTPA-TEA no solo AQ tiveram uma relação significativa somente com o $\mathrm{pH}$; no solo LR, a inclusão do $\mathrm{pH}$ explica $19 \%$ da variação no teor de Fe em função dos tratamentos (Tabela 18). A eficiência do DTPATEA em discriminar a influência do $\mathrm{pH}$ na extração de $\mathrm{Fe}$ foi também verificada por Camargo et al. (1982).

A relação entre os teores de Fe obtidos pelo método Mehlich 3 e DTPA-TEA foi significativa (Figura 3a). Os dois pontos afastados da linha de regressão nesta figura correspondem aos tratamentos do solo $\mathrm{AQ}$ que receberam o termofosfato e tiveram o $\mathrm{pH}$ elevado para valores superiores a 8,0. A inclusão do $\mathrm{pH}$ melhorou a relação, elevando o coeficiente de determinação para 0,86 , sendo que a elevação do $\mathrm{pH}$ provocou um aumento na quantidade extraída, concordando com os resultados obtidos por Camargo et al. (1982): em pH superior a 6,6 houve um aumento no teor de Fe extraído com a solução Mehlich 1 (solução também ácida). 
Segundo Lindsay \& Norvell (1978), teores inferiores a $2,5 \mathrm{mg} \mathrm{kg}^{-1}$ extraídos pelo DTPA-TEA podem provocar sintomas de deficiência de Fe em sorgo. Desta forma, os teores no solo LR estão bastante próximos do nível crítico no solo, apesar das quantidades razoáveis de $\mathrm{Fe}$ adicionadas.

Adams (1965) relata que o teor de manganês disponivel para as plantas é muito mais dependente do $\mathrm{pH}$ do que qualquer outro fator. Ambos extratores usados no presente estudo parecem discriminar esta influência do $\mathrm{pH}$ na disponibilidade de $\mathrm{Mn}$. Para os teores extraídos pelo DTPA-TEA, em ambos solos, o pH explica mais de $70 \%$ da variação de $\mathrm{Mn}$ em função dos tratamentos, sendo que a relação entre as quantidades adicionadas de Mn e os teores extraídos não foi significativa (Tabela 18).

A relação entre os teores de $\mathrm{Mn}$ extraídos pelos métodos foi baixa, apresentando um coeficiente de determinação de 0,31 (Figura 3b). Coeficientes de determinação bastante baixos $\left(\mathrm{R}^{2}=0,22\right.$, para solos não calcários) foram também encontrados por Vocasek \& Friedericks (1994). Como o pH afetou ambos extratores, obteve-se a seguinte equação $\mathrm{Mn}(\mathrm{M} 3)=-8,60+0,96 \mathrm{Mn}(\mathrm{DTPA})+2,14(\mathrm{pH})$, elevando o coeficiente de determinação para 0,75 . Assim, pode-se concluir que os teores extraídos pelo DTPA-TEA decresceram mais acentuadamente com a elevação do $\mathrm{pH}$ do que aqueles extraídos pelo Mehlich 3.

Mascagni \& Cox (1985) calibraram os teores de Mn extraídos pelo método Mehlich 3 em função do $\mathrm{pH}$ do solo com a produção de soja. Verificaram resposta na produção de soja em solos com mais de $3,9 \mathrm{mg} \mathrm{L}^{-1}$ e pH igual a 6,0 e com mais de 8,0 $\mathrm{mg} \mathrm{L}^{-1}$ a pH igual a 7,0. Considerando estes niveis críticos, os teores de $\mathrm{Mn}$ no presente estudo (Tabelas 14 e 15), são elevados nos tratamentos com $\mathrm{pH}$ próximo a 5,0.

A mistura 4-14-8 contém $0,5 \%$ de $\mathrm{Zn} \mathrm{e} 0,1 \%$ de $\mathrm{Cu}$ (Tabela 6). Nos estudos de avaliação de resposta das culturas à estes micronutrientes ou até mesmo no sistema produtivo, é importante analisar os fertilizantes que vão fornecer os macronutrientes quanto ao teor destes elementos. Ao aplicar uma dose de $300 \mathrm{~kg}$ por ha da fonte NPK, estar-se-á aplicando também $1,5 \mathrm{~kg}$ de $\mathrm{Zn}$ e $0,3 \mathrm{~kg}$ de $\mathrm{Cu}$. Estes valores podem, sem dúvida, afetar os resultados a serem obtidos. 
Tabela 18. Coeficientes das equações de regressão linear para boro extraído pelo método da água quente e teores dos elementos extraídos pelos métodos Mehlich $3 \mathrm{e}$ DTPA-TEA, da quantidade adicionada dos elementos e do $\mathrm{pH}$, nos experimentos com os solos AQ e LR. ${ }^{1}$

\begin{tabular}{|c|c|c|c|c|c|c|c|c|}
\hline \multirow[t]{2}{*}{ Elemento } & \multicolumn{4}{|c|}{ Solo AQ } & \multicolumn{4}{|c|}{ Solo LR } \\
\hline & $\mathrm{B}_{0}$ & $\mathrm{~B}_{1}$ & $\mathrm{~B}_{2}$ & $\mathrm{R}^{2}$ & $\mathrm{~B}_{0}$ & $B_{1}$ & $\mathrm{~B}_{2}$ & $\mathrm{R}^{2}$ \\
\hline \multirow[t]{2}{*}{ B } & $-0,7398$ & 0,1736 & 0,0985 & $0,86^{* *}$ & $-0,0523$ & 0,1183 & & $0,88^{* *}$ \\
\hline & \multicolumn{8}{|c|}{ Mehlich 3} \\
\hline $\mathrm{Fe}$ & 95,4385 & 0,2818 & $-5,8695$ & $0,87^{* *}$ & 7,5768 & 0,0598 & & $0,90 * *$ \\
\hline Mn & 14,5840 & 0,4404 & $-1,4715$ & $0,76^{* *}$ & 17,9692 & 0,3296 & $-2,3523$ & $0,57^{*}$ \\
\hline $\mathrm{Zn}$ & $-0,2395$ & 0,3143 & & $0,98^{* *}$ & $-0,0072$ & 0,1531 & & $0,96 * *$ \\
\hline \multirow[t]{2}{*}{$\mathrm{Cu}$} & $-1,0071$ & 0,2376 & 0,1526 & $0,89 * *$ & $-0,3072$ & 0,1742 & 0,2287 & $0,78 * *$ \\
\hline & \multicolumn{8}{|c|}{ DTPA-TEA } \\
\hline $\mathrm{Fe}$ & 28,4443 & 0,0181 & $-3,1008$ & $0,59^{*}$ & 10,9522 & 0,0079 & $-1,4750$ & $0,64 * *$ \\
\hline $\mathrm{Mn}$ & 21,2366 & 0,3908 & $-3,2134$ & $0,76^{* *}$ & 28,3259 & 0,2421 & $-4,6157$ & $0,75^{* *}$ \\
\hline $\mathrm{Zn}$ & $-0,4780$ & 0,2120 & & $0,96 * *$ & $-0,1453$ & 0,1032 & & $0,96 * *$ \\
\hline $\mathrm{Cu}$ & $-0,3434$ & 0,1293 & 0,0535 & $0,90 * *$ & 0,1707 & 0,0582 & 0,0457 & $0,91 * *$ \\
\hline
\end{tabular}

Modelo: $\mathrm{Y}=\mathrm{B}_{0}+\mathrm{B}_{1} \mathrm{X}_{1}+\mathrm{B}_{2} \mathrm{X}_{2}$, onde $\mathrm{Y}=$ teor do metal extraído pelo método Mehlich 3 e do boro pelo método da água quente, em mg kg-1 $; X_{1}=$ quantidade adicionada dos elementos, em $\mathrm{mg} \mathrm{vaso}^{-1}$ e $\mathrm{X}_{2}=$ pH do solo (água). Foi feita a seleção de variáveis através do coeficiente de parâmetros de Mallows, sendo apresentadas as melhores equações.

* e**: significativos ao nível de 5 e $1 \%$, respectivamente.

Como ocorreu para B, a mistura 4-14-8 elevou os teores de $\mathrm{Zn}$ e $\mathrm{Cu}$ no solo para níveis bastante superiores aos níveis críticos para milho, de 0,8 e $0,2 \mathrm{mg} \mathrm{kg}^{-1}$, citados por Lindsay \& Norvell (1978), para o extrator DTPA-TEA (Tabelas 16 e 17). Buzetti (1988), em experimento em vasos com soja, cultivar Paraná, obteve níveis críticos ainda mais baixos para $\mathrm{Zn}$ em tratamentos com $\mathrm{pH}$ igual a 6,1, usando o extrator DTPA-TEA: 0,27 e $0,37 \mathrm{mg} \mathrm{kg}^{-1}$ para $90 \%$ da produção máxima de matéria seca e de grãos, respectivamente; o nível relacionado com a produção máxima, tanto de matéria seca como de grãos, foi de $1,1 \mathrm{mg} \mathrm{kg}^{-1}$. Baseando-se nestes valores, a mistura elevou os teores de $\mathrm{Zn}$ a níveis excessivamente altos no solo. 


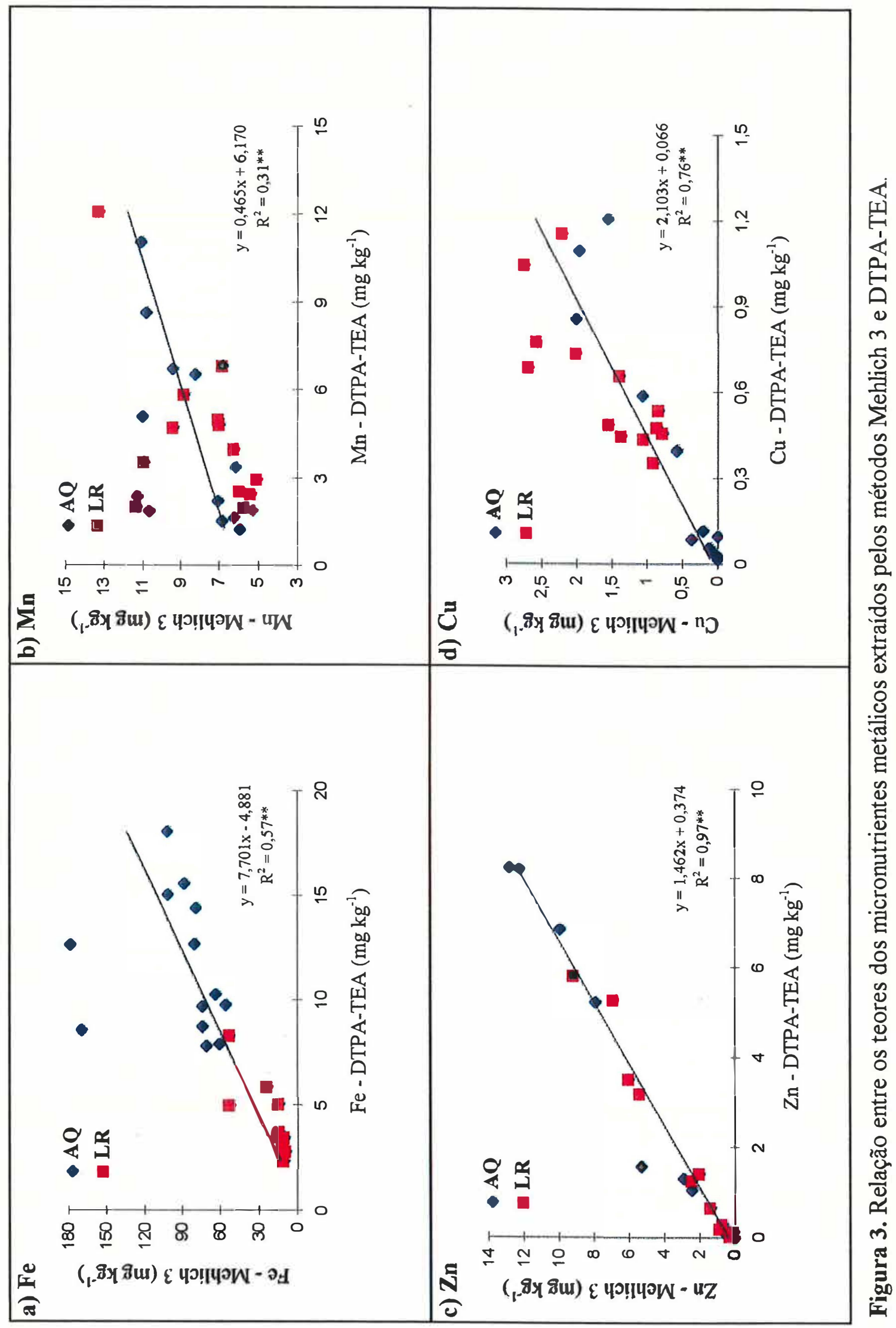


Elevados coeficientes de determinação para as quantidades adicionadas de $\mathrm{Zn}$ e $\mathrm{Cu}$ e os teores extraídos foram obtidos para os dois métodos (Tabela 18). A relação entre os teores extraídos pelos dois métodos também foi alta (Figura $3 \mathrm{c}$ e d). A inclusão do $\mathrm{pH}$ não foi significativa ao nivel de $5 \%$ nem para $\mathrm{Zn}$ nem para $\mathrm{Cu}$.

\subsection{Disponibilidade de micronutrientes e elementos potencialmente tóxicos presentes em calcário e fertilizantes minerais, avaliada através da absorção pela soja}

\subsubsection{Cádmio, crômio, chumbo e níquel}

Como ocorreu na determinação de $\mathrm{Cd}, \mathrm{Cr}$, $\mathrm{Ni}$ e $\mathrm{Pb}$ na análise dos solos, os baixos teores destes elementos na parte aérea das plantas, aliados à diluição provocada pelo método de digestão usado $(1,0000 \mathrm{~g}$ da amostra para $50 \mathrm{~mL})$, levaram a concentração nos extratos para valores muito baixos, não permitindo a sua determinação de maneira satisfatória, a que já se fềz referência por ocasião da discussão dos resultados das análises dos solos.

Os teores na matéria seca da parte aérea das plantas foram sempre inferiores a 1 $\mathrm{mg} \mathrm{kg}^{-1}$ de Cd, $4 \mathrm{mg} \mathrm{kg}^{-1}$ de $\mathrm{Pb}, 0,8 \mathrm{mg} \mathrm{kg}^{-1}$ de $\mathrm{Cr}$ e $3 \mathrm{mg} \mathrm{kg}^{-1}$ de Ni. Segundo valores citados por Kabata-Pendias \& Pendias (1984), estas concentrações são típicas de plantas cultivadas em solos não contaminados.

Desta forma, a utilização da ICP-AES para a determinação destes elementos em solos não contaminados está condicionada à pré-concentração com solvente (Amacher, 1996), sendo isto também válido para a quantificação destes elementos em tecidos vegetais. 


\subsubsection{Teores de micronutrientes na matéria seca, produção de matéria seca e de grãos}

Tanto para o solo AQ como para o LR, houve diferença significativa ao nivel de $1 \%$ entre os tratamentos para as concentrações de $\mathrm{B}, \mathrm{Fe}, \mathrm{Mn}, \mathrm{Cu}$ e $\mathrm{Zn}$ na parte aérea das plantas e para a produção de matéria seca de folhasthastestvagens e de grãos (Tabelas 19 e 20).

Tabela 19. Teores médios de micronutrientes na matéria seca e da produção de matéria seca de folhas thastes+vagens $(f+h+v)$ e de grãos, no experimento com o solo $\mathrm{AQ}$.

\begin{tabular}{|c|c|c|c|c|c|c|c|c|c|c|c|c|c|}
\hline \multirow{3}{*}{ Trat. } & \multicolumn{2}{|l|}{$\bar{B}$} & \multicolumn{2}{|l|}{$\mathrm{Fe}$} & \multicolumn{2}{|c|}{$\mathrm{Mn}$} & \multicolumn{2}{|c|}{$\mathrm{Cu}$} & \multicolumn{2}{|l|}{$\mathrm{Zn}$} & $f+h+v$ & \multicolumn{2}{|l|}{ Grãos } \\
\hline & ....... & $\cdots$ & & & $\ldots \mathrm{mg} \mathrm{k}$ & & &  & & & ............g/vaso & $\ldots \ldots \ldots . . .$. & \\
\hline & 16,2 & $\mathrm{f}$ & 567,0 & c & 367,9 & $\mathrm{e}$ & 1,7 & ef & 28,6 & h & 32,74 a & $1,82 \mathrm{~b}$ & $b c$ \\
\hline 2 & 40,8 & $\mathrm{e}$ & 429,1 & $d$ & 558,1 & c & 5,1 & $b c$ & 171,2 & $\mathrm{f}$ & 26,83 abcde & 7,31 a & $\mathrm{a}$ \\
\hline 3 & 16,5 & f & 613,1 & c & 551,1 & $c$ & 0,9 & f & 26,4 & $\mathrm{~h}$ & 25,99 bcde & $1,42 b$ & $b c$ \\
\hline 4 & 17,7 & $\mathrm{f}$ & 346,5 & def & 362,7 & e & 2,4 & def & 31,6 & $\mathrm{~b}$ & 22,03 def & $0,81 \mathrm{~b}$ & $\mathrm{bc}$ \\
\hline 5 & 18,6 & $\mathrm{f}$ & 977,6 & $\mathrm{a}$ & 350,0 & $\mathrm{e}$ & 3,1 & cde & 23,8 & $\mathrm{~h}$ & $29,24 \quad a b c$ & $2,11 \mathrm{~b}$ & $b c$ \\
\hline 6 & 123,7 & a & 398,1 & de & 761,0 & $\mathrm{~b}$ & 3,3 & cde & 212,9 & e & $19,22 \mathrm{f}$ & $0,45 \mathrm{c}$ & c \\
\hline 7 & 85,8 & c & 270,7 & $\mathrm{fg}$ & 931,5 & a & 13,5 & a & 688,0 & a & $10,10 \mathrm{~g}$ & $0,00 \mathrm{c}$ & c \\
\hline 8 & 16,8 & $\mathrm{f}$ & 886,1 & $\mathrm{~b}$ & 557,3 & $c$ & 1,7 & ef & 23,1 & $\mathrm{~h}$ & 26,47 abcde & $0,51 \mathrm{c}$ & c \\
\hline 9 & 24,4 & $\mathrm{f}$ & 547,2 & c & 235,4 & $\mathrm{f}$ & 4,2 & bod & 20,6 & $\mathrm{~h}$ & 26,86 abcde & $3,24 \mathrm{~b}$ & $b$ \\
\hline 10 & 85,5 & c & 293,3 & $\mathrm{fg}$ & 451,0 & $\mathrm{~d}$ & 2,1 & $\operatorname{def}$ & 135,6 & $\mathrm{~g}$ & $30,12 a b$ & $0,65 \mathrm{c}$ & c \\
\hline 11 & 71,2 & $\mathrm{~d}$ & 275,4 & $\mathrm{fg}$ & 470,2 & $d$ & 5,1 & $b c$ & 430,2 & $b$ & 22,73 cdef & $0,66 \mathrm{c}$ & c \\
\hline 12 & 102,7 & $\mathrm{~b}$ & 310,0 & efg & 423,1 & de & 4,1 & bod & 318,3 & $d$ & $27,95 \mathrm{abcd}$ & $1,59 \mathrm{~b}$ & $b c$ \\
\hline 13 & 115,3 & $a b$ & 234,2 & $\mathrm{~g}$ & 480,5 & $\mathrm{~cd}$ & 5,5 & $b$ & 355,1 & c & 21,12 ef & $0,32 \mathrm{c}$ & c \\
\hline CV\% & 9,1 & & 7,5 & & 6,2 & & 0 & & 5,9 & & 10,8 & 62,9 & \\
\hline DMS & 12,6 & & 88,9 & & 78,1 & & , & & 28,0 & & 6,68 & 2,54 & \\
\hline
\end{tabular}

*Médias seguidas por letras distintas diferem entre si ao nivel de significância de 0,05 pelo teste de Tukey. 
Tabela 20. Teores médios de micronutrientes na matéria seca e da produção de matéria seca de folhas +hastes+vagens $(\mathrm{f}+\mathrm{h}+\mathrm{v})$ e de grãos, no experimento com o solo LR.

\begin{tabular}{|c|c|c|c|c|c|c|c|c|c|c|c|c|c|}
\hline \multirow{2}{*}{ Trat. } & \multicolumn{2}{|l|}{ B } & \multicolumn{2}{|l|}{$\mathrm{Fe}$} & \multicolumn{2}{|c|}{$\overline{\mathrm{Mn}}$} & \multicolumn{2}{|c|}{$\mathrm{Cu}$} & \multicolumn{2}{|c|}{$\overline{\mathrm{Zn}}$} & $\mathrm{f}+\mathrm{h}+\mathrm{v}$ & \multicolumn{2}{|c|}{ Grãos } \\
\hline & $\ldots \ldots \ldots$ & & $\ldots$ & $\cdots$ & $\ldots \mathrm{mg} \mathrm{k}$ & & .... & $\ldots$ & $\ldots$. & $\ldots \ldots$. & ….......... & aso...... & $\ldots \ldots$ \\
\hline 1 & 16,5 & $\mathrm{e}$ & 770,4 & $\mathrm{~b}$ & 615,0 & de & 3,1 & $b c$ & 12,7 & $\mathrm{~h}$ & $33,26 \mathrm{ab}$ & 5,17 & $a b$ \\
\hline 2 & 32,9 & $d$ & 479,5 & cde & 535,9 & $\mathrm{e}$ & 2,6 & cde & 100,2 & $\mathrm{f}$ & $33,18 \mathrm{ab}$ & 5,09 & $a b$ \\
\hline 3 & 13,2 & ef & 1104,9 & a & 921,8 & $b$ & 2,5 & de & 17,8 & $\mathrm{~h}$ & $30,72 \mathrm{ab}$ & 4,77 & $a b c$ \\
\hline 4 & 11,1 & $\mathrm{f}$ & 543,8 & c & 623,8 & de & 2,8 & cde & 20,4 & $\mathrm{~h}$ & $33,07 \mathrm{ab}$ & 4,49 & bcd \\
\hline 5 & 17,0 & $\mathrm{e}$ & 315,8 & g & 244,3 & $\mathbf{g}$ & 2,4 & $\mathrm{e}$ & 22,5 & $\mathrm{~h}$ & 35,12 a & 4,36 & bcd \\
\hline 6 & 71,2 & $\mathbf{a}$ & 454,0 & cdef & 611,1 & de & 3,6 & $a b$ & 122,7 & $\mathrm{e}$ & $30,07 a b$ & 3,15 & cde \\
\hline 7 & 51,8 & $c$ & 309,7 & $\mathrm{~g}$ & 621,4 & de & 2,7 & cde & 238,6 & c & $30,91 \mathrm{ab}$ & 1,89 & $\mathrm{e}$ \\
\hline 8 & 15,2 & ef & 797,0 & $\mathrm{~b}$ & 751,2 & c & 2,3 & ef & 17,8 & $\mathrm{~h}$ & $31,45 a b$ & 5,18 & $a b$ \\
\hline 9 & 14,3 & ef & 361,3 & $\mathrm{fg}$ & 225,8 & $\mathrm{~g}$ & 2,7 & ef & 10,9 & $\mathrm{~h}$ & $29,07 \quad b$ & 4,09 & bcd \\
\hline 10 & 63,8 & $\mathrm{~b}$ & 430,6 & def & 406,2 & $\mathrm{f}$ & 1,7 & $\mathrm{f}$ & 74,28 & $\mathrm{~g}$ & $31,92 \mathrm{ab}$ & 6,56 & a \\
\hline 11 & 55,1 & $\mathrm{c}$ & 527,3 & $\mathrm{~cd}$ & 1077,4 & a & 2,8 & cde & 268,3 & $\mathrm{a}$ & $31,98 \mathrm{ab}$ & 3,78 & bcde \\
\hline 12 & 63,1 & $b$ & 533,4 & $\mathrm{~cd}$ & 723,3 & c & 3,1 & bcd & 184,1 & $d$ & $33,96 \mathrm{ab}$ & 5,36 & $a b$ \\
\hline 13 & 70,1 & $\mathrm{a}$ & 371,1 & efg & 705,3 & $\mathrm{~cd}$ & 3,9 & $\mathrm{a}$ & 252,0 & $b$ & $31,12 \mathrm{ab}$ & 2,78 & de \\
\hline$\overline{\mathrm{CV} \%}$ & $\overline{5,5}$ & & 8.3 & & $\overline{6,2}$ & & 9 & 4 & $\overline{5,0}$ & & 6,5 & & 7,7 \\
\hline$\overline{\mathrm{DMS}}$ & 5,2 & & 111 & & 96 & & $\overline{0}$ & 7 & 13, & & 5,22 & & 93 \\
\hline
\end{tabular}

*Médias seguidas por letras distintas diferem entre si ao nível de significância de 0,05 pelo teste de Tukey. 
No período vegetativo, as plantas do experimento conduzido no solo LR apresentavam-se bastante homogêneas, enquanto que no do solo $A Q$, as plantas mostravam-se com nítidos desequilibrios nutricionais (Figura 4). Houve um reflexo deste comportamento diferenciado na quantidade de matéria seca produzida no final do ciclo.

No solo LR, houve diferença significativa na quantidade de matéria seca produzida apenas entre os tratamentos 5 e 9 , sendo a produção de grãos estatisticamente igual. Embora os teores de $\mathrm{Zn}$ na matéria seca entre estes dois tratamentos não sejam significativamente diferentes, a concentração no tratamento 9 é baixa o suficiente para ter causado a depressão na matéria seca.(Tabela 20). $\mathrm{O}$ pH de 6,7 e 7,3 dos tratamentos pode ter originado esta diferença pois, segundo Lindsay (1979), a solubilidade de $\mathrm{Zn}$ é altamente dependente do $\mathrm{pH}$ e a cada unidade de aumento neste fator, a concentração de $\mathrm{Zn}$ decresce 100 vezes em solução. O teor extraído pelo DTPA-TEA no tratamento 9 é inferior enquanto que no tratamento 5 está acima do nível crítico obtido por Buzetti (1988).

Houve uma amplitude elevada nas concentrações de $\mathrm{Zn}$ nas plantas. É provável que não tenham sido afetadas pela falta de $\mathrm{Zn}$ nos solos, com exceção do tratamento $9 \mathrm{e}$ talvez do tratamento 1 do solo $\mathrm{LR}$, embora a produção de matéria seca e de grãos não tenha sido afetada significativamente quando comparados ao tratamento 2 (completo). A concentração de $\mathrm{Zn}$ na matéria seca destes tratamentos está muito próxima às concentrações verificadas por Bataglia \& Mascarenhas (1978) na parte vegetativa no final do ciclo do cultivar Santa Rosa cultivado em Latossolo Roxo. Com base nos teores extraídos pelo DTPA-TEA (Tabelas 16 e 17) e nos níveis críticos citados para o método na literatura (Lindsay \& Norvell, 1978; Buzetti, 1988; Abreu, 1995), esperava-se níveis deficientes na matéria seca dos tratamentos $1,3,4,5,8$ e 9 de ambos solos. 



Figura 4. Parcelas dos experimentos em Latossolo Roxo (acima) e em Areia Quartzosa (embaixo), com as plantas aos 40 dias após a semeadura. 
Peck (1979) cita como excessivos valores superiores a $75 \mathrm{mg} \mathrm{kg}^{-1}$ de $\mathrm{Zn}$ em folhas de soja. Zinco é um dos micronutrientes que são redistribuídos em maiores quantidades da parte vegetativa para a reprodutiva, sendo que suas concentrações nas folhas e hastes diminuem com o florescimento e aumentam nas vagens e sementes até a maturação (Mascarenhas, 1973; Bataglia \& Mascarenhas, 1978). Desta forma, os teores estão em níveis excessivos nos tratamentos de ambos solos que receberam a mistura 414-8 e BR 5 e também no tratamento completo que recebeu $15 \mathrm{mg}$ de $\mathrm{Zn}$ por vaso na forma de sulfato (Tabelas 19 e 20).

Os teores de Mn também foram elevados nas plantas, ultrapassando o limite para a toxidez de $250 \mathrm{mg} \mathrm{kg}^{-1}$ (Adriano, 1986), em todos os tratamentos de ambos solos, com exceção daqueles que receberam o termofosfato e que apresentaram $\mathrm{pH}$ superior a 7,0.

Não é possível separar o efeito dos elementos na redução da matéria seca produzida, limitação do presente estudo, mas os níveis excessivos de $\mathrm{Zn}$ e Mn estão bastante evidentes nos tratamentos que receberam a mistura 4-14-8 e BR 5 (Tabelas 19 e 20). O excesso de $\mathrm{Zn}$ e $\mathrm{Mn}$, provavelmente, contribuíram mais decisivamente na depressão da matéria seca produzida no solo AQ (Figura 5a e b).

A toxidez de $\mathrm{Zn}$ é caracterizada pelo atrofiamento das plantas, com ou sem clorose internerval (White et al., 1979a) e, segundo Parker et al. (1969), os sintomas de toxicidade de Mn são caracterizados, principalmente, pelo enrugamento das folhas, clorose internerval e má formação de vagens. Os sintomas apresentados pelas plantas do tratamento 7, no solo AQ (Figura 6), provavelmente, são resultantes das elevadas concentrações de $\mathrm{B}, \mathrm{Zn}$ e Mn na matéria seca da parte aérea das plantas. No solo $\mathrm{AQ}$, a reduzida floração não chegou a formar vagens e, no solo LR, a baixa produção de grãos é resultado de vagens com uma ou duas sementes muito pequenas. 
a)

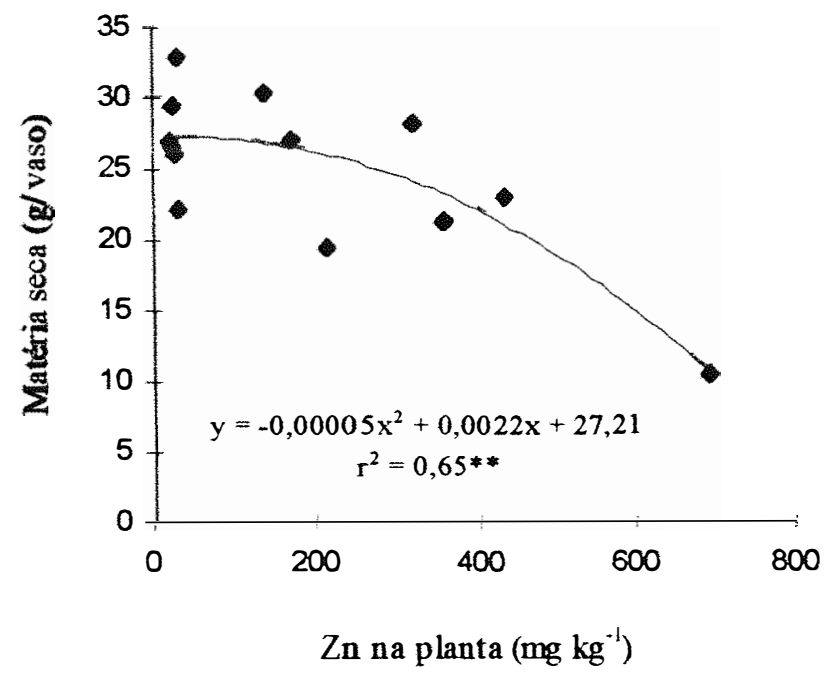

b)

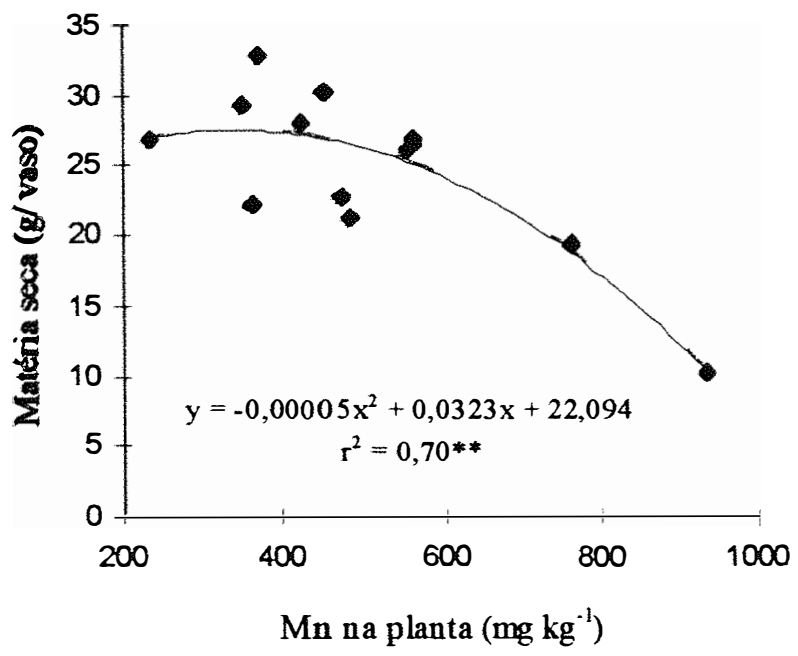

Figura 5. Matéria seca produzida em função das concentrações de a) $\mathrm{Zn}$ e b) $\mathrm{Mn}$ na parte aérea das plantas do experimento no solo $\mathrm{AQ}$. 

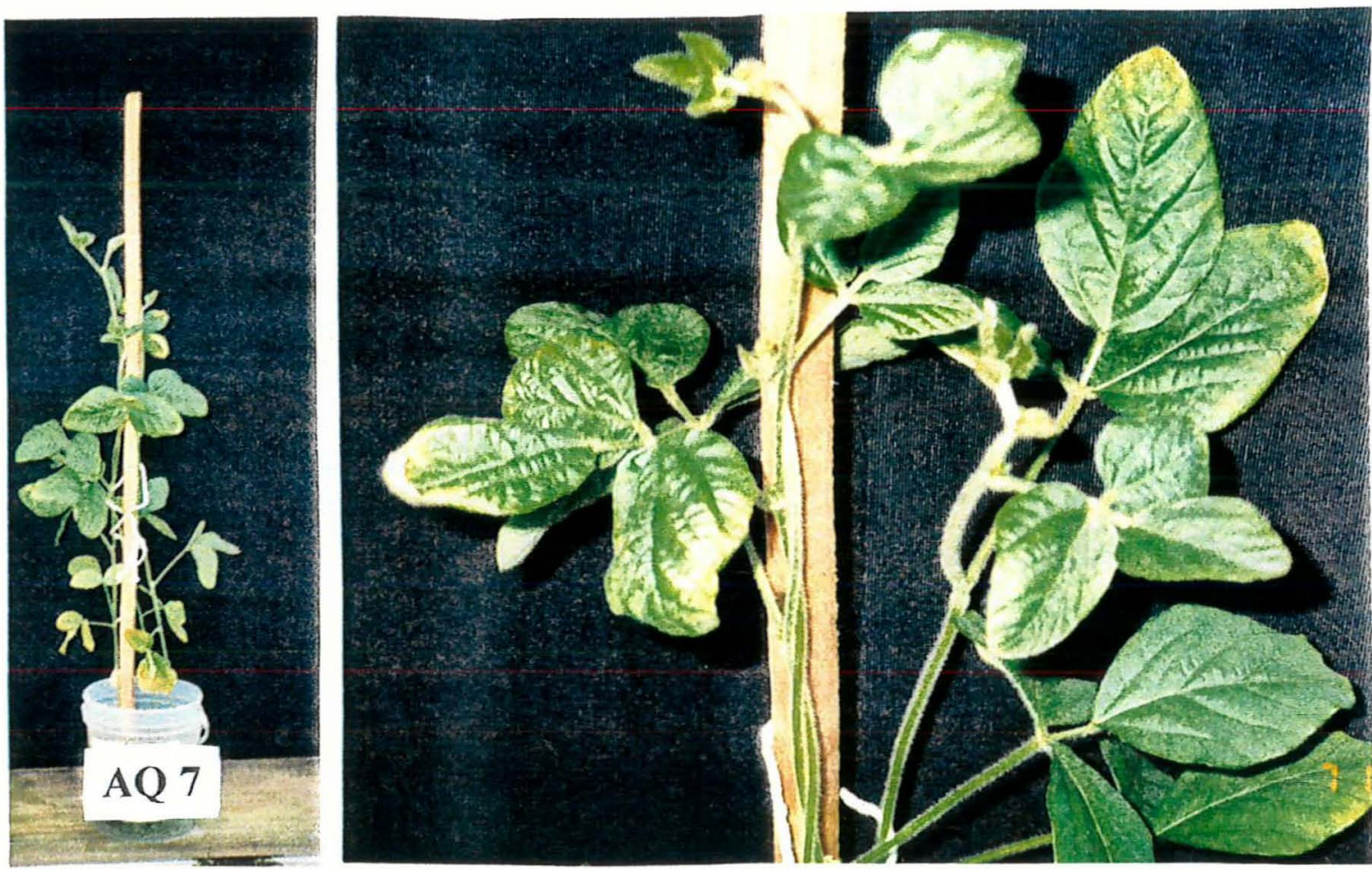

Figura 6. Parcela do tratamento que recebeu a mistura 4-14-8 do solo AQ (à esquerda), e detalhe da metade superior das plantas (à direita), mostrando toxicidade de $\mathrm{Mn}, \mathrm{Zn}$ e B.

Os teores de Fe na matéria seca foram, em geral, bastante elevados nos dois solos (Tabelas 19 e 20), muito superiores aos citados por Peck (1979), como adequados (Tabela 3). Bataglia \& Mascarenhas (1981) verificaram que folhas do cultivar Bossier com teor de $702 \mathrm{mg} \mathrm{kg}^{-1}$ mostravam sintomas de toxidez de Fe e que folhas de plantas sem os sintomas continham $290 \mathrm{mg} \mathrm{kg}^{-1}$.

Os teores superiores a $100 \mathrm{mg} \mathrm{kg}^{-1}$ de $\mathrm{Zn}$ na matéria seca do tratamento 2 de ambos solos podem ter causado a redução significativa de Fe quando comparado ao tratamento 1. Nas Tabelas 19 e 20, pode-se verificar a relação das concentrações mais elevadas de $\mathrm{Zn}$ com as mais baixas de Fe. A interferência de níveis excessivos de $\mathrm{Zn}$ na absorção, na translocação de Fe ou na sua utilização nas folhas foi referida por Chaney (1993). White et al. (1979b) verificaram que doses crescentes de $\mathrm{Zn}$ em soja provocaram um decréscimo na concentração de Fe nas folhas. 
Os sintomas observados nas plantas do tratamento 4 (Figura 7) conduzem à deficiência de $\mathrm{Zn}$ : folhas de cor amarela amarronzada clara, folhas novas pequenas, caule rígido e ereto com entrenós curtos e agrupamento de folhas formando "roseta", sintomas estes descritos por Quaggio et al. (1991). A produção de grãos também foi severamente afetada tendo uma maturação tardia. $\mathrm{O}$ teor de $\mathrm{Zn}$ na matéria seca está dentro da faixa considerada adequada em folhas, mas o fósforo encontra-se em concentrações bem mais elevadas (Tabela 21) do que aquelas observadas na parte vegetativa do cultivar Santa Rosa no final do ciclo $\left(<1 \mathrm{mg} \mathrm{kg}^{-1}\right.$ ) por Bataglia \& Mascarenhas (1978). Desta forma, é provável que o excesso de fósforo tenha afetado a utilização do $\mathrm{Zn}$ nos tecidos como foi sugerido por Mengel \& Kirkby (1987).

O manganês presente no calcário tornou-se bastante solúvel. A concentração no tecido vegetal do tratamento que recebeu apenas calcário (3) foi significativamente superior ao tratamento teste (1) nos dois solos e também superior ao tratamento 2 do solo LR que recebeu $15 \mathrm{mg}$ por vaso na forma de $\mathrm{MnCl}_{2} \cdot 4 \mathrm{H}_{2} \mathrm{O}$ contra os $8,89 \mathrm{mg}$ por vaso adicionados pelo calcário. $\mathrm{O} \mathrm{pH}$ destes três tratamentos são bastante próximos. Isso fica também evidente quando comparados os tratamentos 4 (rocha fosfatada) e 8 (rocha fosfatada + calcário). A quantidade de $\mathrm{Mn}$ adicionada através da rocha fosfatada não provocou aumento do teor nas plantas, apesar do $\mathrm{pH}$ mais baixo do tratamento $4 \mathrm{em}$ relação ao teste (Tabela 19 e 20).

O termofosfato foi o fertilizante que levou aos solos as maiores quantidades de Mn, nos tratamentos 5 e 9 (Tabela 8). No entanto, as concentrações de Mn no tecido vegetal foram as mais baixas (Tabelas 19 e 20), o que provavelmente está ligado ao elevado $\mathrm{pH}$ dos solos. 

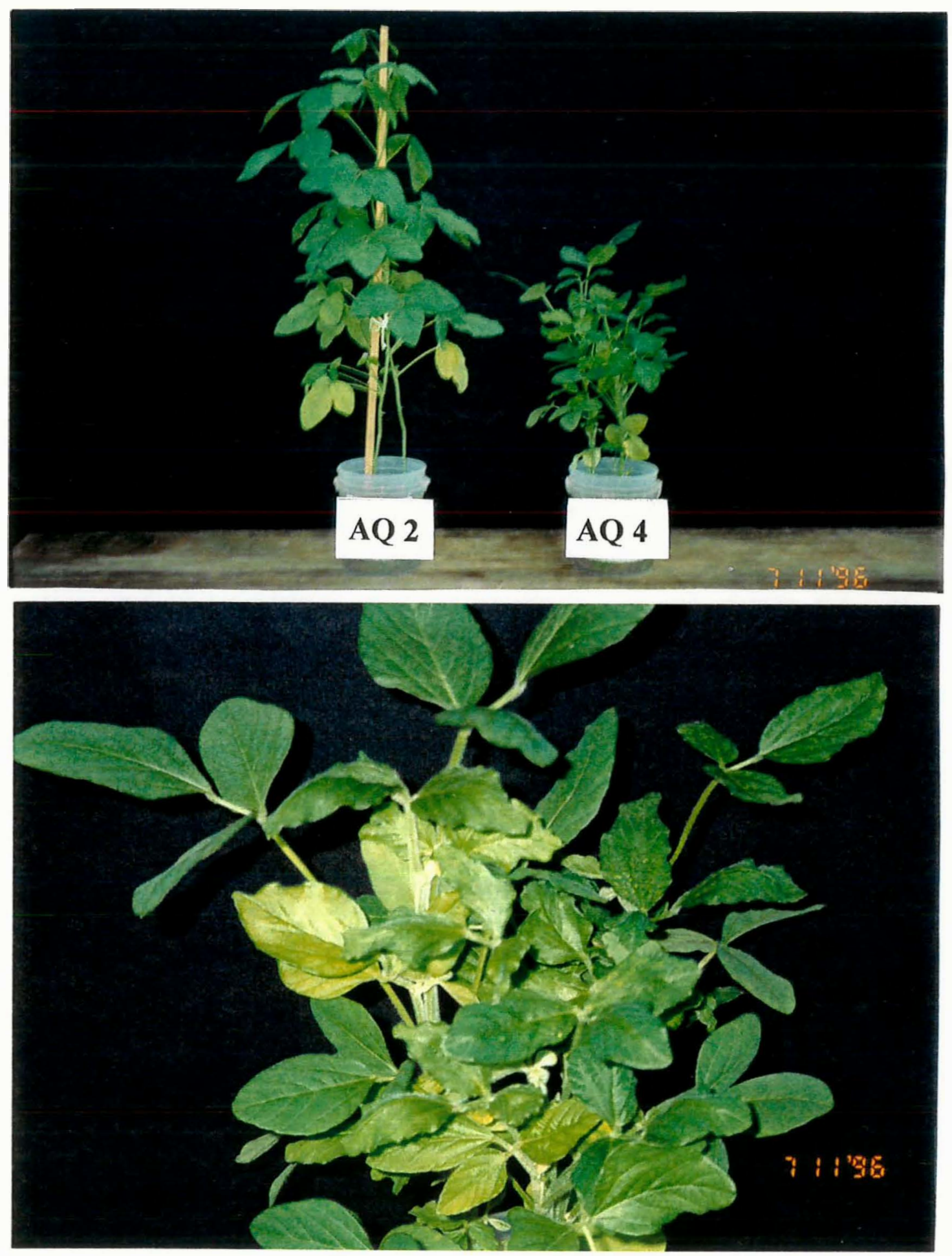

Figura 7. Parcelas dos tratamentos 2 (completo) e 4 (rocha fosfatada) (acima) e detalhe do tratamento 4 (embaixo) do experimento em Areia Quartzosa, mostrando deficiência de $\mathrm{Zn}$. 
Peck (1979) cita concentrações de $\mathrm{Cu}$ de 10 a $30 \mathrm{mg} \mathrm{kg}^{-1}$ como suficientes em folhas de soja. Os teores nas plantas dos dois solos, em geral, foram bastante inferiores a esta faixa de concentração (Tabelas 19 e 20). Considerando a redistribuição do elemento da parte vegetativa para a reprodutiva, os teores na matéria seca no final do ciclo observadas por Bataglia \& Mascarenhas (1978) de 5 a $12 \mathrm{mg} \mathrm{kg}^{-1}$, ainda são superiores que na maioria dos tratamentos.

A mistura 4-14-8 foi o único fertilizante que levou aos solos quantidades de $\mathrm{Cu}$ superiores ou próximas àquela adicionada ao tratamento 2 que recebeu $6 \mathrm{mg}$ de $\mathrm{Cu}$ por vaso na forma de sulfato. No solo $\mathrm{AQ}$, naturalmente pobre em $\mathrm{Cu}$, estas quantidades elevaram os teores nas plantas a niveis iguais ou significativamente maiores do que o tratamento 2. Já no solo LR, o tratamento 2 não foi significativamente diferente do tratamento teste, sendo que apenas os tratamentos 6 e 13 apresentaram teores nas plantas significativamente superiores ao tratamento 2 .

Os tratamentos que receberam calcário (3), termofosfato (5 e 9) e rocha fosfatada (4 e 8 ) não diferiram significativamente do tratamento teste (1), nos dois solos, quanto ao teor de B na parte aérea das plantas (Tabelas 19 e 20). Conforme previsto pelo extrator água quente, o B presente na rocha fosfatada (tratamentos 4 e 8 ) não foi absorvido pelas plantas (Figura 8). Por outro lado, a mistura 4-14-8 e a fonte BR 5 elevaram os teores do elemento a níveis superiores aos citados por Peck (1979), como excessivos em folhas de soja. Sintomas de toxidez foram observados nos tratamentos que receberam estes fertilizantes (Figura 9), sintomas estes descritos por Gupta (1993) como bronzeamento ou queima das bordas das folhas mais velhas. 


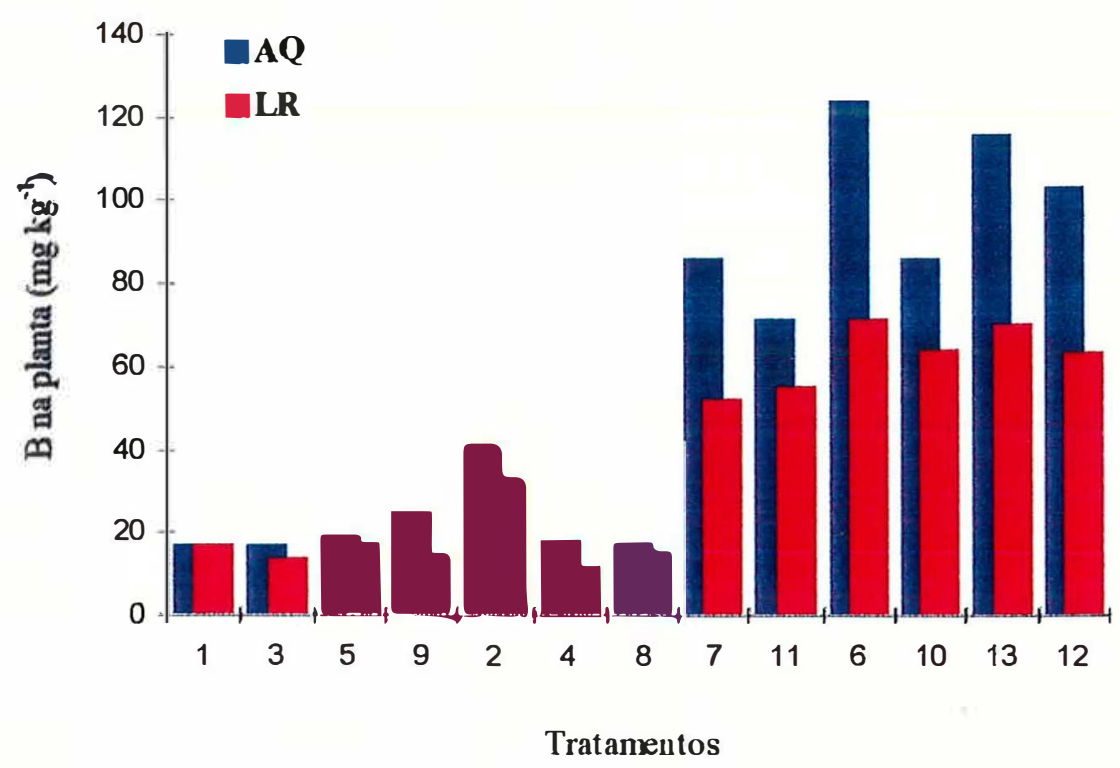

Figura 8. Concentrações de B na parte aérea das plantas em função dos tratamentos (em ordem crescente da quantidade adicionada de B) aplicados aos tratamentos dos experimentos com os solos AQ e LR. 


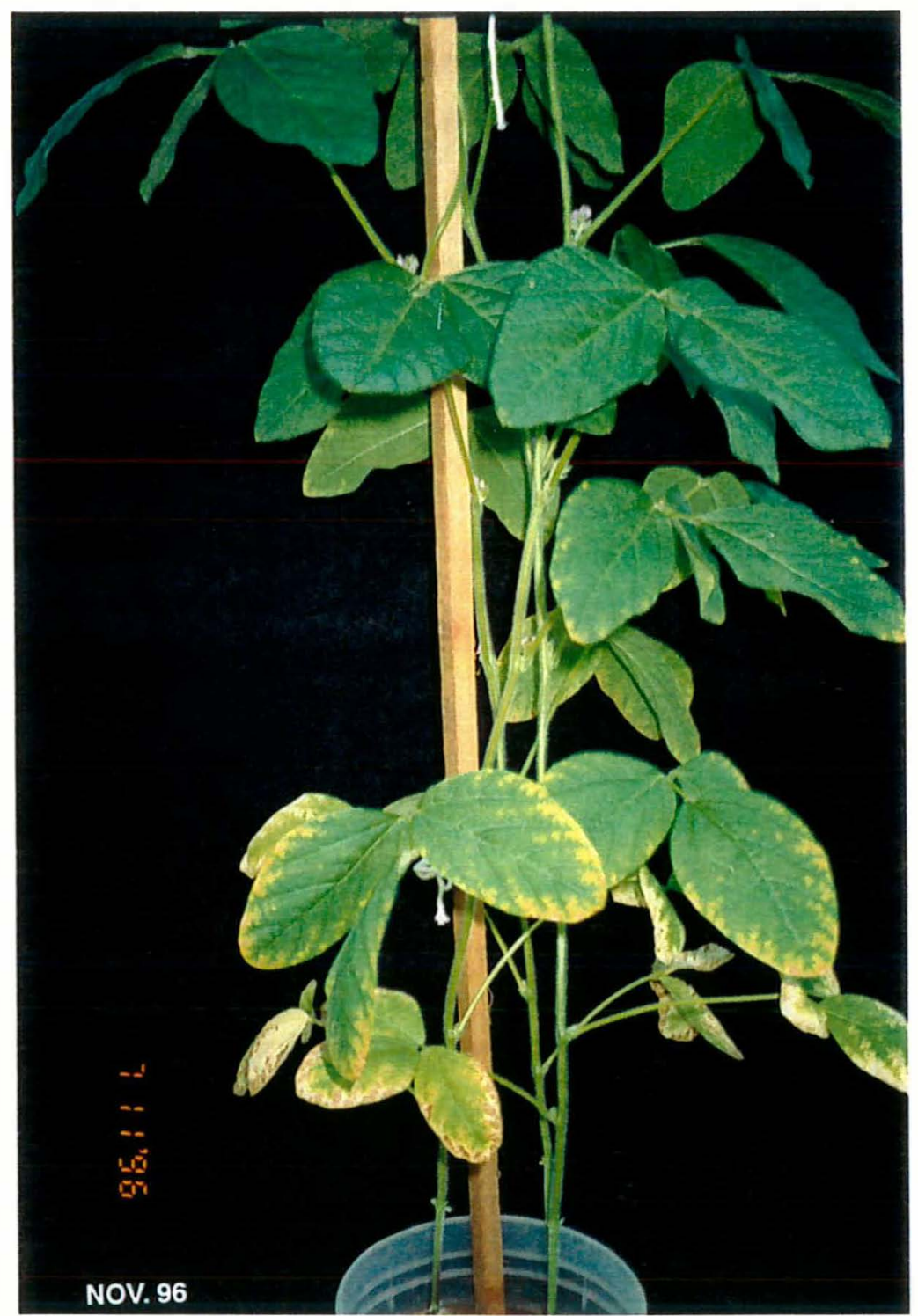

Figura 9. Detalhe do tratamento que recebeu a combinação calcário + rocha fosfatada + mistura NPK + BR 5, do experimento com Areia Quartzosa, mostrando toxicidade de boro. 


\subsubsection{Teores de macronutrientes na matéria seca}

Os tratamentos que não foram contemplados ou que não receberam quantidades suficientes dos macronutrientes presentes nos materiais em estudo (Tabela 7) foram supridos com estes nutrientes na forma de soluções/suspensões de fontes puras (Tabela 10), de maneira que todos os tratamentos recebessem doses idênticas. Os resultados da análise de solo feita antes do plantio permitiram uma noção inicial dos níveis “disponíveis" destes nutrientes nos solos (Tabela 9).

A análise da parte aérea das plantas do experimento no solo LR mostrou teores dos macronutrientes e, também de $\mathrm{Al}$, bastante semelhantes entre os tratamentos (Tabela 21). Os baixos teores de $\mathrm{N}, \mathrm{P}$ e $\mathrm{K}$ indicam, provavelmente, a translocação de elevadas quantidades destes nutrientes para os grãos, uma vez que não foram observados sintomas de carência nas plantas e que os teores estão coerentes com os apresentados na literatura (Hanway \& Weber, 1971a; Hanway \& Weber, 1971b; Bataglia \& Mascarenhas, 1978). Ao contrário, $\mathrm{Ca}, \mathrm{Mg}$ e $\mathrm{S}$ são translocados da parte vegetativa para as sementes em quantidades bastante inferiores às de N, P e K (Bataglia \& Mascarenhas 1978), sendo que se encontram dentro ou muito próximo a faixa de concentração considerada adequada em folhas na fase de florescimento.

No solo $A Q$, observou-se diferenças consideráveis nas concentrações destes nutrientes entre os tratamentos. As concentrações mais elevadas estão relacionadas com os tratamentos que produziram as menores quantidades de matéria seca ou de grãos.

Os teores de $\mathrm{P}$ na matéria seca das plantas do experimento no solo AQ foram muito mais elevados que no solo LR. O tratamento que recebeu a rocha fosfatada pode ter proporcionado níveis excessivos às plantas, sem efeitos fitotóxicos mas afetando a absorção, translocação ou a utilização de outros nutrientes nos tecidos das plantas.

$\mathrm{O}$ tratamento 7 do solo $\mathrm{AQ}$, apresentou uma concentração elevada de $\mathrm{Al}$ na parte aérea das plantas. Bataglia \& Mascarenhas (1978) verificaram que a concentração de $\mathrm{Al}$ na parte vegetativa da soja diminuiu até os 60 dias do ciclo e depois voltou a aumentar; aos 30 dias observaram teores maiores que $500 \mathrm{mg} \mathrm{kg}^{-1}$ na matéria seca. No presente 
estudo, a concentração do elemento pode ter permanecido alta até o final do ciclo devido ao reduzido crescimento das plantas depois dos 30 dias após a semeadura, ou seja, não houve o efeito da diluição do elemento tóxico na parte vegetativa das plantas.

Tabela 21. Teores de macronutrientes e de alumínio na matéria seca da parte aérea das plantas, nos tratamentos dos experimentos com os solos AQ e LR (média das quatro repetições).

\begin{tabular}{ccccccccc}
\hline \hline Solo & Trat. & $\mathrm{Al}$ & $\mathrm{N}$ & $\mathrm{Ca}$ & $\mathrm{K}$ & $\mathrm{Mg}$ & $\mathrm{P}$ & $\mathrm{S}$ \\
\hline & & $\mathrm{mg} \mathrm{kg}^{-1}$ & $\ldots \ldots \ldots \ldots \ldots \ldots \ldots \ldots \ldots \ldots . . \mathrm{gg}^{-1} \ldots \ldots \ldots \ldots \ldots \ldots \ldots \ldots \ldots \ldots$ \\
& & & & & & & & \\
& 1 & 134,8 & 8,6 & 7,6 & 13,7 & 3,1 & 3,0 & 4,9 \\
& 2 & 164,6 & 8,3 & 7,0 & 12,8 & 2,9 & 2,0 & 4,3 \\
& 3 & 91,8 & 13,7 & 5,7 & 17,9 & 3,9 & 4,4 & 6,1 \\
& 4 & 120,6 & 17,3 & 6,9 & 20,8 & 2,9 & 6,1 & 6,7 \\
& 5 & 63,3 & 11,5 & 12,0 & 13,2 & 7,4 & 3,4 & 3,1 \\
& 6 & 167,8 & 13,3 & 6,9 & 20,8 & 2,7 & 3,6 & 8,4 \\
$\mathrm{AQ}$ & 7 & 417,1 & 25,7 & 9,9 & 24,5 & 3,6 & 2,9 & 9,0 \\
& 8 & 93,5 & 19,4 & 7,6 & 18,6 & 4,0 & 4,7 & 5,9 \\
& 9 & 54,4 & 9,4 & 12,1 & 13,1 & 6,5 & 2,9 & 2,4 \\
& 10 & 130,4 & 12,2 & 5,9 & 12,5 & 2,7 & 2,7 & 5,1 \\
& 11 & 130,5 & 12,3 & 10,4 & 18,7 & 3,2 & 2,3 & 7,6 \\
& 12 & 93,3 & 8,7 & 11,5 & 13,8 & 2,9 & 3,7 & 5,6 \\
& 13 & 169,1 & 9,6 & 8,2 & 18,4 & 2,4 & 4,0 & 7,0 \\
& & & & & & & & \\
& 1 & 53,3 & 5,8 & 10,5 & 10,2 & 2,5 & 0,4 & 1,9 \\
& 2 & 40,6 & 5,8 & 9,3 & 10,8 & 2,3 & 0,4 & 2,4 \\
& 3 & 54,9 & 6,4 & 9,9 & 11,6 & 4,4 & 0,5 & 1,9 \\
& 4 & 53,8 & 6,1 & 10,0 & 11,0 & 1,8 & 0,6 & 2,0 \\
& 5 & 60,4 & 6,2 & 8,4 & 10,5 & 4,7 & 0,5 & 2,2 \\
& 6 & 79,1 & 5,9 & 6,0 & 13,6 & 2,0 & 0,6 & 2,5 \\
LR & 7 & 78,4 & 7,1 & 7,2 & 15,9 & 1,7 & 0,7 & 4,5 \\
& 8 & 28,1 & 5,9 & 12,8 & 11,2 & 4,6 & 0,8 & 1.9 \\
& 9 & 35,3 & 6,1 & 9,7 & 11,6 & 4,5 & 0,5 & 1,8 \\
& 10 & 44,9 & 5,8 & 11,8 & 10,2 & 3,6 & 0,4 & 2,3 \\
& 11 & 50,0 & 6,5 & 13,0 & 13,0 & 4,3 & 0,6 & 3,2 \\
& 12 & 41,9 & 5,8 & 13,3 & 10,9 & 3.8 & 0,5 & 3,4 \\
& 13 & 70,4 & 6,1 & 7,8 & 13,1 & 1,8 & 1,1 & 2,9 \\
\hline \hline
\end{tabular}




\subsubsection{Teores de micronutrientes na matéria seca em função da quantidade adicionada e dos teores extraídos pelo DTPA-TEA e} Mehlich 3

As concentrações de $\mathrm{Fe}$ nas plantas tiveram uma relação muito baixa com as quantidades adicionadas (Tabela 22) e também com os teores extraídos dos solos pelos métodos (Figura 10a e b). Bataglia e Raij (1989) também encontraram correlações não significativas entre a quantidade absorvida de Fe pelo girassol e sorgo para diversos extratores, inclusive o DTPA-TEA. A inclusão do $\mathrm{pH}$ nas equações de regressão para as concentrações nas plantas e os teores extraídos pelos métodos não foi significativa para o solo $\mathrm{LR}$, mas no $\mathrm{AQ}$, o pH explica $17,6 \%$ da variação na concentração de $\mathrm{Fe}$ nas plantas em função dos teores extraídos pelo DTPA-TEA $\left(R^{2}=0,64^{* *}\right)$. No solo $A Q$, as concentrações nas plantas tiveram correlação significativa com o pH do solo (Figura 10c), mas com os teores extraídos pelo Mehlich 3 esta relação não foi significativa.

Tabela 22. Coeficientes das equações de regressão para as quantidades de micronutrientes adicionadas $\mathrm{e}$ das concentrações na matéria seca (folhasthastes+vagens), dos experimentos com os solos AQ e LR. ${ }^{1}$

\section{Coeficientes}

Elemento

Solo AQ

Solo LR

$\begin{array}{ccccccc} & \mathrm{B}_{0} & \mathrm{~B}_{1} & \mathrm{R}^{2} & \mathrm{~B}_{0} & \mathrm{~B}_{1} & \mathrm{R}^{2} \\ \mathrm{~B} & 17,723 & 11,223 & 0,77^{* *} & 15,632 & 4,919 & 0,76^{* *} \\ \mathrm{Fe} & 375,811 & 0,832 & 0,26^{* *} & 594,290 & -0,290 & 0,10^{* *} \\ \mathrm{Mn} & 582,779 & -12,745 & 0,20^{* *} & 749,671 & -12,871 & 0,22^{* *} \\ \mathrm{Cu} & 1,977 & 0,715 & 0,61^{* *} & 2,622 & 0,034 & 0,06 * * \\ \mathrm{Zn} & 8,062 & 12,765 & 0,90^{* *} & 14,545 & 4,965 & 0,95 * *\end{array}$

Modelo, $Y=B_{0}+B_{1} X$, onde: $Y=$ concentração dos micronutrientes na matéria seca (folhas+hastes+vagens), em mg kg $; \mathrm{X}_{1}=$ quantidade adicionada dos micronutrientes, em $\mathrm{mg} / \mathrm{vaso}$.

** Significativo ao nível de $1 \%$. 
Tanto o Mehlich 3 como o DTPA-TEA apresentaram boas relações com as concentrações de Zn nas plantas (Figura 11). Bataglia e Raij (1989) também verificaram que o DTPA-TEA consegue discriminar a variação na disponibilidade de $\mathrm{Zn}$ em solos de diferentes texturas e mineralogia, com e sem calagem.

Os coeficientes de determinação obtidos para os teores de $\mathrm{Mn}$ extraídos pelos métodos e as concentrações nas plantas foram muito baixos, sendo significativos apenas no solo LR (Figura 12). A inclusão do pH na equação de regressão não foi significativa para nenhum dos extratores. Boas correlações entre teores no solo e na planta são raramente observadas devido a complexidade do comportamento do manganês no solo, sujeito a variações no teor disponível por influências ocasionais de aeração e por condições de oxirredução (Raij e Bataglia, 1988). A eficiência do método Mehlich 3 na avaliação da disponibilidade de Mn ainda foi pouco estudada e os resultados existentes não reunem informações consistentes (Sims, 1985; Mascagni e Cox, 1985; Haddad e Evans, 1993; Vocaseck e Friedericks, 1994).

As boas relações obtidas entre as quantidades adicionadas de $\mathrm{Cu}$ e os teores extraídos pelos métodos, tanto para o solo AQ como para o LR (Tabela 18) não se repetiram entre os teores extraídos pelos métodos e as concentrações nas plantas. Provavelmente, os extratores removeram formas de $\mathrm{Cu}$ não acessíveis para as plantas no solo LR. No solo AQ, as relações foram melhores, mas houve a aglomeração dos pontos em concentrações mais baixas e poucos pontos em concentrações mais elevadas (Figura 13).

$\mathrm{O}$ coeficiente de determinação linear $\left(\mathrm{R}^{2}\right)$ entre a quantidade de $\mathrm{B}$ adicionado e a concentração do elemento na matéria seca (Tabela 22) passa de 0,77 para 0,86 no solo AQ e de 0,76 para 0,87 no solo LR, quando excluídos os tratamentos que receberam a rocha fosfatada. Os teores de $\mathrm{B}$ extraídos pela água quente foram maiores no solo $\mathrm{AQ}$ (Figura 14), mas mesmo considerando os dois solos, a relação com as concentrações na parte aérea das plantas foi alta $\left(r^{2}=0,83\right)$. 




Figura 10. Relação entre as concentrações de Fe na parte aérea das plantas e os teores extraídos dos solos, usando: a) DTPA-TEA; b) Mehlich 3 e c) relação entre as concentrações de $\mathrm{Fe}$ nas plantas e os valores de $\mathrm{pH}$ do solo $\mathrm{AQ}$. 




Figura 11. Relação entre as concentrações de $\mathrm{Zn}$ na parte aérea das plantas e os teores extraídos dos solos, usando: a) DTPA-TEA e b) Mehlich 3. 




Figura 12. Relação entre as concentrações de Mn na parte aérea das plantas e os teores extraídos dos solos, usando: a) DTPA-TEA e b) Mehlich 3. 


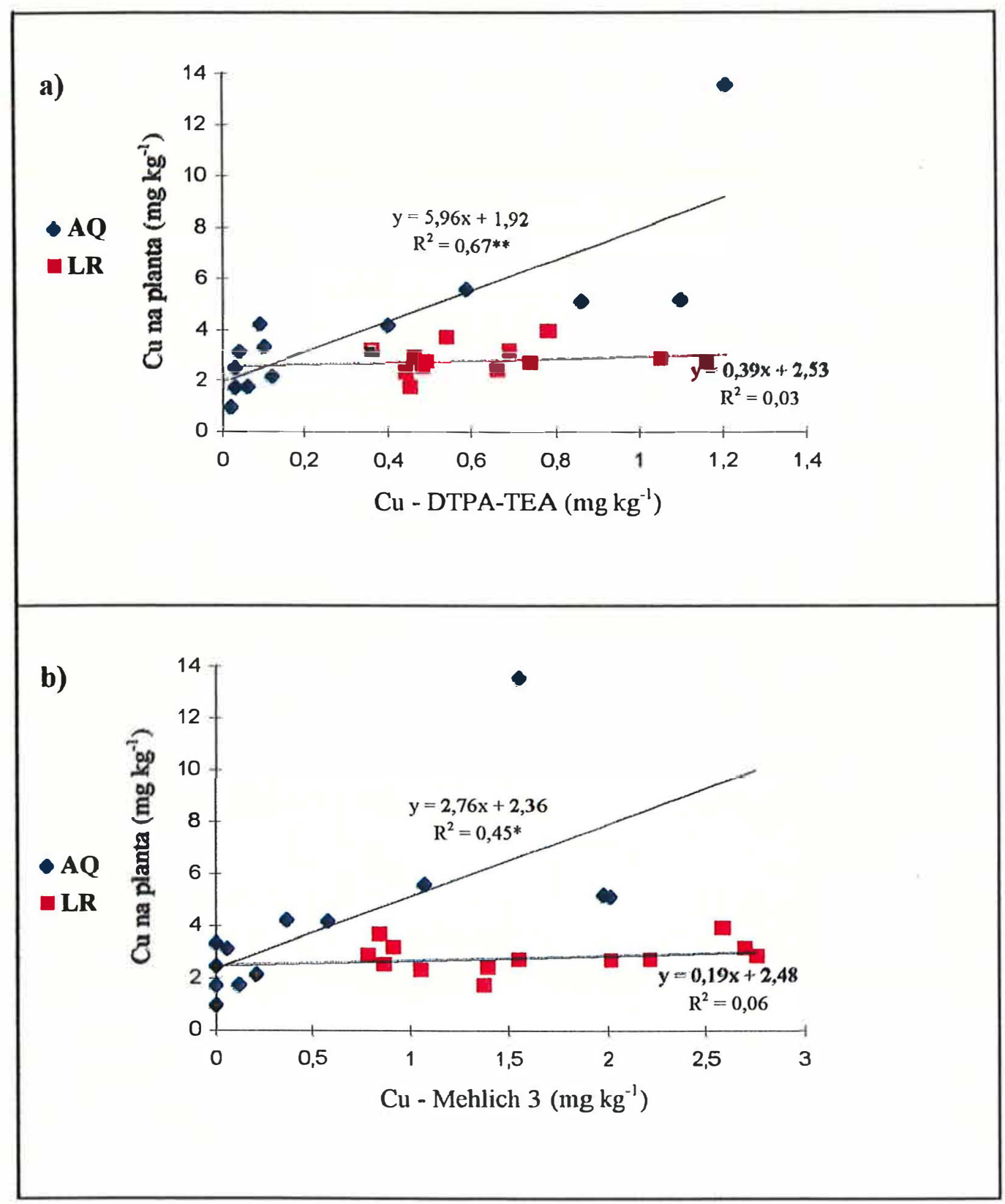

Figura 13. Relação entre as concentrações de $\mathrm{Cu}$ na parte aérea das plantas e os teores extraídos dos solos, usando: a) DTPA-TEA e b) Mehlich 3. 


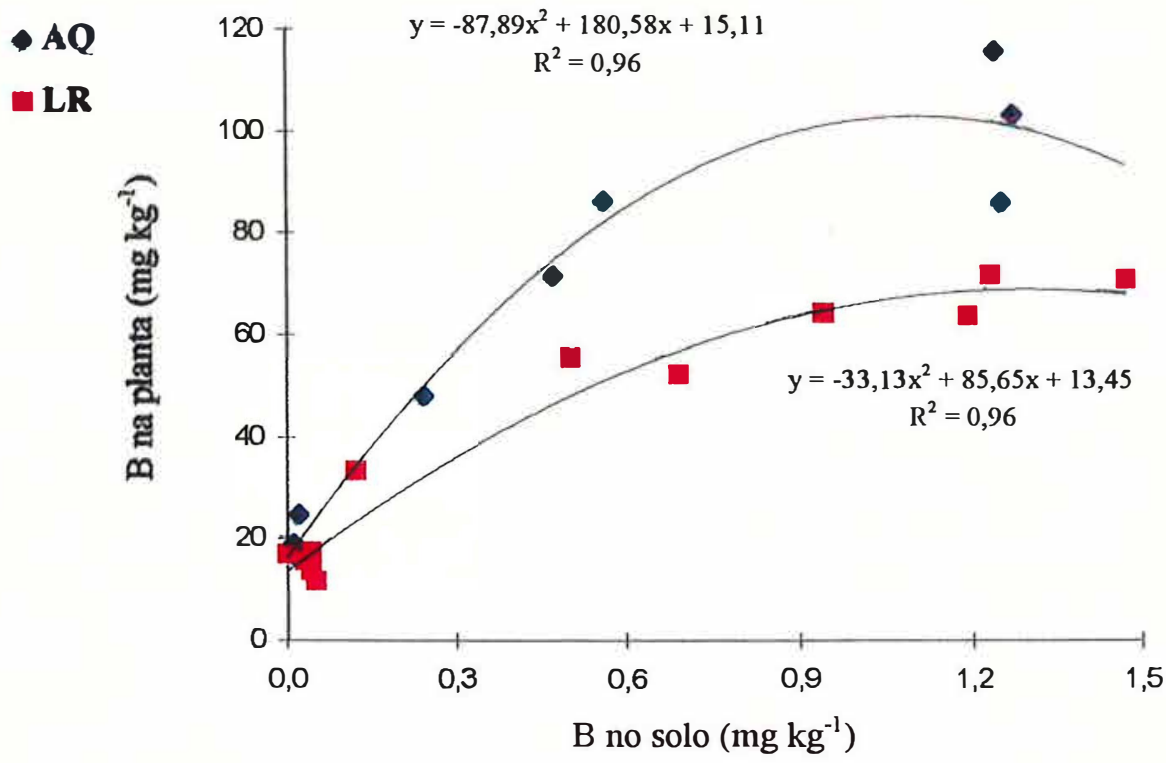

Figura 14. Relação entre as concentrações de $B$ nas plantas e os teores nos solos extraídos pelo método da água quente. 


\section{CONCLUSÕES}

Considerando as condições em que foi desenvolvido o presente estudo, algumas conclusões podem ser destacadas.

\section{Quanto aos teores nos fertilizantes e calcários}

- As determinações de $\mathrm{Cu}$ através de ICP-AES tiveram interferência espectral de $\mathrm{Ca}$. Os materiais com concentrações de 1,0 a $4,0 \mathrm{mg} \mathrm{mL}^{-1}$ de Ca nos extratos proporcionaram cerca de $25 \mathrm{mg} \mathrm{kg}^{-1}$ de $\mathrm{Cu}$ mais elevados quando determinados através de ICP-AES do que através de AAS.

- Micronutrientes não declarados na composição dos fertilizantes, estiveram presentes em quantidades significantes: Fe e Mn na maioria das amostras estudadas; B em algumas rochas e fertilizantes fosfatados e Fe, $\mathrm{Zn}, \mathrm{Mn}$ e Ni nos termofosfatos.

- Altas concentrações de $\mathrm{Cr}$ foram detectadas nas amostras de termofosfatos.

- A maioria das amostras dos materiais estudados apresentou baixas concentrações de $\mathrm{Cd}$, $\mathrm{Co}$, $\mathrm{Ni}$ e $\mathrm{Pb}$.

\section{Quanto à disponibilidade dos elementos}

- A mistura 4-14-8 mostrou ser uma eficiente fonte de B, $\mathrm{Zn}, \mathrm{Mn}$ e $\mathrm{Cu}$.

- $\mathrm{B}, \mathrm{Fe}$ e Mn presentes na rocha fosfatada não se mostraram acessíveis para as plantas.

- O calcário elevou as concentrações de Fe e Mn nas plantas. 
- Zn e Mn presentes no termofosfato não aumentaram os teores na parte aérea das plantas.

- A fonte de B e Zn, BR 5, apresentou alta disponibilidade destes elementos para as plantas.

- A correlação entre os teores extraídos pelo método Mehlich 3 e DTPA-TEA foi significativa para $\mathrm{Zn}, \mathrm{Cu}, \mathrm{Fe}$ e $\mathrm{Mn}$.

- Boa correlação entre as quantidades extraídas pelos métodos Mehlich 3 e DTPA-TEA e as concentrações na parte aérea das plantas foi obtida apenas para $\mathrm{Zn}$.

- Tanto as quantidades adicionadas de B como as extraídas pelo método da água quente estiveram bem correlacionadas com as concentrações nas plantas.

- $\mathrm{O} \mathrm{pH}$ e a textura mostraram ser importantes atributos dos solos controlando a disponibilidade dos elementos estudados.

- Os micronutrientes, de forma geral, foram mais disponíveis para as plantas no solo AQ do que no solo LR.

- As elevadas quantidades de Mn, $\mathrm{Zn}$ e B adicionadas ao solo AQ pela mistura 4-14-8 proporcionaram um nivel tóxico destes elementos na parte aérea das plantas e a mais baixa produção de matéria seca e grãos entre os tratamentos.

- Os materiais estudados não elevaram os teores de elementos potencialmente tóxicos nos solos e nas plantas a um nível que pudesse ser determinado satisfatoriamente através de ICP-AES, ou seja, estiveram sempre abaixo de $1 \mathrm{mg} \mathrm{kg}^{-1}$ de Cd, $4 \mathrm{mg} \mathrm{kg}^{-1}$ de $\mathrm{Pb}, 0,8 \mathrm{mg} \mathrm{kg}^{-1}$ de $\mathrm{Cr}$ e $3 \mathrm{mg} \mathrm{kg}^{-1}$ de $\mathrm{Ni}$ na matéria seca da parte aérea das plantas e de $0,1 \mathrm{mg} \mathrm{kg}^{-1}$ de $\mathrm{Cd}, 0,5 \mathrm{mg} \mathrm{kg}^{-1}$ de $\mathrm{Pb}, 0,2 \mathrm{mg} \mathrm{kg}^{-1}$ de $\mathrm{Cr}$ e $0,3 \mathrm{mg} \mathrm{kg}^{-1}$ de Ni nos solos. 


\section{REFERÊNCIAS BIBLIOGRÁFICAS}

ABREU, C. A.; ABREU, M. F.; RAIJ, B. van; BATAGLIA, O. C. Extraction of boron from soil by microwave heating for ICP-AES determination. Communications in Soil Science and Plant Analysis, v.25, p.3321-3333, 1994.

ABREU, C. A.; ABREU, M. F.; RAIJ, B. van; SANTOS, W. R. Comparação de métodos de análise para avaliar a disponibilidade de metais pesados em solos. Revista Brasileira de Ciência do Solo, v. 19, p.463-468, 1995.

ABREU, C. A. Análise de solo para micronutrientes - Tema de reuniões de laboratórios. Boletim informativo da Sociedade Brasileira de Ciência do Solo, v.20, p.128130, 1995.

ADAMS, F. Manganese. In: BLACK, C. A. (Ed.) Methods of soil analysis, part 2. Madison: American Society of Agronomy, 1965. p.1011-1018.

ADRIANO, D. C. Trace elements in the terrestial environment. New York: SpringerVerlag, 1986. 533p.

ALCARDE, J. C.; RODELLA, A. A. Caracterização de fertilizantes simples contendo zinco. Scientia Agricola, v.50, p.121-126, 1993.

ALLOWAY, B. J. The origins of heavy metals in soils. In: ALLOWAY, B. J. (Ed.) Heavy metals in soils. New York: John Wiley, 1990. p.29-39.

AMACHER, M. C. Nickel, cadmium, and lead. In: SPARKS, D. L. (Ed.) Methods of soil analysis: Part 3 Chemical Methods. Wisconsin: Soil Science Society of America, American Society of Agronomy, 1996. cap. 28, p. 91-140.

AMARAL SOBRINHO, N. M. B.; COSTA, L. M.; OLIVEIRA, C.; VELlOSO, A. C. $\mathrm{X}$. Metais pesados em alguns fertilizantes e corretivos. Revista Brasileira de Ciência do Solo, v.16, p.271-276, 1992.

AMARAl, A. S. Liberação de $\mathrm{Zn}, \mathrm{Fe}, \mathrm{Mn}, \mathrm{Cd}$ e $\mathrm{Pb}$ de quatro corretivos da acidez do solo e absorção por plantas de alface, em dois solos de diferentes texturas. Viçosa, 1993. 87p. Dissertação (M. S.) - Universidade Federal de Viçosa.

ARORA, C. L.; NAYYAR, V. K.; RANDHAWA, N. S. Note on secundary and microelement contents of fertilizers and manures. Indian Journal of Agricultural Science, v.45, p.80-85, 1975. 
BATAGLIA, O. C.; FURLANI, A. M. C.; TEIXEIRA, J. P. F.; FURLANI, P. R.; GALLO, J. R. Métodos de análise química de plantas. Campinas: Instituto Agronômico, 1983. 48p. (Boletim Técnico, 78).

BATAGLIA, O. C.; MASCARENHAS, H. A. A. Absorção de nutrientes pela soja. Campinas: Instituto Agronômico, 1977. 36 p. (Boletim Técnico, 41).

BATAGLiA, O. C.; MASCARENHAS, H. A. Toxicidade de Fe em soja. Bragantia, v.40, p.199-203, 1981.

BATAGLIA, O. C.; RAIJ, B. van Eficiência de extratores de micronutrientes na análise de solo. Revista Brasileira de Ciência do Solo, v.13, p.205-212, 1989.

BATAGLIA, O. C.; RAIJ, B. van Eficiência de extratores na determinação de boro em solos. Revista Brasileira de Ciência do Solo, v.14, p.25-31, 1990.

BATAGLIA, O. C.; RAIJ, B. van. Soluções extratoras na avaliação da fitodisponibilidade do zinco em solos. Revista Brasileira Ciência do Solo, v. 18, p.457-461, 1994.

BERGMANN, W. Nutrition disorders of plants-development, visual and analytical diagnosis. Stuttgart: Gustav Fischer Verlag Jena, 1992. 741 p.

BINGHAM, F. T.; MITCHELL, G. A.; PAGE, A. L. Cadmium availability rice in sludge amended soils under "flood" and "nonflood" culture. Journal of Environmental Quality, v.50, p.715-718, 1976.

BRASIL. Ministério da agricultura. Laboratório Nacional de Referência Vegetal. Análise de corretivos, fertilizantes e inoculantes. Brasília: LANARV, 1988. 104p.

BRENNAN, R. F.; ARMOUR, J. D.; REUTER, D. J. Diagnosis of Zinc deficiency. In: ROBSON, A. D. (Ed.) Zinc in soil and plants. Dordrecht, Boston, London: Kluwer Academic Publishers, 1993. cap.12, p. 167-181.

BUZETTI, S. Efeitos de doses de boro e de zinco, em diferentes condições de acidez de um solo de cerrado, na cultura da soja (Glicine max (L.) Merril). Piracicaba, 1988. 112p. Tese (Doutorado) - Escola Superior de Agricultura "Luiz de Queiroz", Universidade de São Paulo.

CAMARGO, O. A.; VALADARES, J. M. A. S.; DECHEN, A. R. Efeitos do pH e da incubação na extração do manganês, zinco, cobre e ferro do solo. Revista Brasileira de Ciência do Solo, v.6, p.83-88, 1982.

CHANEY, R. L. Zinc Phytotoxicity. In: ROBSON, A. D. (Ed.) Zn in soils and plants. Dordrecht, Boston, London: Kluwer Academic Publishers, 1993. p.135-150. 
CHARTER, R. A.; TABATABAI, M. A.; SCHAFER, J. W. Metals contents of fertilizers marketed in Iowa. Communications in Soil Science and Plant Analysis, v.24, p.961-972, 1993.

CHICHILO, P; WHITTAKER, W. Trace elements in agricultural limestones of Atlantic Coast Regions. Agronomy Journal, v.50, p.131-135, 1958.

CHICHILO, P.; WHITTAKER, W. Trace elements in agricultural limestones of the United States. Agronomy Journal, v.53, p.139-144, 1961.

COX, F. R.; KAMPRATH, E. J. Micronutrients soil tests. In: MORTVEDT, J. J.; GIORDANO, P. M.; LINDSAY, W. L. (Ed.) Micronutrients in agriculture. Madison: Soil Science Society of America, 1972. p.289-317.

DANG, Y. P.; CHHABRA, R.; VERMA, K. S. Effect $\mathrm{Cd}, \mathrm{Ni}, \mathrm{Pb}$ and $\mathrm{Zn}$ on growth and chemical composition of onions and fenugreek. Communications in Soil Science and Plant Analysis, v.21, p.717-735, 1990.

deMOOY, C. J.; PESEK, J.; SPALDON, E. Mineral nutrition. In: CADWELL, B. E. (Ed.) Soybeans: Improvement, production, and uses. Madison: American Society of Agronomy, 1973. cap.9, p.267-352.

EMPRESA BRASILEIRA DE PESQUISA AGROPECUÁRIA - Serviço Nacional de Levantamento e Conservação de Solos/EMBRAPA-SNLCS. Manual de métodos de análise de solo. Rio de Janeiro, 1979.

ESKEW, D. L.; WELCH, R. M.; CARY, E. E. Nickel: an essential micronutrient for legumes and possibly all higher plants. Science, v.222, p.621-623, 1983.

FULLER, W. H.; KORTE, N. E.; NIEBLA, E. E.; ALESII, B. A. Contribuition of soil to the migration of certain common and trace elements. Soil Science, v.122, p.223-235, 1976.

GOLDBERG, S. Chemistry and Mineralogy of boron in soils. In: Gupta, U. C. (Ed.). Boron and its role in crop production. Boca Raton: CRC Press, 1993. p.3-44.

GOLDBERG, S.; GLAUBIG, R. A. Boron adsorption on aluminum and iron oxide minerals. Soil Science Society of America Journal, v.49, p.1374-1379, 1985.

GUARDANI, R. Termofosfato magnesiano fundido: novos desenvolvimentos na tecnologia de produção. Fertilizantes, v.9, p.9-13, 1987.

GUPTA, U. C. Deficiency and toxicity symptoms of boron in plants. In: GUPTA, U. C. (Ed.) Boron and its role in crop production. Boca Raton: CRC Press, 1993. p.147-155. 
HADDAD, K. S.; EVANS, J. C. Assessment of chemical methods for extracting zinc, manganese, copper and iron from New South Wales soils. Communications in Soil Science and Plant Analysis,v.24, p.29-44, 1993.

HANNAM, R. J.; OHKI, K. Detection of manganese deficiency and toxicity in plants. In: GRAHAM, R. D.; HANNAM, R. J.; UREN, N. C.(Ed.) Manganese in soil and plants. Dordrecht, Boston, London: Kluwer Academic Publishers, 1988. p.243-259.

HANWAY, J. J.; WEBER, C. R. Accumulation of N, P, and K by soybean (Glycine max (L.) Merril) plants. Agronomy Journal, v.63, p.406-408, 1971.

HANWAY, J. J.; WEBER, C. R. N, P, and K percentages in soybean (Glycine max (L.) Merril) plant parts. Agronomy Journal, v. 63, p.286-290, 1971.

HAQ, A. U.; BATES, T. E.; SOON, Y. K. Comparison of extractants for plant available Zinc, cadmium, nickel, and copper in contaminated soils. Soil Science Society of America Journal, v.44, p.772-777, 1980.

HAQ, A. U.; MILLER, M. H. Prediction of available soil $\mathrm{Zn}, \mathrm{Cu}$, and $\mathrm{Mn}$ using chemical extractants. Agronomy Journal, v.64, p.779-782, 1972.

KABATA-PENDIAS, A.; PENDIAS, H. Trace elements in soil and plants. Boca Raton: CRC Press, 1984. 315p.

KANE, P. F. Fertilizers. In: CUNNIFF, P. (Ed.) Official Methods of analysis of AOAC International. 16. ed. Arlington: Association of Official Analytical Chemists International, 1995. cap.2.

KPOMBLEKOU-A, K.; TABATABAI, M. A. Metals contents of phosphate rocks. Communications in Soil Science and Plant Analysis, v.25, p.2871-2882, 1994.

LANGENBACH, T.; SARPA, M. Teor de cádmio nos fertilizantes fosfatados brasileiros. Revista Brasileira de Ciência do Solo, v.9, p.179-181, 1985.

LANTMANN, A. F. \& MEURER, E. J. Estudo da eficiência de extratores para avaliação do zinco disponível do solo para o milho. Revista Brasileira de Ciência do Solo, v.6, p.131-135, 1982.

LINDSAY, W. L. Chemical equilibria in soils. New York: John Wiley \& Sons, 1979. 449 p.

LINDSAY, W. L.; COX, F. R. Micronutrients soil testing for the tropics. Fertilizer Research, v.7, p.169-200, 1985. 
LINDSAY, W. L.; NORVELL, W. Development of DTPA soil for zinc, iron, manganese and copper. Soil Science Society of America Journal, v.42, p.421-428, 1978.

LOGAN, T. J.; CHANEY, R. L. Metals. In: WORKSHOP ON UTILIZATION OF MUNICIPAL WASTEWATER AND SLUDGE ON LAND, Riverside, 1983. Proceedings. Riverside: University of California, 1983. p.235-323.

LOPES, A. S.; GUILHERME, L. R. G. Preservação ambiental e produção de alimentos. São Paulo: ANDA, 1991. 16p.

MALAVOLTA, E. Fertilizantes e seu impacto ambiental: micronutrientes e metais pesados - mitos, mistificação e fatos. São Paulo: Produquímica, 1994. 153p.

MALAVOLTA, E. Elementos de nutrição mineral de plantas. São Paulo: Editora Agronômica Ceres Ltda., 1980. 251p.

MALAVOLTA, E.; VITTI, G. C.; OLIVEIRA, S. A. Avaliação do estado nutricional das plantas: princípios e aplicações. Piracicaba: POTAFOS, 1989. 201p.

MARSCHNER, H. Mineral nutrition of higher plants. New York: Academic Press, 1986. 674p.

MASCAGNI Jr., H. J.; COX, F. R. Calibration of a manganese availability index for soybean soil test data. Soil Science Society of America Journal, v.49, p.382-390, 1985.

MASCARENHAS, H. A. A. Acúmulo de matéria seca, absorção e distribuição de elementos durante o ciclo vegetativo da soja. Campinas: Instituto Agronômico, 1973. 48 p. (Boletim Técnico, 6).

MASCARENHAS, H. A. A.; KIIHL, R. A. S.; NAGAI, V.; BATAGLIA, O. C. Aplicação de micronutrientes em soja cultivada em solos de cerrado. O Agronômico, v.25, p.71-77, 1973.

MASCARENHAS, H. A. A.; MIYASAKA, S.; FREIRE, E. S.; IGUE, T. Adubação da soja. VI. Efeitos do enxofre e de vários micronutrientes $(\mathrm{Zn}, \mathrm{Cu}, \mathrm{B}, \mathrm{Mn}, \mathrm{Fe}$ e $\mathrm{Mo})$ em solo Latossolo Roxo com vegetação de cerrado. Bragantia, v.26, p.373-380, 1967.

MARSCHNER, H. Mineral nutrition of higher plants, Orlando: Academic Press, 1986. 674p.

MEHLICH, A. Mehlich 3 soil test extractant: a modification of Mehlich 2 extractant. Communications in Soil Science and Plant Analysis, v. 15, p. 1409-1416, 1984. 
MENGEL, K.; KIRKBY, E. A. Principles of plant nutrition. 4. ed. Bern: International Potash Institute, 1987. 687 p.

MTYASAKA, S.; FREIRE, E. S.; MASCARENHAS, H. A. A. Adubação da soja. III. Efeito de NPK, do enxofre e de micronutrientes, em solo do arenito Botucatu com vegetação de cerrado. Bragantia, v.23, p.65-71, 1964.

MORTVEDT, J. J. Cadmium levels in soils and plants from some long-term soil fertility experiments in the United States of America. Journal of Environmental Quality, v. 6, p.137-142, 1987.

MORTVEDT, J. J. Micronutrient fertilizers and fertilization pratices. Fertilizer Research, v.7, p.221-235, 1985a.

MORTVEDT, J. J. Plant uptake of heavy metals in zinc fertilizers made from industrial by-products. Journal of Environmental Quality, v. 14, p.424-427, 1985b.

MORTVEDT, J. J.; MAYS, D. A.; OSBORN, G. Uptake by wheat of cadmium and other heavy metal contaminants in phosphate fertilizers. Journal of Environmental Quality, v.10, p.193-197, 1981.

MULCHI, C. L.; ADAMU, C. A.; BELL, P. F.; CHANEY, R. L. Residual heavy metal concentration in sludge-amended Coastal Plain soil - I. Comparison of extractants. Communications in Soil Science and Plant Analysis., v.22, p.919-941, 1991.

MULLA, D. J.; PAGE, A. L.; GANJE, T. J. Cadmium accumulations and bioavailability in soils from long-term phosphorus fertilization. Journal of Environmental Quality, v.9, p.408-412, 1980.

MURAOKA, T.; NEPTUNE, A. M. L.; NASCIMENTO, V. F. Avaliação da disponibilidade de zinco e de manganês do solo para o feijoeiro. II. Manganês. Revista Brasileira de Ciência do Solo, v.7, p.177-182, 1983 b.

MURAOKA, T.; NEPTUNE, A. M. L.; NASCIMENTO, V. F. Avaliação da disponibilidade de zinco e de manganês do solo para o feijoeiro. I. Zinco. Revista Brasileira de Ciência do Solo, v.7, p.167-175, 1983a.

NELSON, W. L.; BARBER, S. A. Nutrient deficiencies in legumes for grain and forage, In: SPRAGUE, H. B. (Ed.) Hunger signs in crops. New York: David Mc.Kay, 1964. p. 143-180.

PARKER, M. B.; HARRIS, H. B.; MORRIS, H. D.; PERKINS, H. F. Manganese toxicity of soybeans as related to soil and fertility treatments. Agronomy Journal, Madison, v.61, p.515-518, 1969. 
PARSONS, M. L.; MAJOR, S.; FORSTER, A. R. Trace element determination by atomic spectroscopic methods - state of the art. Applied Spectroscopy, v.37, p.411$418,1983$.

PECK, T. R. Plant analysis for production agriculture. In: SOIL PLANT ANALYST'S WORKSHOP, 7., Bridgetown, 1979. Proceedings. Bridgetown, 1979. p.1-45.

PIERZYNSKI, G. M,; SCHWAB, A. P. Bioavailability of Zinc, cadmium, and lead in a metal-contaminated alluvial soil. Journal of Environmental Quality, v.22, p.247254, 1993.

PONCHIO, C. O.; BALLIO, L. A. C. Fontes de enxofre e micronutrientes para a agricultura brasileira. In: Enxofre e micronutrientes na agricultura brasileira, Londrina, 1988. Anais do Simpósio..., Londrina, EMBRAPA-NPSo/IAPAR/SBCS. 1988. p.265-275.

QUAGGIO, J.; SILVA, N. M.; BERTON, R. S. Culturas oleaginosas. In: FERREIRA, M. E.; CRUZ, M. C. P. (Ed.) Micronutrientes na agricultura. Piracicaba: POTAFOS/CNPQ, 1991. p.445-484.

RAIJ, B. van. Geoquímica de micronutrientes. In: FERREIRA, M. E.; CRUZ, M. C. P. (Ed.) Micronutrientes na agricultura. Piracicaba: POTAFOS/CNPQ, 1991. p.99111 .

RAIJ, B. van; BATAGLIA, O. C. Análise química do solo para micronutrientes. In: Simpósio sobre micronutrientes na agricultura. Anais. Jaboticabal, UNESP, 1988. v.2, p.537-569.

RAIJ, B. van; BATAGLIA, O. C. Análise química do solo. In: FERREIRA, M. E.; CRUZ, M. C. P. (Ed.) Micronutrientes na agricultura. Piracicaba: POTAFOS/CNPQ, 1991. p.334-355.

RAIJ, B van; QUAGGIO, J. A.; CANTARELA, H.; FERREIRA, M. E.; LOPES A. S.; BATAGLIA, O. C. Análise química do solo para fins de fertilidade. Campinas: Fundação Cargill, 1987. 170 p.

RAVEN, K. P.; LOEPPERT, R. H. Trace element composition of fertilizers and soil amendments. Journal of Environmental Quality, v.26, p.551-557, 1997.

REISENAUER, H. M.; WALSH, L. M.; HOEFT, R. G. Testing soils for sulphur, boron, molybdenum and chlorine. In: WALSH, L. M.; BEATON, J. D. (Ed.) Soil testing and plant analysis. Madison: Soil Science of America, 1973. p.173-200. 
RIBEIRO, A. C.; TUCUNANGO SARABIA, W. A. Avaliação de extratores para zinco e boro disponíveis em latossolos do Triângulo Mineiro. Revista Brasileira de Ciência do Solo, v. 8, p.85-89, 1984.

RITCHEY, K. D.; COX, F. R.; GALRÃO, E. Z.; YOST, R. S. Disponibilidade de Zn para as culturas do milho, sorgo e soja em Latossolo Vermelho Escuro argiloso. Pesquisa Agropecuária Brasileira, v.21, p.215-225, 1986.

ROCA, J.; POMARES, F. Prediction of available heavy metals by six chemical extractants in a sewage sludge-amended soil. Communications in Soil Science and Plant Analysis v.22, p.2119-2136, 1991.

SAUERBECK, D. The environmental significance of the cadmium content in phosphorus fertilizers. Plant Research Development, v.19, p.24-34, 1985.

SENESI, N.; POLEMIO, M. Trace element addition to soil by application of NPK fertilizers. Fertilizer Research, v.2, p.289-302, 1981.

SENESI, N.; POLEMIO, M.; LORUSSO, L. Evaluation of barium, rubidium and strontium contents in commercial fertilizers. Fertilizer Research, v.4, p.135-144, 1983.

SIMS, J. T. A comparison of Mehlich 1 and Mehlich 3 extractants as predictions of manganese, copper and zinc availability in four Delaware soils. Communications in Soil Science and Plant Analysis, v. 16, p. 1039-1052, 1985.

SINGH, J. P.; DAHIYA, D. J. NARWAL, R. P. Boron uptake and toxicity in wheat in relation to zinc supply. Fertilizer Research, v. 24, p. 105-110, 1990.

SOUSA, D. G.; LOBATO, E.; MIRANDA, L. N. Correção do solo e adubação da cultura da soja. In: ARANTES, N. E.; SOUZA, P. I. M. (Ed.) Cultura da soja nos cerrados. Piracicaba: POTAFOS, 1993. p.137-158.

SPOSITO, G. The chemistry of soils. New York: Oxford University Press, 1989. 277p.

TANAKA, R. T.; MASCARENHAS, H. A. A.; BORKERT, C. M. Nutrição mineral da soja. In: ARANTES, N. E.; SOUZA, P. I. M. (Ed.) A cultura da soja nos cerrados. Piracicaba: POTAFOS, 1993, p.105-136.

URE, A. M. Methods of analysis for heavy metals in soils. In: ALLOWAY, B. J. (Ed.) Heavy metals in soils. New York: John Wiley \& Sons, 1990. p.40-80. 
VALADARES, J. M. A. S.; BATAGLIA, O. C .; FURLANI, P. R. Estudo de materiais calcários usados como corretivos do solo no Estado de São Paulo. III Determinação de Mo, Co, Cu, Zn, Mn e Fe. Bragantia, v.33, p. 147-152, 1974.

VALE, F. Avaliação química da disponibilidade de micronutrientes contidos nos fertilizantes. Piracicaba, 1997. 67 p. Dissertação (Mestrado) - Escola Superior de Agricultura "Luiz de Queiroz", Universidade de São Paulo.

VITTI, G. C. Efeitos de doses de enxofre e de zinco na cultura da soja (Glycine max (L.) Merril), cultivada em condições de casa de vegetação. Piracicaba, 1982. 175p. Tese (Doutorado) - Escola Superior de Agricultura 'Luiz de Queiroz", Universidade de São Paulo.

VOCASEK, F. F.; FRIEDERICKS, J, B. Soil micronutrientes extraction by Mehlich-3 compared to $\mathrm{CaCl}_{2}$-DTPA. Communications in Soil Science and Plant Analysis, v.25, p.1583-1593, 1994.

VOLKWEISS, S. J. Fontes e métodos de aplicação. In: FERREIRA, M. E.; CRUZ, M. C. P. (Ed.) Micronutrientes na agricultura. Piracicaba: POTAFOS/CNPQ, 1991. p.391-412.

WALLACE, G. A.; WALLACE, A. Lead and other potentially toxic heavy metals in soil. Communications in Soil Science and Plant Analysis, v.25, p.137-141, 1994.

WATANABE, H. Accumulation of cromium from fertilizers in cultivated soils. Soil Science and Plant Nutrition, v.30, p.543-554, 1984.

WHITE, M. C.; CHANEY, R. L.; DECKER, A. M. Differential tolerance in soybean to phytotoxic levels of soil $\mathrm{Zn}$. II. Range of $\mathrm{Zn}$ additions and the uptake and translocation of Zn, Mn, Fe and P. Agronomy Journal, v.77, p. 126-131, 1979b.

WHITE, M. C.; DECKER, A. M.; CHANEY, R. L. Differential cultivar tolerance in soybean to phytotoxic levels of soil $\mathrm{Zn}$. I. Range of cultivar response. Agronomy Journal, v.71, p.121-131, 1979a.

WILLIAMS, C. H.; DAVID, D. J. The effect of superphosphate on the cadmium content of soil and plants. Australian Journal of Soil Research, v. 11, p.43-53, 1973.

WINGE, R. K.; FASSEL, V. A.; PETERSON, V. J.; FLOYD, M. A. Inductively coupled plasma atomic emission spectroscopy: an atlas of spectral information. New York: Elsevier, 1985. 574 p.

WOLF, B. Improvements in the azometine $\mathrm{H}$ method for determination of boron. Communications in Soil Science and Plant Analysis, v.5, p.39-44, 1974. 